\title{
A Study on the Relationship between Dose Rate and Decay Heat for Spent Nuclear Fuel Casks
}

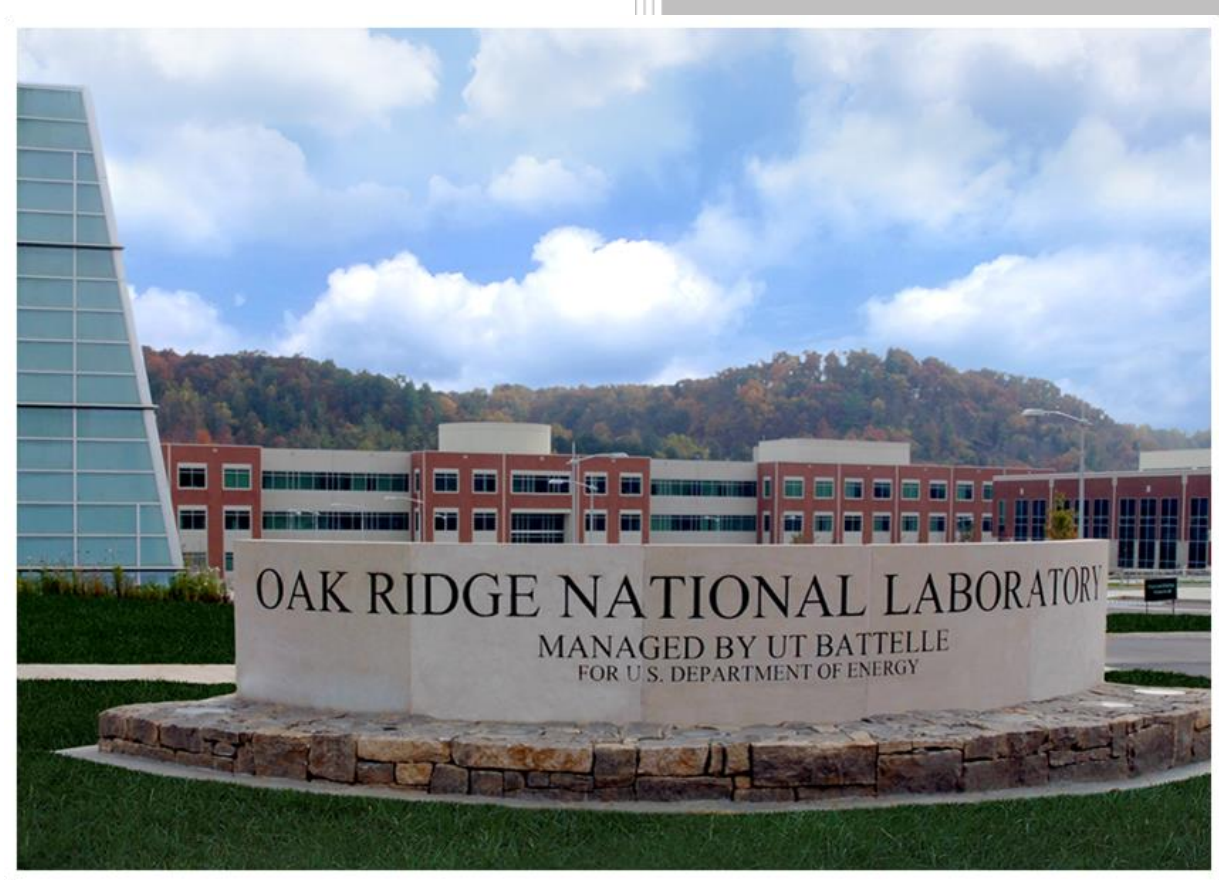

Approved for public release. Distribution is unlimited.

Riley Cumberland Georgeta Radulescu Kaushik Banerjee June 17, 2020 


\title{
DOCUMENT AVAILABILITY
}

Reports produced after January 1, 1996, are generally available free via US Department of Energy (DOE) SciTech Connect.

Website www.osti.gov

Reports produced before January 1, 1996, may be purchased by members of the public from the following source:

\author{
National Technical Information Service \\ 5285 Port Royal Road \\ Springfield, VA 22161 \\ Telephone 703-605-6000 (1-800-553-6847) \\ TDD 703-487-4639 \\ Fax 703-605-6900 \\ E-mail info@ntis.gov \\ Website http://classic.ntis.gov/
}

Reports are available to DOE employees, DOE contractors, Energy Technology Data Exchange representatives, and International Nuclear Information System representatives from the following source:

Office of Scientific and Technical Information

PO Box 62

Oak Ridge, TN 37831

Telephone 865-576-8401

Fax 865-576-5728

E-mail reports@osti.gov

Website http://www.osti.gov/contact.html

This report was prepared as an account of work sponsored by an agency of the United States Government. Neither the United States Government nor any agency thereof, nor any of their employees, makes any warranty, express or implied, or assumes any legal liability or responsibility for the accuracy, completeness, or usefulness of any information, apparatus, product, or process disclosed, or represents that its use would not infringe privately owned rights. Reference herein to any specific commercial product, process, or service by trade name, trademark, manufacturer, or otherwise, does not necessarily constitute or imply its endorsement, recommendation, or favoring by the United States Government or any agency thereof. The views and opinions of authors expressed herein do not necessarily state or reflect those of the United States Government or any agency thereof. 
ORNL/SPR-2020/1441

Reactor and Nuclear Systems Division

\title{
A Study on the Relationship between Dose Rate and Decay Heat for Spent Nuclear Fuel Casks
}

\author{
Riley Cumberland \\ Georgeta Radulescu \\ Kaushik Banerjee
}

June 17, 2020

\author{
Prepared by \\ OAK RIDGE NATIONAL LABORATORY \\ Oak Ridge, TN 37831-6283 \\ managed by \\ UT-BATTELLE, LLC \\ for the \\ US DEPARTMENT OF ENERGY \\ under contract DE-AC05-00OR22725
}





\section{CONTENTS}

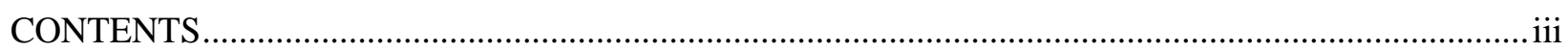

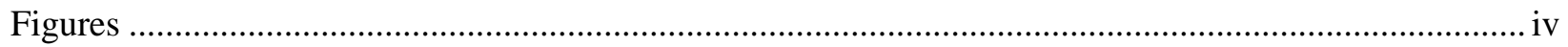

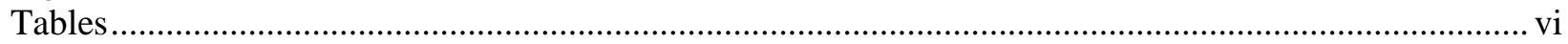

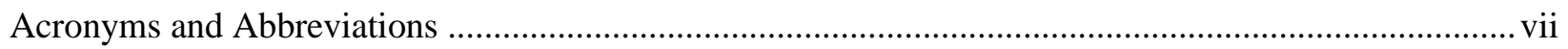

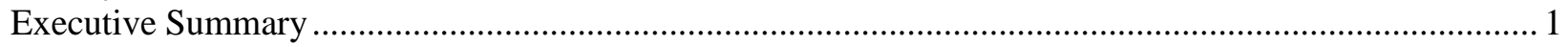

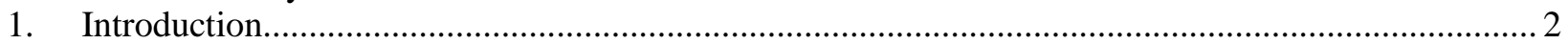

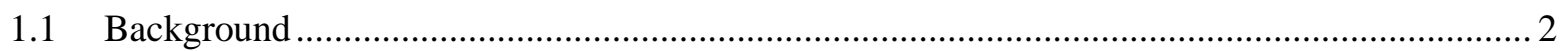

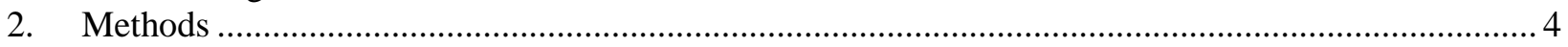

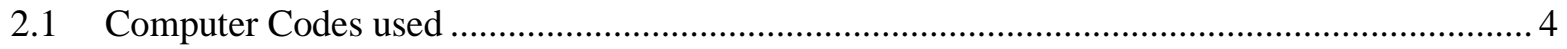

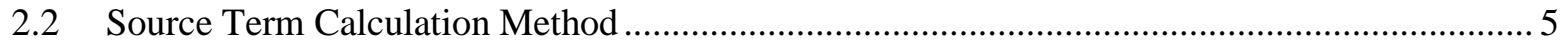

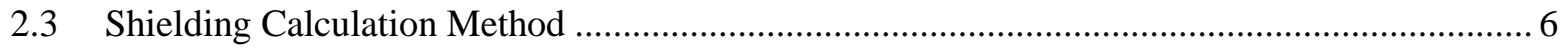

2.4 Method to Compute Cooling Times for a Decay Heat ............................................................ 6

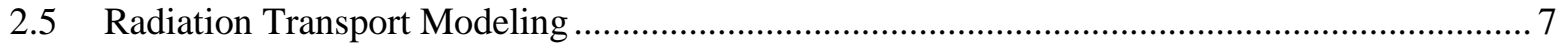

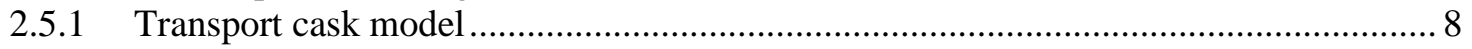

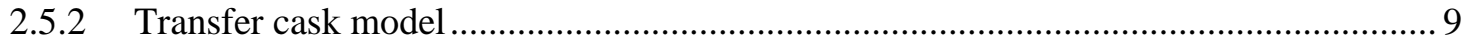

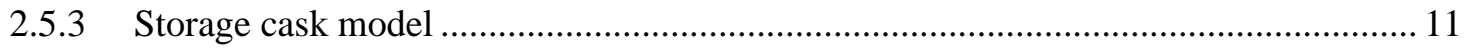

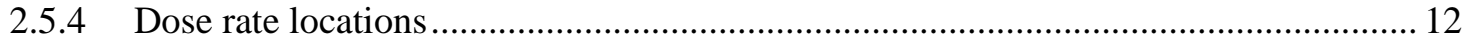

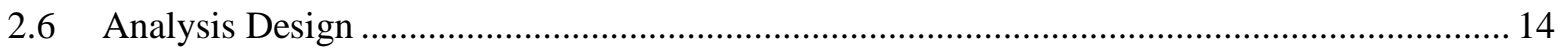

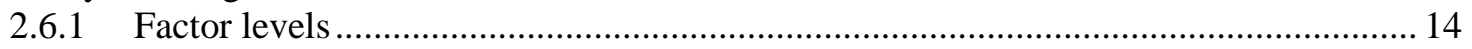

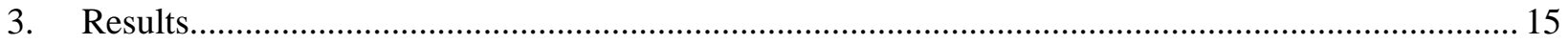

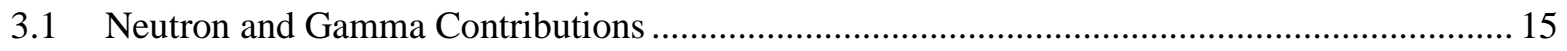

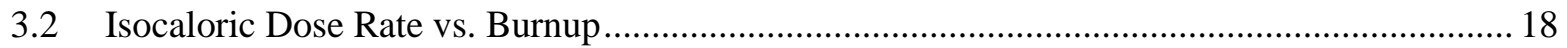

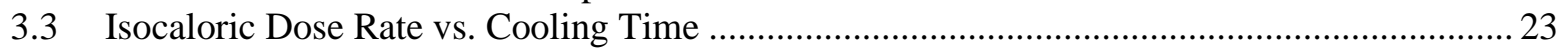

4. Follow-on: Loading a High-dose transportation cask ................................................................ 27

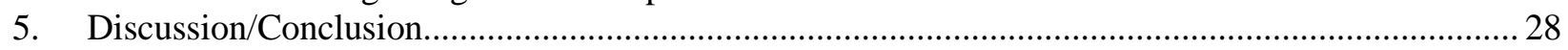

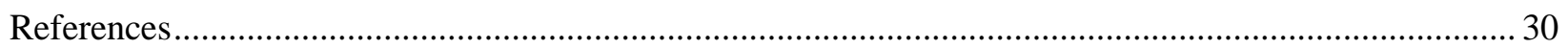

APPENDIX A. Comparison of RG 3.54 and UNF-ST\&DARDS Decay Heats ...................................... 32

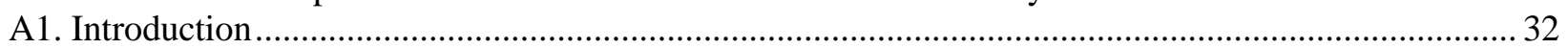

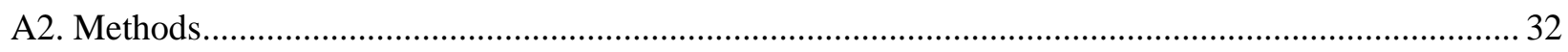

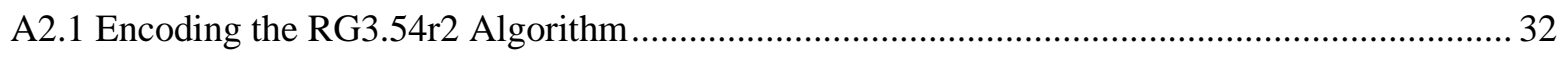

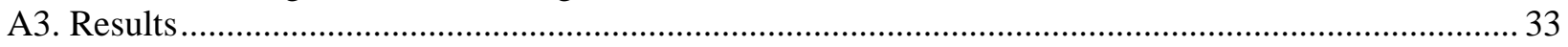

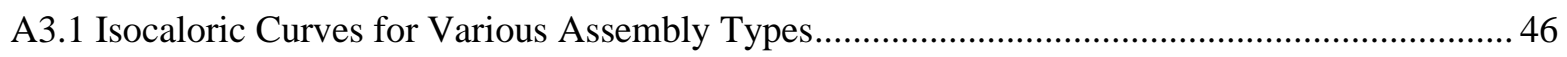

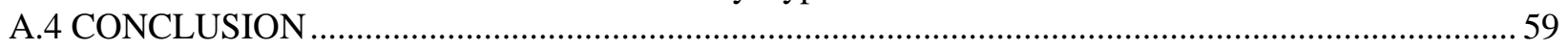




\section{FIGURES}

Figure 1. Cross section views of the generic transportation cask models for (a) normal conditions of transport (left) and (b) hypothetical accident conditions (right).

Figure 2. Transfer cask model for normal conditions (not used in this analysis). ................................... 10

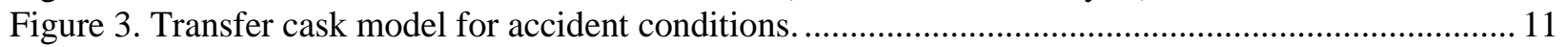

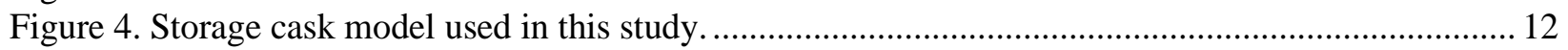

Figure 5. Illustration of the air volume at $1 \mathrm{~m}$ from the radial surface of the storage cask. ...................... 13

Figure 6. Isocaloric dose rate curves for neutrons and gammas for 1,200 $\mathrm{W}$ per assembly transfer cask, without a neutron shield, loaded with B\&W 14×14 B10 SNF assemblies.......................... 16

Figure 7. Isocaloric dose rate curves for neutrons and gammas for 1,200 $\mathrm{W}$ per assembly transfer cask, without a neutron shield, loaded with CE 14×14 C SNF assemblies. ................................ 17

Figure 8. Isocaloric dose rate curves for neutrons and gammas for 1,200 W per assembly transfer cask, without a neutron shield, loaded with Westinghouse Vantage 5H SNF assemblies............. 17

Figure 9. Isocaloric dose rate curves for neutrons and gammas for 1,200 W storage cask loaded

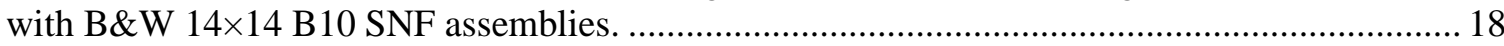

Figure 10. Isocaloric neutron dose fractions for $1,200 \mathrm{~W}$ storage cask loaded with $\mathrm{B} \& \mathrm{~W} 14 \times 14$

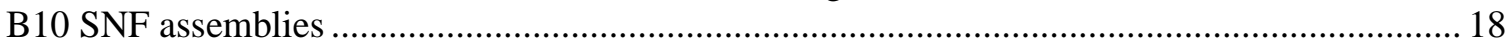

Figure 11. Isocaloric dose rate vs. burnup curves for casks loaded with B\&W 14×14 B10 SNF

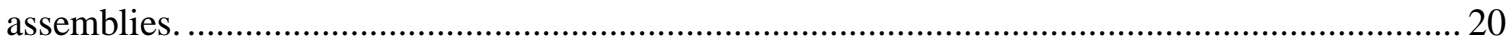

Figure 12. Isocaloric dose rate vs. burnup curves for casks loaded with CE $14 \times 14$ C SNF assemblies.

Figure 13. Isocaloric dose rate vs. burnup curves for casks loaded with Westinghouse Vantage 5H SNF assemblies.

Figure 14. Isocaloric dose rates along the side and bottom of a transportation cask under normal conditions of transport.

Figure 15. Isocaloric dose rate vs. cooling time curves for casks loaded with B\&W 14×14 B10 SNF assemblies.

Figure 16. Isocaloric dose rate vs. cooling time curves for casks loaded with CE $14 \times 14 \mathrm{C}$ SNF assemblies.

Figure 17. Isocaloric dose rate vs. cooling time curves for casks loaded with Westinghouse

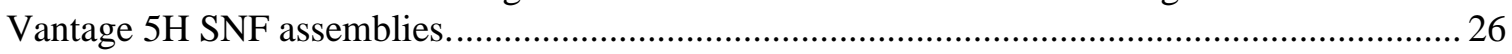

Figure 18. Concrete storage cask isocaloric dose rates for all fuel types in uniformly loaded casks. ........ 27

Figure 19. Burnup map for $860 \mathrm{~W}$ per assembly uniformly loaded (from decay heat perspective) transportation cask (GWd/MTU) ....................................................................................... 28

Figure 20. Cumulative distribution of time PWR assemblies in the UDB were operated at power.......... 33

Figure 21. Comparison of UDB bounding decay heat data for all PWR assemblies to RG3.54r2 isocaloric decay heat curves for PWR fuel. ............................................................................... 35

Figure 22. Comparison of UDB bounding decay heat data for all PWR assemblies to RG3.54r2 isocaloric decay heat curves for PWR fuel, zoomed time scale. ............................................. 36

Figure 23. Comparison of UDB bounding decay heat data for PWR assemblies to RG3.54r2 isocaloric decay heat curves for 5\% enriched fuel burned for various times................................ 37

Figure 24. Comparison of UDB bounding decay heat data for PWR assemblies to RG3.54r2 isocaloric decay heat curves for 5\% enriched fuel burned for various times, zoomed time scale.

Figure 25. Comparison of UDB bounding decay heat data for assemblies burned for over 2.11 years to RG3.54r2 isocaloric decay heat curves for PWR fuel.

Figure 26. Comparison of UDB bounding decay heat data for assemblies burned for over 2.11 years to RG3.54r2 isocaloric decay heat curves for PWR fuel, zoomed time scale. 
Figure 27. Comparison of UDB bounding decay heat data for assemblies burned for over 3.23 years to RG3.54r2 isocaloric decay heat curves for PWR fuel.

Figure 28. Comparison of UDB bounding decay heat data for assemblies burned for over 3.23 years to RG3.54r2 isocaloric decay heat curves for PWR fuel, zoomed time scale.

Figure 29. Comparison of UDB bounding decay heat data for assemblies burned for over 5.04 years to RG3.54r2 isocaloric decay heat curves for PWR fuel.

Figure 30. Comparison of UDB bounding decay heat data for assemblies burned for over 5.04 years to RG3.54r2 isocaloric decay heat curves for PWR fuel, zoomed time scale.

Figure 31. Components of SNF decay heat as predicted by RG3.54r2 for 5\% enriched PWR SNF burned for 3.23 years, producing $1.5 \mathrm{~W} / \mathrm{kgU}$ of decay heat. Burnup to obtain $1.5 \mathrm{~W} / \mathrm{kgU}$ of decay heat is plotted on the secondary y-axis.

Figure 32. Comparison of UDB bounding decay heat data for Westinghouse Electric (WE) Vantage $5 \mathrm{H}$ assemblies to RG3.54r2 isocaloric decay heat curves.

Figure 33. Comparison of UDB bounding decay heat data for WE Vantage 5H assemblies to RG3.54r2 isocaloric decay heat curves, zoomed time scale.

Figure 34. Comparison of UDB bounding decay heat data for WE Vantage 5H assemblies to RG3.54r2 isocaloric decay heat curves for $5 \%$ enriched fuel burned for various times

Figure 35. Comparison of UDB bounding decay heat data for WE Vantage 5H assemblies to $\mathrm{RG} 3.54 \mathrm{r} 2$ isocaloric decay heat curves for $5 \%$ enriched fuel burned for various times, zoomed time scale.

Figure 36. Comparison of UDB bounding decay heat data for CE $14 \times 14 \mathrm{C}$ assemblies to RG3.54r2 isocaloric decay heat curves.

Figure 37. Comparison of UDB bounding decay heat data for CE $14 \times 14 \mathrm{C}$ assemblies to RG3.54r2 isocaloric decay heat curves, zoomed time scale.

Figure 38. Comparison of UDB bounding decay heat data for CE $14 \times 14 \mathrm{C}$ assemblies to $\mathrm{RG} 3.54 \mathrm{r} 2$ isocaloric decay heat curves for $5 \%$ enriched fuel burned for various times

Figure 39. Comparison of UDB bounding decay heat data for CE $14 \times 14 \mathrm{C}$ assemblies to $\mathrm{RG} 3.54 \mathrm{r} 2$ isocaloric decay heat curves for $5 \%$ enriched fuel burned for various times, zoomed time scale.

Figure 40. Comparison of UDB bounding decay heat data for B\&W Mark B10 assemblies to $\mathrm{RG} 3.54 \mathrm{r} 2$ isocaloric decay heat curves.

Figure 41. Comparison of UDB bounding decay heat data for B\&W Mark B10 assemblies to RG3.54r2 isocaloric decay heat curves, zoomed time scale.

Figure 42. Comparison of UDB bounding decay heat data for B\&W Mark B10 assemblies to RG3.54r2 isocaloric decay heat curves for 5\% enriched fuel burned for various times.

Figure 43. Comparison of UDB bounding decay heat data for B\&W Mark B10 assemblies to $\mathrm{RG} 3.54 \mathrm{r} 2$ isocaloric decay heat curves for $5 \%$ enriched fuel burned for various times, zoomed time scale. 


\section{TABLES}

Table 1. Top 5 decay heat contributing isotopes at fixed cooling times [3] ........................................... 3

Table 2. Top 5 dose contributing isotopes for 5 year cooled SNF [3] .................................................. 4

Table 3. Assumptions relevant to cobalt activation radiation source term ............................................. 5

Table 4. Cooling times (years) to achieve $1,200 \mathrm{~W}$ decay heat for various burnups.................................. 7

Table 5. Cooling times (years) to achieve $860 \mathrm{~W}$ decay heat for various assembly average

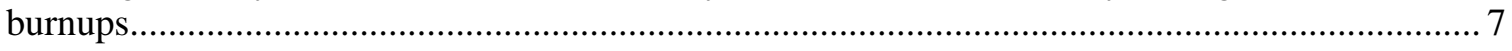

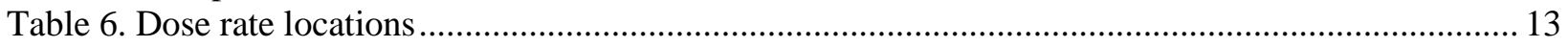

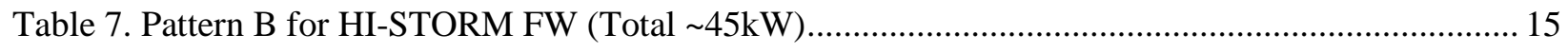

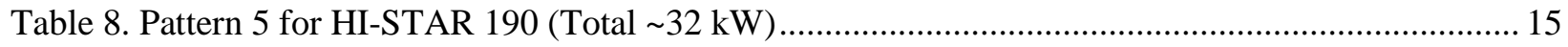

Table 9. Changes in dose rate for a cask with a constant decay heat load ............................................... 27

Table 10. Summary of assembly type data in UNF-ST\&DARDS database ............................................. 46 


\section{ACRONYMS AND ABBREVIATIONS}

ANS
ANSI
ARP
ASME
B\&W
BPR
BWR
CE
ENDF
FSAR
FW-CADIS
GWd
HAC
HI
HI-STORM FW
LWR
MPC
MTU
NCT
NQA
NRC
ORIGAMI
ORIGEN
ORNL
PWR
RG
SNF
UDB
UNF-ST\&DARDS
VW
WE

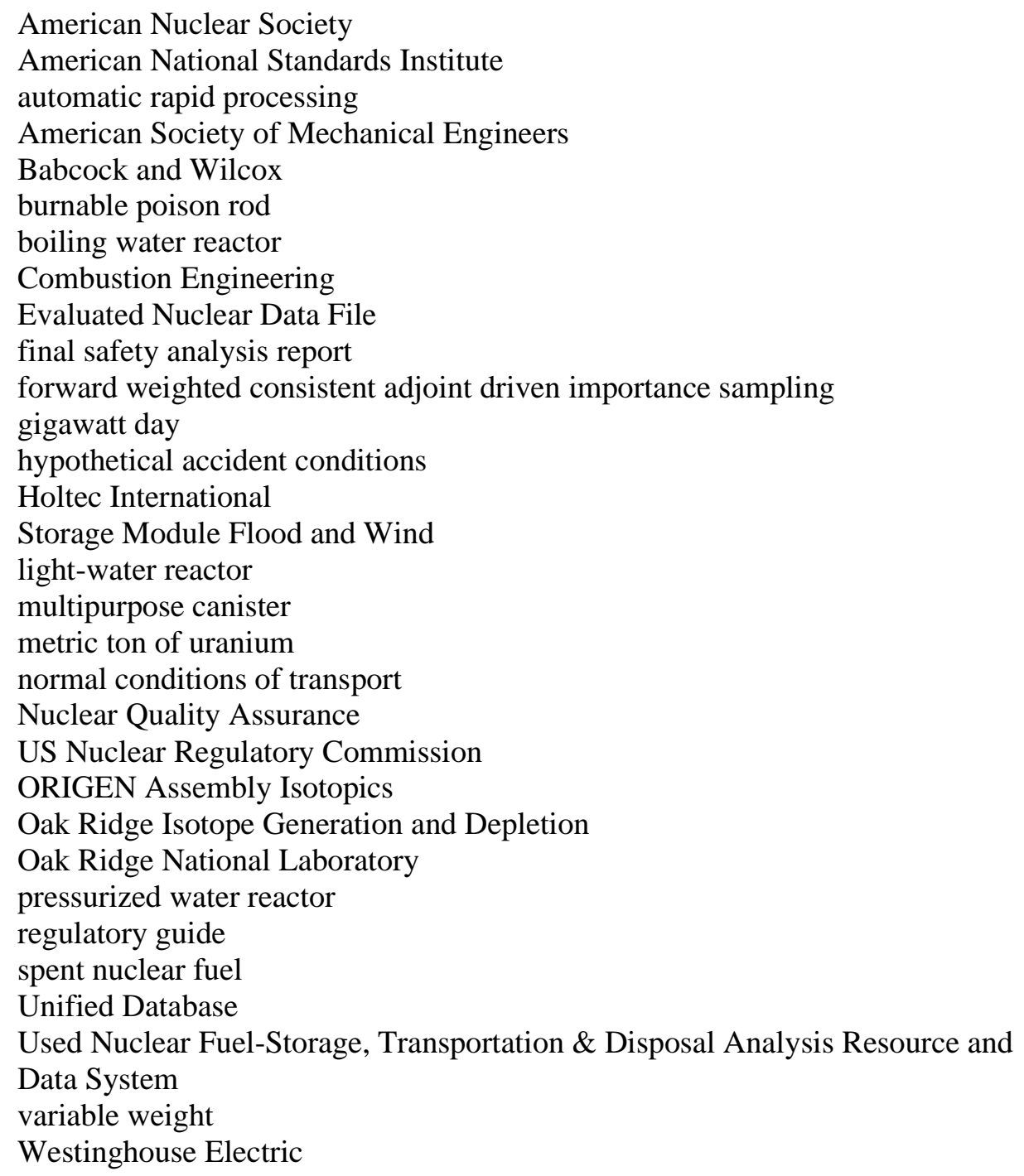




\section{EXECUTIVE SUMMARY}

Decay heat and dose rate are two important limits used for determining the allowable contents of spent fuel (SNF) in dry storage systems and transportation packages. While the decay heat limit is used to maintain fuel cladding integrity and ensure retrievability, dose rates are used to demonstrate compliance with regulatory requirements on radiation protection. Because both dose rate and decay heat result from decay of radioisotopes in SNF, this study is an attempt to examine the relationship between dose rate and decay heat for a given cask design.

Dose rates were evaluated for 198 cask configurations, that include various SNF system designs (e.g., storage, transfer, transport), SNF characteristics (e.g., fuel types, burnup, cooling time), and loading maps (e.g., uniform loading, zone loading), while a constant decay heat was maintained. The decay heat was calculated using US Nuclear Regulatory Commission (NRC) Regulatory Guide (RG) 3.54, Revision 2 [1], and verified using ORIGEN sequence within SCALE code system [2]. The ORIGEN outputs were used as source terms in the dose analysis using 198 different configurations.

A computer script was developed to calculate the cooling time necessary to achieve a given decay heat for a given enrichment, assembly average burnup, assembly mass, and in-core history using a rootfinder algorithm. Initially the computer script was developed to provide cooling time and burnup calculations directly to the analysis of dose rates and decay heats, so a comparison between Used Nuclear FuelStorage Transportation and Disposal Analysis Resource Data System (UNF-ST\&DARDS) results and RG3.54 data was made; results are included in the appendix to this document. However, an iterative approach was used to compute cooling time, and its accuracy did not depend on the results of the RG3.54r2 algorithm, although the algorithm was still used.

The results of the evaluation presented herein clearly demonstrate that a given decay heat does not correspond to a unique dose rate for a variety of cask and package designs. There is no clear pattern to develop a correlation between decay heat and the source terms. Depending on burnup, enrichment, cask type, and loading pattern, dose rates varied for the exact same decay heat - in some cases by $400 \%$ for a given cask. For cases in which decay heat was held constant through selection of the appropriate cooling time, dose rates would decrease with increasing burnup, and in other cases, dose rates would increase. The large variation in dose rates for a constant decay heat indicates that casks loaded based on decay heat - that is allowing any burnup, cooling time, and enrichment combinations that yield the qualified decay heat limit(s) - cannot ensure that an Independent Spent Fuel Storage Installation or a spent fuel transportation package will meet the regulatory limits set forth by the respective regulations, i.e., 10 CFR 72 or 10 CFR 71. 


\section{INTRODUCTION}

This report examines dose rates near casks loaded with spent nuclear fuel (SNF) by varying several factors while maintaining a constant heat load. This analysis was performed to understand whether decay heat can be used to simplify content specifications for the purposes of restricting the dose. If constant decay heat ensures that dose rate remains unchanged or follows some derivable function when some other parameter is varied, SNF specifications in the Technical Specifications of an Independent Spent Fuel Storage Installation (ISFSI) or package could be simplified. Assembly inserts such as burnable poison rods (BPRs), control rods, or thimble plug devices are not considered here.

The overall approach of this work is to maintain SNF decay heat as a constant when simulating loaded casks. When decay heat is maintained as a constant the adjective "isocaloric" may be used to convey the meaning. The approach exposes behavior that goes beyond common sense heuristics, such as: dose decreases with increased cooling time; dose increases with burnup; and dose slightly decreases with increased enrichment. Decay heat is one of the SNF management considerations and follows trends similar to those associated with dose, including decreasing decay heat with increasing cooling time and increasing decay heat with increasing burnup. With the issuing of Regulatory Guide 3.54, Revision 2 (RG3.54r2) [1], decay heat for an individual assembly can be calculated quickly. Because of the similar overall behavior of decay heat and dose rate, determining the character of their relationship is of interest.

Pressurized water reactor (PWR) systems are examined in this study, but the findings are expected to be applicable to boiling water reactor (BWR) systems. This expectation is based on the small changes in contribution importance of PWR source term nuclides versus BWR source term nuclides as discussed in NUREG/CR-6700 [3], presented in Tables 11 and 12 of that report. The largest overall change was in ${ }^{60} \mathrm{Co}$, which was due to the PWR model used in NUREG/CR-6700.

The relationship between decay heat and dose rate in SNF cask systems is complex. Both decay heat and dose rate depend on SNF assembly isotopic content through separate physical processes. This work attempted to identify any straightforward relationship between dose rate and decay heat. This work performed a factorial study to search for a relationship between dose rate and decay heat. A factorial study is a study design to determine how a response variable is affected by numerous factors (or independent variables). Each factor (e.g. burnup) is assigned several factor levels (e.g. 20, 40, and 65 GWD/MTHM). A factorial study is the evaluation of the response variable for many combinations of factor levels to characterize interaction effects and single factor effects. The factors examined were burnup, enrichment, cask type, assembly type, and uniform cask loading. A straightforward relationship could exist if dose rate remained constant as one or more of these factors changes. A monotonic trend would suggest that bounding behavior may exist to facilitate demonstration of compliance. A plotted concave-up behavior would suggest that bounding behavior exists at the endpoints of the curve, so the midpoints might not need to be evaluated to demonstrate compliance. It is important to understand that even if a relation exists between decay heat and dose rate, and a bounding shielding source term is identified for a given decay heat for uniform loadings; it does not automatically guarantee compliance with any regulatory dose limits due to complicating factors such as non-uniform loading.

\subsection{BACKGROUND}

Decay heat results from attenuation of alpha, beta, gamma, and neutron radiation, as well as recoil energy of decay product nuclei. Radiation particles with higher linear energy transfer (alpha, beta, and recoil nuclei) tend to produce more decay heat than lower linear energy transfer particles (neutron and gamma). High linear energy transfer radiation does not leave the cask, but can produce low linear energy transfer particles that can travel further. Alpha particles have a charge of +2 and have energies typically exceeding $1 \mathrm{MeV}$, so they can deposit a substantial amount of energy in distances of microns. Because of their 
charge, they can impart a substantially larger portion of their energy per meter. The alphas are emitted largely by longer lived, heavy nuclides which are often produced through one or more neutrons being absorbed by uranium nuclei in the nuclear fuel. These include ${ }^{244} \mathrm{Cm}$ and nuclides that do not produce neutrons directly such as ${ }^{238} \mathrm{Pu}$. Note that ${ }^{244} \mathrm{Cm}$ most often decays through alpha emission, with the spontaneous fission decay mode accounting for approximately 1 in 700,000 decays [4]. Betas are emitted more often by fission products and daughter nuclei. Betas are also charged, giving them a high linear energy transfer rate. Recoil nuclei from spontaneous fission also deposit decay heat via their high charge. The first two columns of Table 1 show the relative contributions of the top five contributors to decay heat for five-year cooled PWR SNF as calculated in NUREG/CR-6700 [3]. The first column shows contributors to low burned, lower enriched fuel, and the second shows contributions to higher burned, higher enriched fuel. The contributions change due to the differences in the amount of neutron activation experienced during the burn. For the lower burnup fuel, fission products are the principal contributors of decay heat. For the higher burnup fuel, the actinides ${ }^{244} \mathrm{Cm}$ and ${ }^{238} \mathrm{Pu}$ appear in the top-five list.

Table 1. Top 5 decay heat contributing isotopes at fixed cooling times [3].

\begin{tabular}{llll}
\hline \multicolumn{2}{c}{ 20 GWd/MTU 3\% } & \multicolumn{2}{c}{ 70 GWd/MTU 5\% } \\
decay heat contributors & \multicolumn{2}{c}{ decay heat contributors } \\
\hline${ }^{90} \mathrm{Y}$ & 23.08 & ${ }^{134} \mathrm{Cs}$ & 17.74 \\
${ }^{137 \mathrm{~m}} \mathrm{Ba}$ & 20.10 & ${ }^{137 \mathrm{~m}} \mathrm{Ba}$ & 16.51 \\
${ }^{134} \mathrm{Cs}$ & 10.88 & ${ }^{90} \mathrm{Y}$ & 16.15 \\
${ }^{106} \mathrm{Rh}$ & 10.08 & ${ }^{244} \mathrm{Cm}$ & 14.91 \\
${ }^{144} \mathrm{Pr}$ & 8.42 & ${ }^{238} \mathrm{Pu}$ & 8.66 \\
\hline
\end{tabular}

Radiation leaving the cask is always in the form of neutrons and gammas and their knock-on particles. Gammas tend to result from decays of both heavy nuclei and fission products. Neutrons, however, come from actinides. Some neutrons are produced by a few heavy nuclei that spontaneously fission. These nuclei are ultimately produced through neutron absorption of ${ }^{238} \mathrm{U}$ and the resulting actinides. Additional neutrons are produced through $(\alpha, n)$ reactions with light nuclides, contributing to the neutron source term. Alphas are produced by actinides in the majority of cases. Because many neutrons must be absorbed to make higher activity actinides, and spontaneous fission neutron emitters such as ${ }^{244} \mathrm{Cm}$, neutron production rate is dependent on both enrichment and burnup. Additionally, the type of cask can impact the dose rate. Depending on concrete composition, concrete casks can absorb more neutron dose, reducing the contribution of neutron emitters such as ${ }^{244} \mathrm{Cm}$. Because gamma energy absorption coefficients are different for different materials, the contribution from each gamma emitter also changes based on changes in the cask material. This can be seen in the findings contained in NUREG/CR-6700 [3], shown in Table 2 on the next page. The table lists the top five contributing isotopes for the metric listed in each column. The ${ }^{244} \mathrm{Cm}$ contributes to only $8.3 \%$ of the dose rate for the concrete cask, but it contributes $36 \%$ to the dose rate for the lead cask. Note that neither set of isotopes corresponds closely to the decay heat contributors for the same $70 \mathrm{GWd} / \mathrm{MTU}, 5 \mathrm{wt} \%$ SNF. Appendix B of NUREG/CR-6802 [5] demonstrates how dynamic these rankings are. In Figure B.3. of the NUREG, it is notable that ${ }^{144} \mathrm{Pr}$ and ${ }^{106} \mathrm{Rh}$ are substantially larger gamma dose contributors for two-year cooled $50 \mathrm{GWd} /$ metric ton of uranium (MTU) assemblies in a steel cask. At five years, the dose rankings for gamma emitters in Figure B.3 look more like those shown in Table 2 on the next page. 
Table 2. Top 5 dose contributing isotopes for 5 year cooled SNF [3]

\begin{tabular}{llll}
\hline \multicolumn{2}{c}{$\begin{array}{c}70 \text { GWd/MTU 5\% } \\
\text { concrete cask } \\
\text { dose contributors }\end{array}$} & \multicolumn{2}{c}{$\begin{array}{c}\text { 70 GWd/MTU 5\% } \\
\text { lead cask } \\
\text { dose contributors }\end{array}$} \\
\hline${ }^{60} \mathrm{Co}$ & 34.6 & ${ }^{244} \mathrm{Cm}$ & 36.6 \\
${ }^{134} \mathrm{Cs}$ & 26.7 & ${ }^{60} \mathrm{Co}$ & 29.9 \\
${ }^{154} \mathrm{Eu}$ & 10.9 & ${ }^{134} \mathrm{Cs}$ & 15 \\
${ }^{137 \mathrm{~m}} \mathrm{Ba}$ & 8.9 & ${ }^{154} \mathrm{Eu}$ & 6.9 \\
${ }^{244} \mathrm{Cm}$ & 8.3 & ${ }^{106} \mathrm{Rh}$ & 4.5 \\
\hline
\end{tabular}

Given that different isotopes drive decay heat and dose rate, it would be a coincidence if dose rate were to track with decay heat. Clearly, there are some common contributors to decay heat and dose rate, such as ${ }^{244} \mathrm{Cm}$, and ${ }^{134} \mathrm{Cs}$. However, ${ }^{60} \mathrm{Co}$ from activation is a large dose contributor, but it does not appear as a decay heat-producing isotope, and ${ }^{90} \mathrm{Y}$ produces substantial decay heat with little associated dose. To show that such a coincidence does not exist, the objective is to identify any trends or to show unequivocally that dose rate and decay heat do not track together in a straightforward way.

\section{METHODS}

Several factors (or parameters) were varied to examine how dose rate changes for a given decay heat. These included burnup, enrichment, cask type, assembly type, and uniform vs zone loading. Several discrete values were assumed for each factor. For the factor enrichment, the factor levels applied were 2, 3,4 and $5 \mathrm{wt} \%$. All combinations of factor levels (or parameter values) were applied, and the resulting dose rates were examined for trends.

\subsection{COMPUTER CODES USED}

All calculations were performed using the SCALE code package (version 6.2.3) [6]. The ORIGEN (Oak Ridge Isotope Generation and Depletion) sequence computes isotopic compositions in SNF for over 1,000 nuclides. As described in the article by Gauld et al. [2], ORIGEN has been validated extensively for a wide range of applications, including reactor analysis, SNF dry storage and transportation, fuel reprocessing, etc. To ensure satisfactory performance, this sequence was evaluated against approximately 200 fuel assembly decay heat measurements for various PWR and BWR commercial SNF assemblies with burnups up to $51 \mathrm{GWd} / \mathrm{MTU}$ for PWRs and $47 \mathrm{GWd} / \mathrm{MTU}$ for BWRs, and cooling times ranging from $~ 2.5-27$ years after fuel discharge from the reactor. The neutron and gamma radiation sources and energy spectra generated by ORIGEN were also compared to measurements for individual radionuclides for validation. Radiation transport calculations were performed with the MAVRIC sequence, which applies variance reduction techniques to Monte Carlo transport calculations to accelerate convergence. The MAVRIC shielding code has been validated by comparing its results to experimental measurements that tested photon and neutron transmission through various shielding materials [7]. The code also reproduced gamma dose measurements on the radial surface of a spent nuclear fuel cask containing rods without assembly hardware [8]. MAVRIC is thus well suited to high-fidelity modeling of SNF cask shielding analyses. In this work, the Used Nuclear Fuel-Storage, Transportation \& Disposal Analysis Resource and Data System (UNF-ST\&DARDS) [9] was used to drive the simulations. See the paper by Radulescu et al. [10] for an example calculation. SCALE 6.2 development practices follow various quality standards, enabling compliance with American Society of Mechanical Engineers (ASME) Nuclear Quality Assurance (NQA)-1 [11]. 


\subsection{SOURCE TERM CALCULATION METHOD}

Assembly-specific radiation source terms were generated with ORIGEN Assembly Isotopics (ORIGAMI), a new SCALE code dedicated to calculating nuclide inventories, decay heat, and radiation source terms for SNF assemblies based on axial burnup profile and/or variable pin power specifications. This code performs fast ORIGEN [2] depletion calculations using pre-generated ORIGEN cross section libraries. These pre-generated ORIGEN cross section libraries were developed for SNF and SNF systems (e.g., an SNF cask) characterizations. SNF radiation sources and radiation sources produced by activation of light elements found in fuel assembly structural components are generated in separate ORIGAMI calculations. The SNF neutron source is produced by spontaneous fission and $(\alpha, n)$ reactions in the $\mathrm{UO}_{2}$. The SNF photon sources are produced as a result of decay of fission products and actinides.

${ }^{60} \mathrm{Co}$ is produced by activation of the cobalt impurity in assembly structural materials. This radioisotope dominates the dose rate produced by activated stainless steel and Inconel alloys for cooling times larger than approximately 2 years because other activation products found in assembly hardware materials are either short lived (e.g., ${ }^{59} \mathrm{Fe},{ }^{61} \mathrm{Cr},{ }^{58} \mathrm{Co}$ ) or do not emit substantial gamma radiation (e.g., $\left.{ }^{55} \mathrm{Fe},{ }^{63} \mathrm{Ni}\right) \cdot{ }^{60} \mathrm{Co}$ source strength for assembly hardware was obtained by scaling down the ${ }^{60} \mathrm{Co}$ source strength calculated with ORIGAMI by assuming that the cobalt impurity in assembly hardware was exposed to the flux in the fuel region. The flux scaling factors for top and bottom assembly hardware regions were taken from a report by Luksic [12]. The flux scaling factors partially account for reduced flux in assembly hardware regions, where there is no fissile material. These assumptions are standard practice and incorporated in the UNF-ST\&DARDS templates for SNF assembly shielding source terms. The cobalt impurity amount was calculated based on standard material specifications, the weights of hardware materials listed in a report numbered DOE/RW-0184 vol 3 [13], and assumed cobalt impurity concentrations in the various hardware materials. This assumed the cobalt impurity concentration is $10 \mathrm{ppm}$ for Zircaloy-2 and $-4,800$ ppm for stainless steel, $4700 \mathrm{ppm}$ for Inconel 718, and $6500 \mathrm{ppm}$ for Inconel X750 [14]. The cobalt impurity amount and flux scaling factors for the top and bottom nozzles and for the gas plenum of the three PWR fuel assembly types analyzed in this report are provided in Table 3.

Table 3. Assumptions relevant to cobalt activation radiation source term

\begin{tabular}{l|cc|cc|cc} 
& \multicolumn{2}{|c|}{ Top Nozzle } & \multicolumn{2}{c|}{ Gas Plenum } & \multicolumn{2}{c}{ Bottom Nozzle } \\
Assembly & Flux Factor & Cobalt $(\mathbf{g})$ & Flux Factor & Cobalt $(\mathbf{g})$ & Flux Factor & Cobalt (g) \\
\hline B1414B10 & 0.15 & 15.63 & 0.3 & 4.95 & 0.3 & 12.83 \\
C1414C & 0.075 & 4.61 & 0.3 & 0.11 & 0.3 & 4 \\
W1717V5H & 0.15 & 10.02 & 0.3 & 10.02 & 0.3 & 4.72
\end{tabular}

For dose rate calculations, SNF source terms are generated using a fine energy group structure to adequately represent neutron energy spectra and discrete gamma rays (i.e., 200-neutron and 999-photon energy groups). Spectra output may be in a text file or contained in the standard binary concentration output file from ORIGEN (i.e., the ft71 binary file).

UNF-ST\&DARDS calculations use ORIGEN libraries for representative PWR and BWR fuel assemblies generated with depletion parameters that are conservative from a criticality standpoint (e.g., theoretical fuel density, moderator density within the lower range of the typical moderator density values during normal operation, and full fuel exposure to burnable absorber rods/control blades) [15]. These modeling parameters have been shown to increase the concentrations of nuclides with important contributions to neutron (e.g., ${ }^{244} \mathrm{Cm}$ ) and gamma (e.g., ${ }^{154} \mathrm{Eu}$ ) dose rates for cooling time beyond five years. The aforementioned assumptions produce conservative radiation source terms $[16,3,5]$. The fission product nuclide ${ }^{137} \mathrm{Cs}\left(\mathrm{T}_{1 / 2}=30.07\right.$ years $)$ is the dominant gamma radiation source for cooling time beyond ten 
years, producing $0.662-\mathrm{MeV}$ photons from the decay of daughter nuclide ${ }^{137 \mathrm{~m}} \mathrm{Ba}\left(\mathrm{T}_{1 / 2}=2.552 \mathrm{~min}\right)$. The

${ }^{137} \mathrm{Cs}$ concentration in SNF composition was found to be insensitive to the depletion parameters [5].

\subsection{SHIELDING CALCULATION METHOD}

Dose rate calculations were performed with Monaco with Automated Variance Reduction using Importance Calculations (MAVRIC) [7], which is a Monte Carlo shielding sequence in SCALE 6.2.3. MAVRIC has the following calculation capabilities: (1) continuous-energy Monte Carlo transport, (2) automated variance reduction, (3) point detector, region, and mesh tallies, (4) simplified source term descriptions (e.g., direct use of radiation source terms from ORIGEN produced binary files), and (5) automated post-processing of mesh tally files.

Variance reduction refers to methods and techniques that significantly increase the efficiency of Monte Carlo radiation transport calculations. A variance reduction method referred to as forward-weighted consistent adjoint driven importance sampling (FW-CADIS) [17] was used to obtain dose rate estimates with good statistical accuracy in air regions surrounding the cask. This method requires both forward and adjoint discrete ordinates calculations with Denovo [18] to generate space- and energy-dependent scalar forward and adjoint fluxes. The adjoint calculation solution identifies the source spatial regions and energy ranges that make important contributions to dose rate in the external regions of a cask. The particles that make important contributions to dose rate are sampled more often to increase calculation efficiency.

Dose rate calculations presented in this report used the FW-CADIS method for variance reduction, the SCALE continuous-energy cross section data library based on the ENDF/B-VII.1 data, cylindrical mesh tallies, and the American National Standards Institute (ANSI) / American Nuclear Society (ANS) 6.1.11977 neutron and photon flux-to-dose-rate conversion factors [19].

\subsection{METHOD TO COMPUTE COOLING TIMES FOR A DECAY HEAT}

To maintain decay heat as a constant, a reliable means was needed to compute a cooling time for a given decay heat, enrichment, and burnup. A python script developed from RG3.54r2 [1] which was capable of computing a decay heat was used with a root finder function to accomplish this task. It produced results similar to those in the UNF-ST\&DARDS database, as seen in Appendix A.

The decay heat inverse calculator was then used to provide inputs to ORIGAMI through UNFST\&DARDS to obtain decay heats close to those desired. The initial plan was to provide the inputs directly, but an iterative approach was taken. In each iteration, the proportional difference in the desired decay heat, and the resultant decay heat from ORIGAMI was applied to the decay heat requested from the inverse function. This resulted in decay heats from ORIGAMI well within $1 \%$ of the desired decay heat on the second iteration. Because the decay heat was verified using ORIGAMI, the RG-3.54r2 script is only a labor-saving tool, and its performance does not affect the final result in any way. Burnup, enrichment, and cooling time combinations used in this study are presented in Table 4 for decay heats of $1,200 \mathrm{~W}$ per assembly, and in Table 5 for decay heat of $860 \mathrm{~W}$ per assembly. In producing these cooling times, a burn time of 3.23 years, which is the median assembly burn time obtained from UNFST\&DARDS (see Appendix A for more detail). Additional cooling time-burnup calculations, not shown here, were also computed for the assemblies in zone-loaded casks. 
Table 4. Cooling times (years) to achieve $1,200 \mathrm{~W}$ decay heat for various burnups

\begin{tabular}{lccccc}
\hline \multirow{2}{*}{ Assembly type } & Enrichment (w\%) & $\mathbf{2 . 0}$ & $\mathbf{3 . 0}$ & $\mathbf{4 . 0}$ & $\mathbf{5 . 0}$ \\
\cline { 2 - 6 } & Burnup (GWd/MTU) & & & & \\
\hline BnW_Mark_B10 & 20 & 2.29 & 2.17 & 2.09 & 2.02 \\
& 28 & 3.32 & & & \\
& 40 & & 4.97 & 4.73 & 4.56 \\
42 & & 5.37 & & \\
& 56 & & & 9.52 & \\
& 65 & & & & 14.57 \\
\hline C1414C & 20 & 1.80 & 1.68 & 1.61 & 1.56 \\
& 28 & 2.66 & & & \\
& 40 & & 3.85 & 3.67 & 3.53 \\
& 42 & & 4.11 & & \\
& 56 & & & 6.21 & \\
WE_Vantage_5H & 65 & & & & 8.19 \\
& 20 & 2.17 & 2.06 & 1.98 & 1.92 \\
& 28 & 3.15 & & & \\
& 40 & & 4.68 & 4.47 & 4.31 \\
& 42 & & 5.05 & & \\
& 56 & & & 8.57 & \\
& 65 & & & & 12.82 \\
\hline
\end{tabular}

Table 5. Cooling times (years) to achieve $860 \mathrm{~W}$ decay heat for various assembly average burnups

\begin{tabular}{lccccc}
\hline & Enrichment (\%) & $\mathbf{2 . 0}$ & $\mathbf{3 . 0}$ & $\mathbf{4 . 0}$ & $\mathbf{5 . 0}$ \\
\cline { 2 - 6 } Assembly type & Burnup (GWd/MTU) & & & & \\
\hline BnW_Mark_B10 & 20 & 3.05 & 2.91 & 2.81 & 2.74 \\
& 28 & 4.45 & & & \\
40 & & 7.70 & 7.25 & 6.93 \\
& 42 & & 8.74 & & \\
& 56 & & & 21.47 & \\
& 65 & & & & 30.75 \\
\hline C1414C & 20 & 2.44 & 2.31 & 2.22 & 2.15 \\
& 28 & 3.52 & & & \\
& 40 & & 5.37 & 5.09 & 4.88 \\
& 42 & & 5.84 & & \\
& 56 & & & 11.09 & \\
WE_Vantage_5H & 65 & & & & 17.29 \\
& 20 & 2.89 & 2.76 & 2.67 & 2.60 \\
& 28 & 4.21 & & & \\
& 40 & & 7.03 & 6.63 & 6.36 \\
& 42 & & 7.88 & & \\
& 56 & & & 18.99 & \\
& 65 & & & & 28.24 \\
\hline
\end{tabular}

\subsection{RADIATION TRANSPORT MODELING}

MAVRIC cask templates were used to evaluate dose rates stemming from the computed source terms using ORIGEN. UNF-ST\&DARDS was used as an automation engine producing the thousands of lines required for each MAVRIC input file and the inputs for each ORIGEN depletion case. Generic cask 
templates were developed based on the Holtec International (HI)-STAR 190 transportation cask, the HISTAR variable weight (VW) transfer cask, and the Holtec International Storage Module Flood and Wind (HI-STORM FW) storage cask. A generic canister based on Holtec International's multipurpose canister (MPC)-37 design was modeled for all cases. All combinations of assembly types and enrichments were modeled in each cask.

\subsubsection{Transport package model}

The generic transport cask models for normal conditions of transport (NCT) and hypothetical accident conditions (HAC) are illustrated in Figure 1. The generic transport cask model for NCT has a carbon steel structural shell, a carbon steel base plate, and a top carbon steel lid, gamma shield, and neutron shield. Shielding against gamma radiation emitted in the radial direction is provided by $8.89 \mathrm{~cm}$ of lead and a total of $14.5 \mathrm{~cm}$ of carbon steel. A layer of $16 \mathrm{~cm}$ of borated hydrogenous material provides shielding against neutrons emitted in the radial direction. The cask's bottom plate has a thickness of $30 \mathrm{~cm}$, which includes an upper $15 \mathrm{~cm}$ carbon steel plate, a $5 \mathrm{~cm}$ layer of lead, and a lower $10 \mathrm{~cm}$ carbon steel plate. The carbon steel cask lid has a thickness of $17 \mathrm{~cm}$. The generic cask model under HAC is on the right side of Figure 1 and has no neutron shield. This study used the cask model for NCT, which is shown on the left-hand side of the figure. 


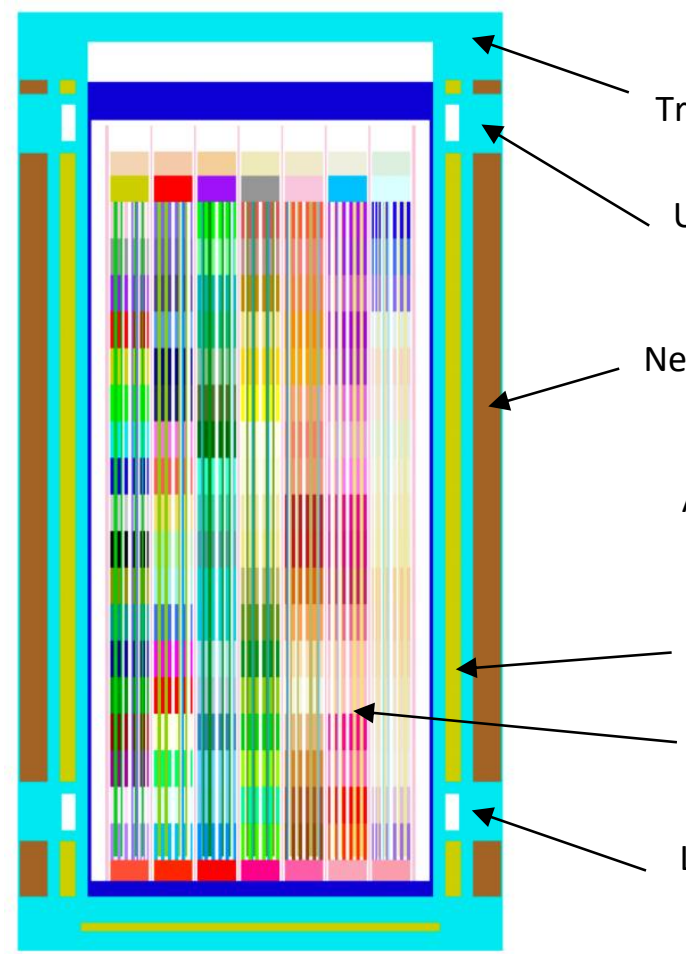

(vertical midplane cross section)

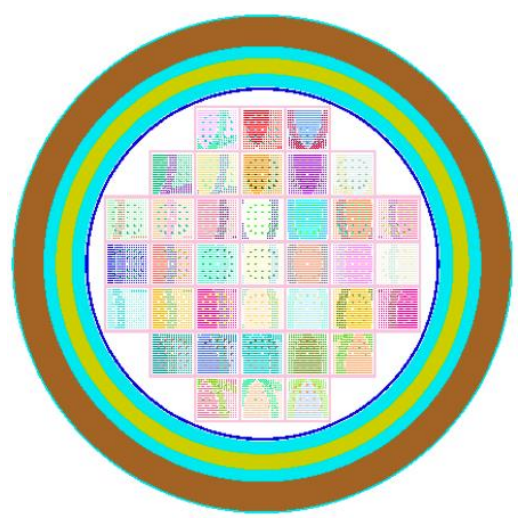

(axial cross section)

(a) NCT

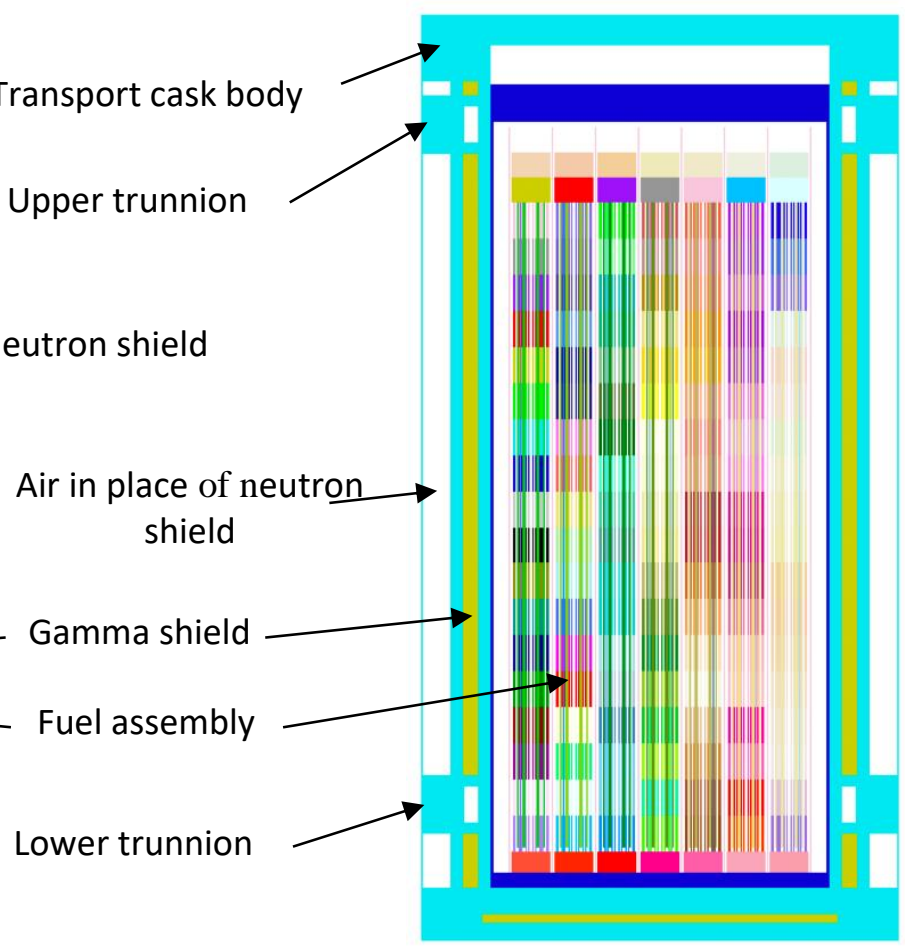

(vertical midplane cross section)

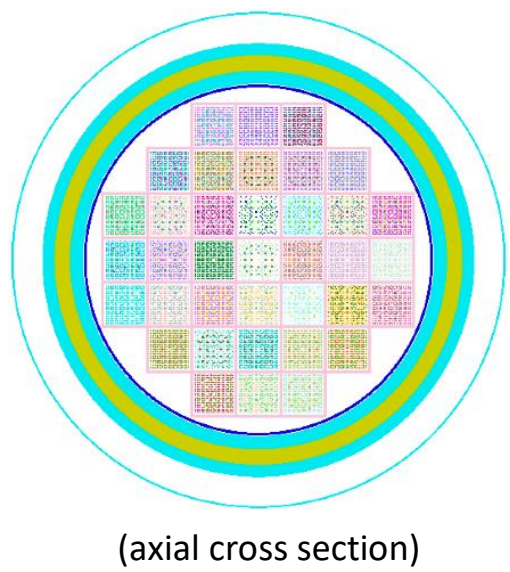

(b) HAC (not used in this analysis)

Figure 1. Cross section views of the generic transportation cask models for (a) normal conditions of transport (left) and (b) hypothetical accident conditions (right).

\subsubsection{Transfer cask model}

A transfer cask is used to move fuel from the spent fuel pool to the dry storage system. The transfer cask model for normal conditions is presented in Figure 2, and the model for accident conditions is provided in

Figure 3. The transfer cask has a $7 \mathrm{~cm}$ radial layer of lead for gamma shielding and a $12 \mathrm{~cm}$ radial layer of water for neutron shielding. For the accident scenario assumed in this study, the cask model contains air 
in place of water in the water jacket. The cask is sitting on a $30 \mathrm{~cm}$ thick concrete slab, and it is surrounded by a layer of air with a thickness of $400 \mathrm{~m}$ in the radial and upward directions. The dose rate for the accident condition is calculated at $1 \mathrm{~m}$ and $100 \mathrm{~m}$ from the radial surface of the transfer cask.

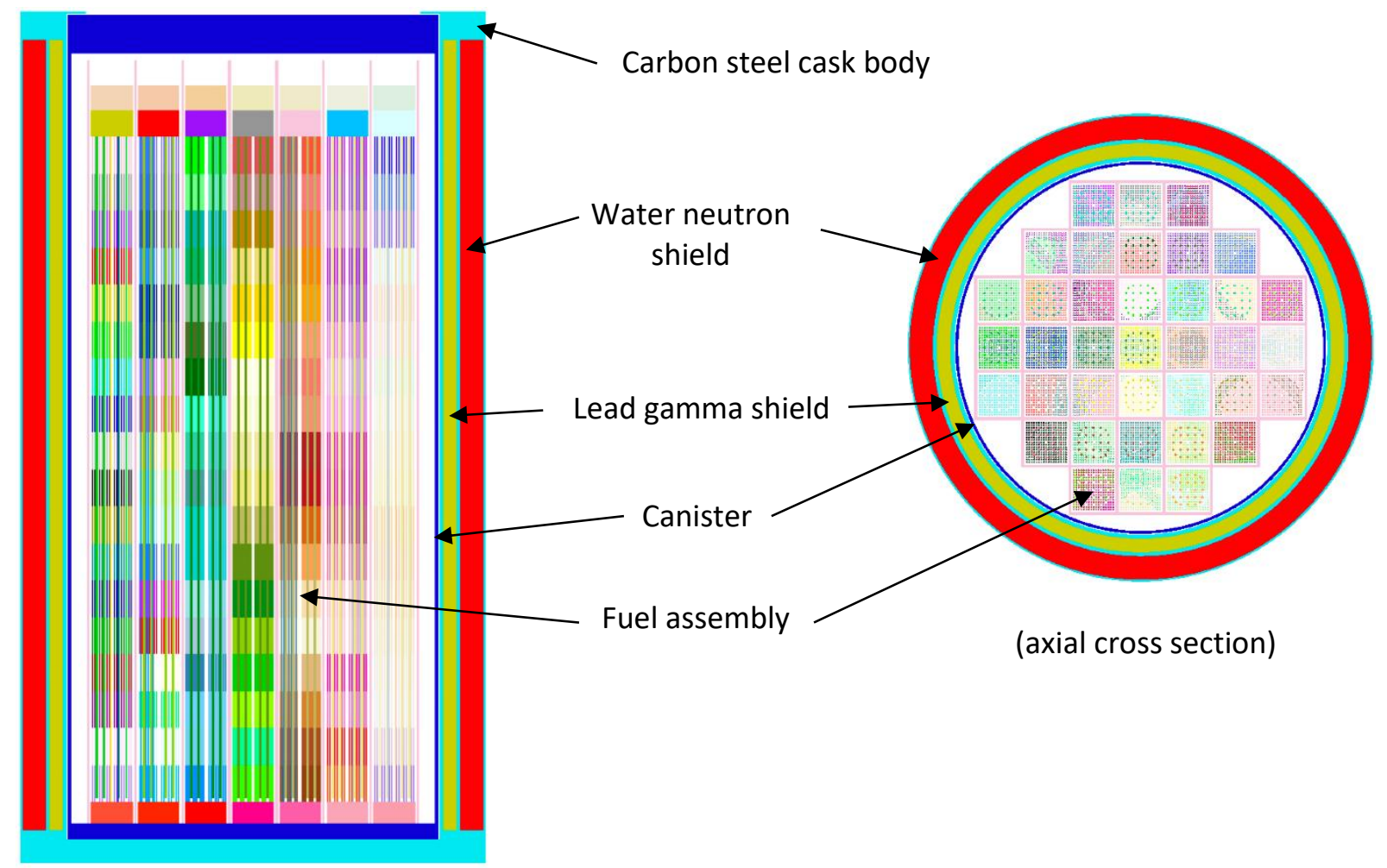

(vertical midplane cross section)

Figure 2. Transfer cask model for normal conditions (not used in this analysis). 


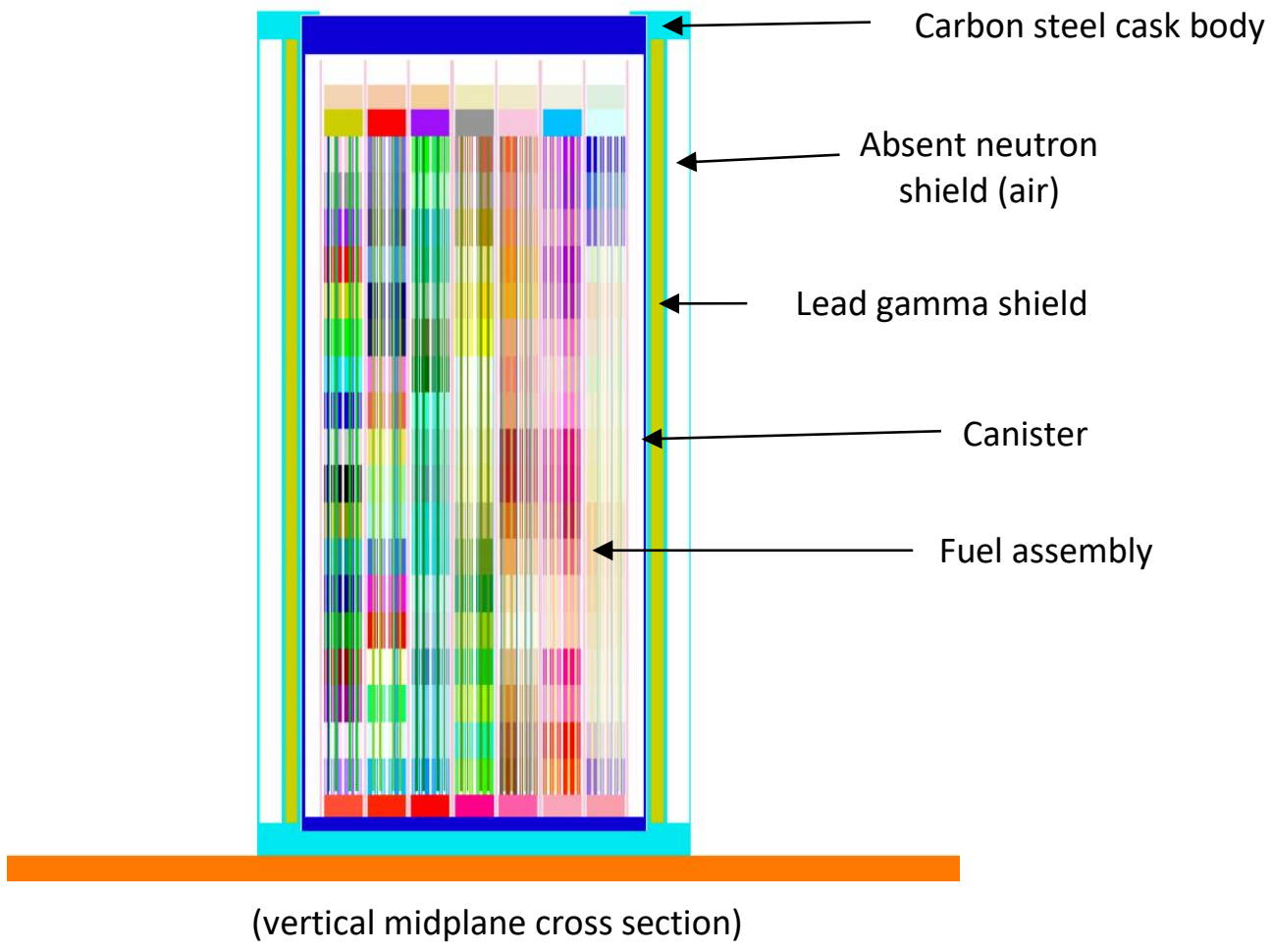

Figure 3. Transfer cask model for accident conditions.

\subsubsection{Storage cask model}

The storage cask model is illustrated in Figure 4. Unlike the transfer and transportation casks, it uses concrete as a shielding material. The storage cask is roughly equivalent to the concrete cask described in NUREG/CR-6700. The cask in this model has a wall thickness of $75 \mathrm{~cm}$, whereas the cask in the NUREG has a $50 \mathrm{~cm}$ wall thickness, so attenuation by the cask represented in the NUREG is less. 

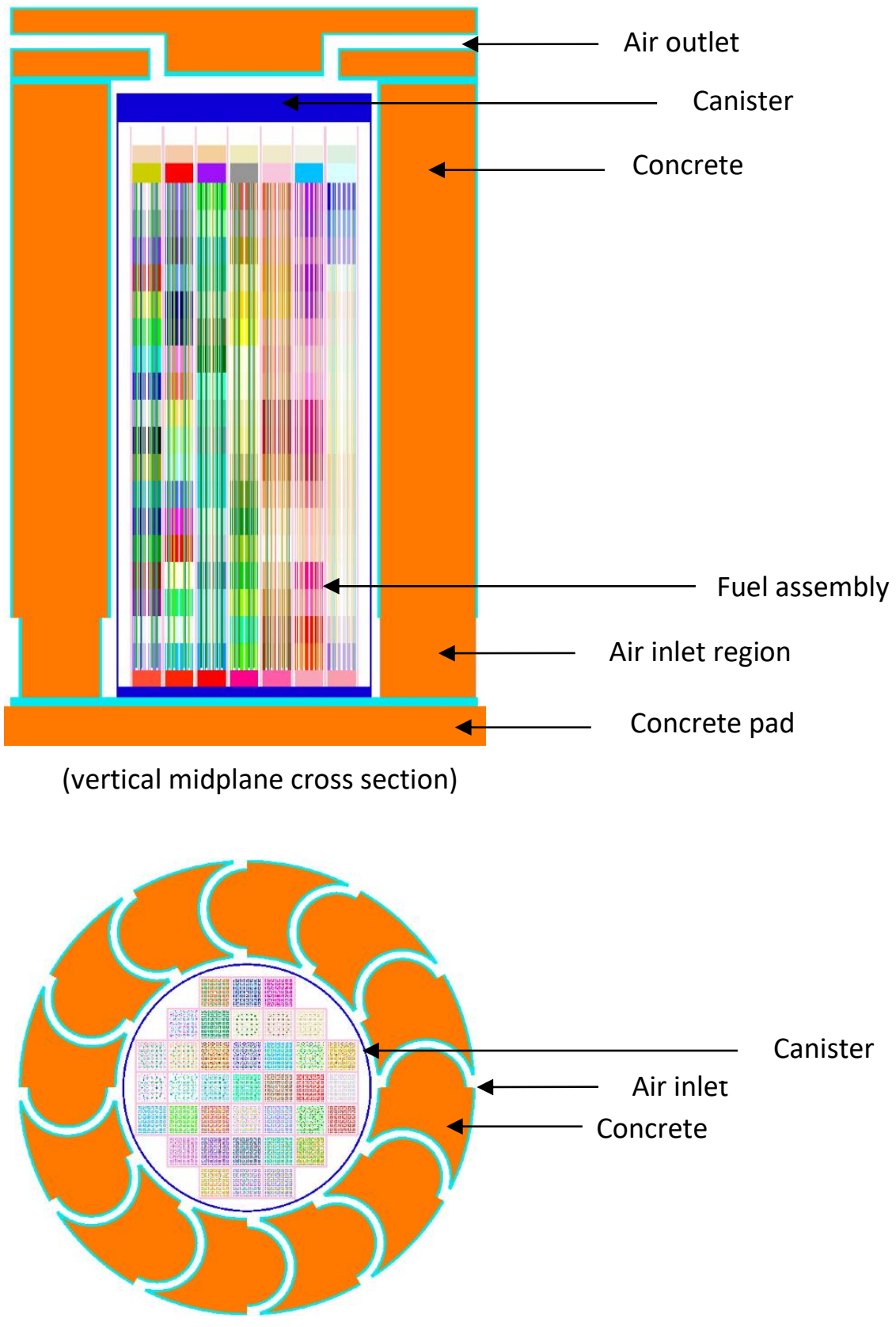

(axial cross section)

Figure 4. Storage cask model used in this study.

\subsubsection{Dose rate locations}

Average dose rate values are calculated in air at 1,2, or $100 \mathrm{~m}$ from the radial surface of the cask, depending on overpack type (see Table 6), or they are calculated at the cask's bottom surface. 
Table 6. Dose rate locations

\begin{tabular}{ll}
\hline Overpack type and condition & Dose rate location \\
\hline Storage, normal conditions & $1 \mathrm{~m}$ from cask radial surface \\
\hline Transfer, normal conditions & $1 \mathrm{~m}$ from cask radial surface \\
(not evaluated in this report) & Cask bottom surface (not evaluated) \\
\hline Transfer, accident conditions & $1 \mathrm{~m}$ from cask radial surface \\
\hline Transportation, NCT & $100 \mathrm{~m}$ from cask radial surface \\
\hline Transportation, HAC & $2 \mathrm{~m}$ from cask radial surface \\
(not evaluated in this report) & Cask bottom surface (not evaluated) \\
\hline
\end{tabular}

The radial dose rate was used to assess the effects of fuel assembly characteristics on dose rate produced by the active fuel. The dose rate at the cask's bottom surface was used to assess the effects of fuel assembly characteristics on dose rate produced by the ${ }^{60} \mathrm{Co}$ activation source in fuel hardware. The dose rate tally volume at $1 \mathrm{~m}$ from the storage cask's radial surface is illustrated in Figure 5.
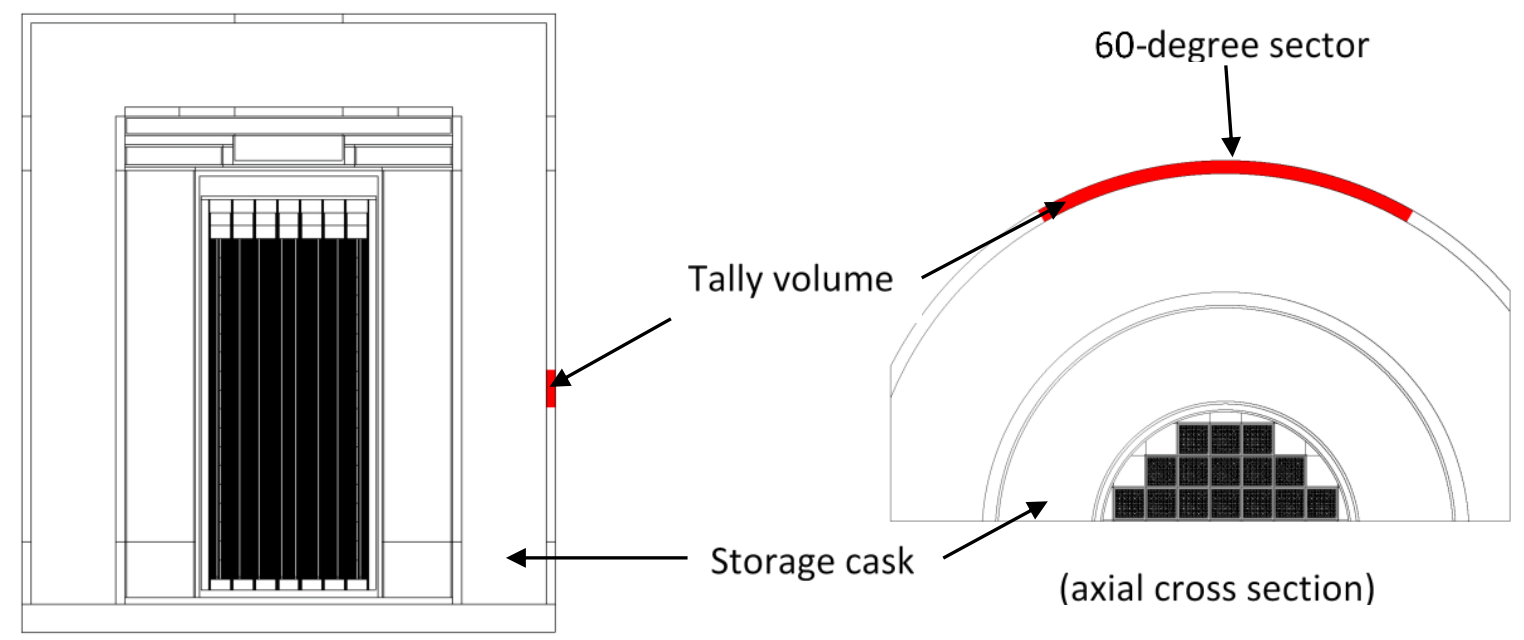

(vertical midplane cross section)

Figure 5. Illustration of the air volume at $1 \mathrm{~m}$ from the radial surface of the storage cask.

For the transfer cask under accident conditions, dose rate was calculated at 1 and $100 \mathrm{~m}$ from the radial cask surface. To calculate dose rate in air at $1 \mathrm{~m}$ from the radial cask surface, a cylindrical tally mesh was defined at $1 \mathrm{~m}$ from the radial cask surface. This cylindrical tally mesh was $3 \mathrm{~cm}$ wide and $450 \mathrm{~cm}$ high, and it contained 25 uniform axial segments and 20 uniform azimuthal segments. The reported dose rate value at $1 \mathrm{~m}$ from the radial cask surface is the maximum dose rate value within the voxels of this tally mesh. To calculate dose rate in air at $100 \mathrm{~m}$ from the radial cask surface, a cylindrical tally mesh was defined at $100 \mathrm{~m}$ from the radial cask surface. This cylindrical tally mesh was $100 \mathrm{~cm}$ wide and $\sim 40 \mathrm{~cm}$ high, and it contained 10 uniform axial segments. The reported dose rate value at $100 \mathrm{~m}$ from the radial cask surface is the maximum dose rate value within the voxels of this tally mesh.

The dose rate at $2 \mathrm{~m}$ from the radial transport cask's surface was averaged within a $10 \mathrm{~cm}$ wide, $40 \mathrm{~cm}$ high cylindrical axial location at fuel midplane. The azimuthal extent was 60 degrees. Maximum mesh tallies are reported. 


\subsection{ANALYSIS DESIGN}

A factorial design was used to examine the contributions of the factors considered in this work including burnup, enrichment, cask type, assembly type, and uniform cask loading. These are listed in section 2.6.1. In the factorial study, dose measurement location, the total decay heat and loading map used for nonuniform loading change with cask type, but they are consistent for each individual cask type.

Benefitting from the knowledge gained from the factorial study, a follow-on case was evaluated to show that a transportation cask having uniform decay heat but non-uniform burnups can give higher dose rates than any of the corresponding cases in the factorial study. The follow-on case will be discussed in its own section of this report to avoid confusion with the broader factorial study.

Combinations of burnups and cooling times were obtained using a root-finder algorithm coupled to the RG3.54r2 script. As previously mentioned in section 2.4, these did not exactly produce the desired decay heat in UNF-ST\&DARDS. To remedy this, the ratio of desired decay heat to the first iteration's resulting decay heat was multiplied by the desired decay heat. The product was entered into the RG3.54r2 root finder to obtain burnups that produced decay heats that were well within $1 \%$ of the desired decay heat in UNF-ST\&DARDS produced Origen simulations.

\subsubsection{Factor levels}

Burnup: Three principal factor levels were selected for assembly average burnup: $20 \mathrm{GWd} / \mathrm{MTU}, 40$ GWd/MTU, and $65 \mathrm{GWd} / \mathrm{MTU}$. The maximum applicable value of burnup in RG3.54r2 is 65 GWd/MTU. RG3.54r2 also is only applicable for burnups (in GWd/MTU) that are 14 times the initial enrichment (in weight percent) of the assembly. At this burnup, ${ }^{235} \mathrm{U}$ has been depleted for a time, so assemblies burnt beyond this point are far from representative. Therefore, the maximum burnup of 14 times the enrichment in terms of weight percent is used in lieu of higher burnup points, consistent with the regulatory guide.

Enrichment: Enrichment factor levels were chosen to be $2 \mathrm{wt} \%$, 3wt $\%$, 4wt $\%$ and $4.999 \mathrm{wt} \%$. A factor level of $4.999 \mathrm{wt} \%$ was used as an approximation of $5 \mathrm{w} \%$ to avoid the edge of an interpolation table in the RG3.54r2 python script. This interpolation issue has since been resolved.

Cask type: Generic casks loosely based on the HI-STORM FW, HI-TRAC VW and HI-STAR 190 are developed and used to roughly represent the range of casks encountered in SNF storage and transportation. Hypothetical accident condition was assumed for the transfer cask to include a case under accident conditions. Normal conditions of transport were assumed for the transportation cask.

Assembly type: PWR assemblies representing the range of masses of assemblies specified in GC-859 [20,21] are listed: Combustion Engineering 14×14 (C1414C), Westinghouse Vantage 5 (WE Vantage 5), and Babcock and Wilcox Mark 10 (B\&W Mark B10).

Uniform cask loading versus zone loading: Two decay heat limit maps were applied for each cask, one uniform, and one non-uniform. Because transportation casks have lower thermal capacities, the loadings vary with cask type. The analyses were performed for PWR fuel using MPC-37 canisters.

The decay heat limits in Table 7 were used for storage and transfer. These limits are taken from HISTORM FW Final Safety Analysis Report (FSAR). Pattern B from the FSAR (Table 7) was used because it supports loading the highest decay heat assemblies at the peripheral locations. Assemblies self-shield gamma dose, so placing higher heat assemblies toward the periphery of the cask is expected to increase gamma dose rate at the tally location outside the cask. 
Table 7. Pattern B for HI-STORM FW (Total $\sim 45 \mathrm{~kW}$ )

\begin{tabular}{ccc}
\hline Zone & $\begin{array}{c}\text { Decay heat } \\
(\mathbf{k W})\end{array}$ & $\begin{array}{c}\text { Number of } \\
\text { assemblies }\end{array}$ \\
\hline 1 & 1.0 & 9 \\
2 & 1.2 & 12 \\
3 & 1.35 & 16 \\
\hline
\end{tabular}

A hypothetical uniform loading was also applied for storage and transfer. It maintained heat generation rates at $1.2 \mathrm{~kW}(\sim 45 \mathrm{~kW} / 37)$ per assembly in all locations of the storage and transfer casks.

Similarly, Pattern 5 (Table 8) was used for the transportation cask (total $\sim 32 \mathrm{~kW}$ ). Unlike the storage map, pattern 5 places hotter assemblies in an intermediate zone (between peripheral and central locations).

Table 8. Pattern 5 for HI-STAR 190 (Total $\sim 32 \mathrm{~kW}$ )

\begin{tabular}{ccc}
\hline Zone & $\begin{array}{c}\text { Decay heat } \\
(\mathbf{k W})\end{array}$ & $\begin{array}{c}\text { Number of } \\
\text { assemblies }\end{array}$ \\
\hline 1 & 0.8 & 9 \\
2 & 0.95 & 12 \\
3 & 0.84 & 16 \\
\hline
\end{tabular}

For the transportation cask, a hypothetical uniform loading, was applied, with $0.86 \mathrm{~kW}(\sim 32 \mathrm{~kW} / 37)$ assemblies loaded at all locations.

\section{RESULTS}

\subsection{NEUTRON AND GAMMA CONTRIBUTIONS}

Perhaps the first notable characteristic of the results is their non-monotonic nature in some cases. In the burnup ranges examined, gamma dose tends to decrease linearly with increasing burnup when cooling time is adjusted to keep decay heat constant, while neutron dose tends to increase with increasing burnup. As seen in the figures below, dose rates from transfer casks can either be neutron or gamma dominated, with gamma dominating at lower burnups and neutrons dominating at higher burnups. This can be seen in the isocaloric neutron and photon dose rate curves in Figure 6 through Figure 8. The dose rate at a midrange burnup along an isocaloric curve can be lower than either high or low burnup fuel. Note that the transfer cask is assumed to have no neutron shield throughout this report because it represents a hypothetical accident case. Throughout this report, error bars are 1 standard deviation, and they correspond to the Monte Carlo uncertainty produced in the MAVRIC radiation transport calculation. Colors correspond to enrichment level.

Neutron dose for spent fuel casks increases with burnup due to increased production of spontaneous fission sources such as ${ }^{244} \mathrm{Cm}$ and production of transuranic actinides that indirectly produce neutrons through $(\alpha, n)$ reactions $[3,5]$. This is driven by neutron absorption of ${ }^{238} \mathrm{U}$, so lower enrichment produces more actinides for a given burnup. These neutron producing isotopes often have longer half-lives, so the increase in cooling time to maintain constant decay heat does not readily reduce their activity. Therefore, higher burnup and higher cooling time assemblies are generally dominated by neutron dose. 
Gamma sources are often dominated by shorter lived isotopes such as ${ }^{144} \mathrm{Pr}$ at short cooling times [3,5]. Also, gamma sources are more often the result of fission directly. For the timeframes of interest, long lived actinides become a larger portion of the decay heat at longer cooling times and higher burnups, while fission products tend to decay faster than actinides. These considerations suggest that fewer fission products might remain at higher burnups under the isocaloric constraint (high cooling time to maintain same decay heat) than at lower burnups (low cooling time to maintain same decay heat). In other words, under isocaloric condition, lower burnup and lower cooling time assemblies are expected to be gamma dominated, whereas higher burnup and higher cooling time assemblies are expected to be neutron dominated. This could then drive the dose trends as observed in Figures 6 through 8 .

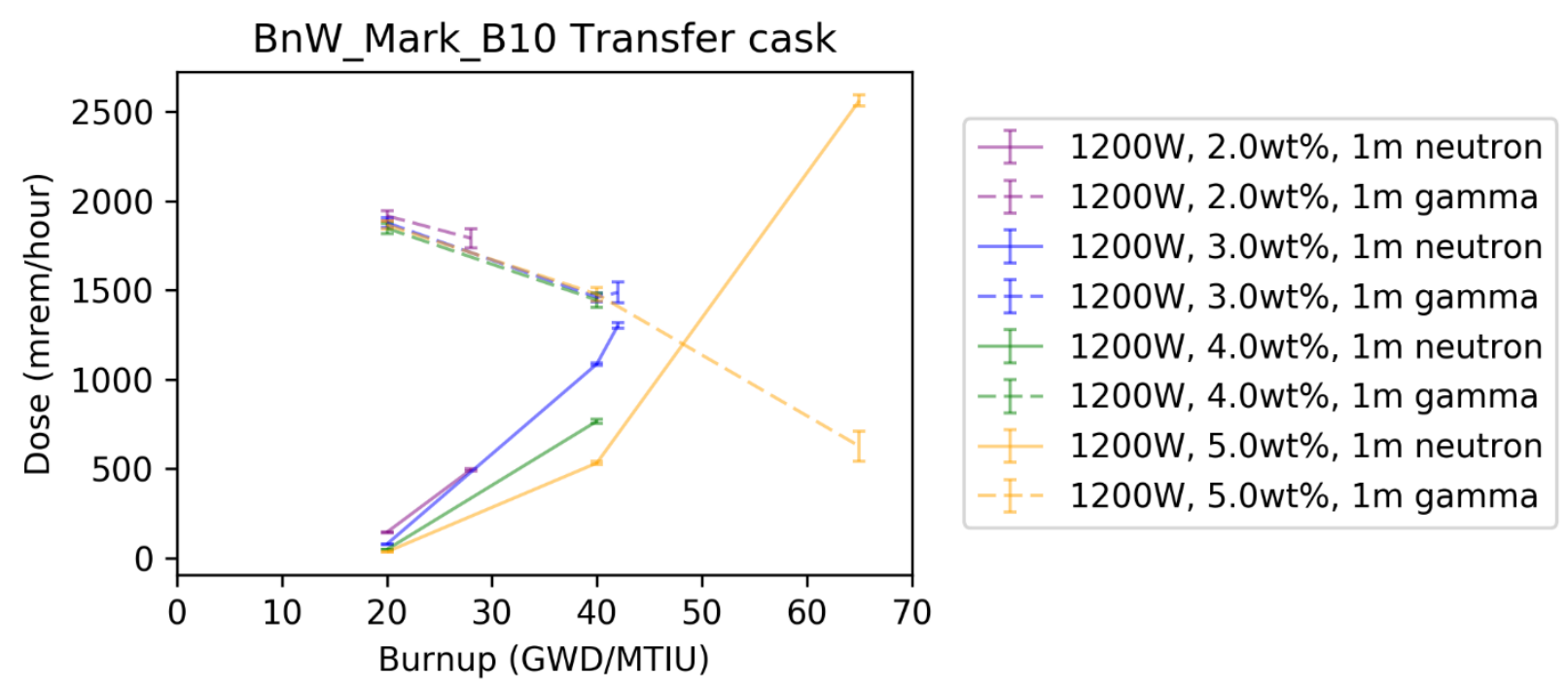

Figure 6. Isocaloric dose rate curves for neutrons and gammas for $1,200 \mathrm{~W}$ per assembly transfer cask, without a neutron shield, loaded with B\&W 14×14 B10 SNF assemblies.

A notable feature of the isocaloric neutron dose rate curves is that the dose rate varies with enrichment. In contrast, the isocaloric gamma dose rate curves do not vary as strongly for the transfer cask. 


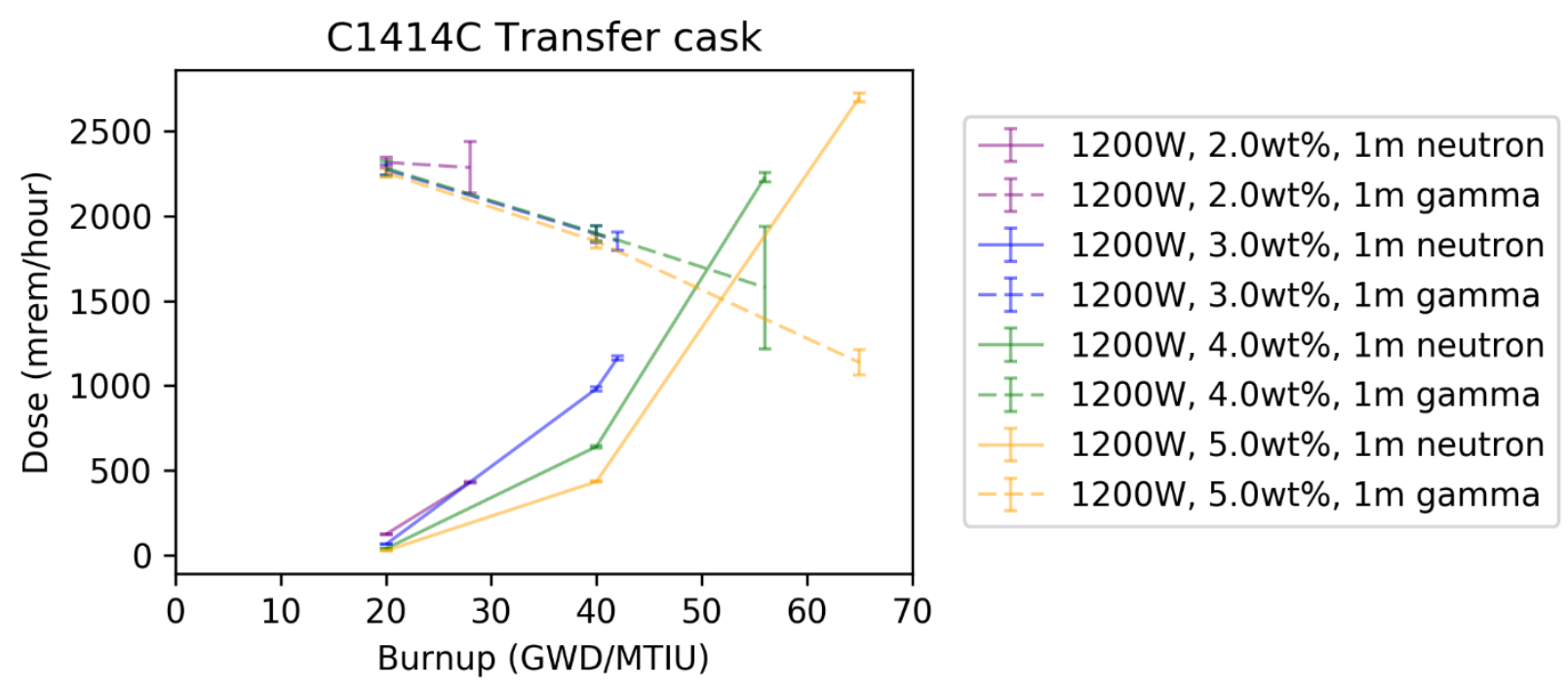

Figure 7. Isocaloric dose rate curves for neutrons and gammas for $1,200 \mathrm{~W}$ per assembly transfer cask, without a neutron shield, loaded with CE 14×14 C SNF assemblies.

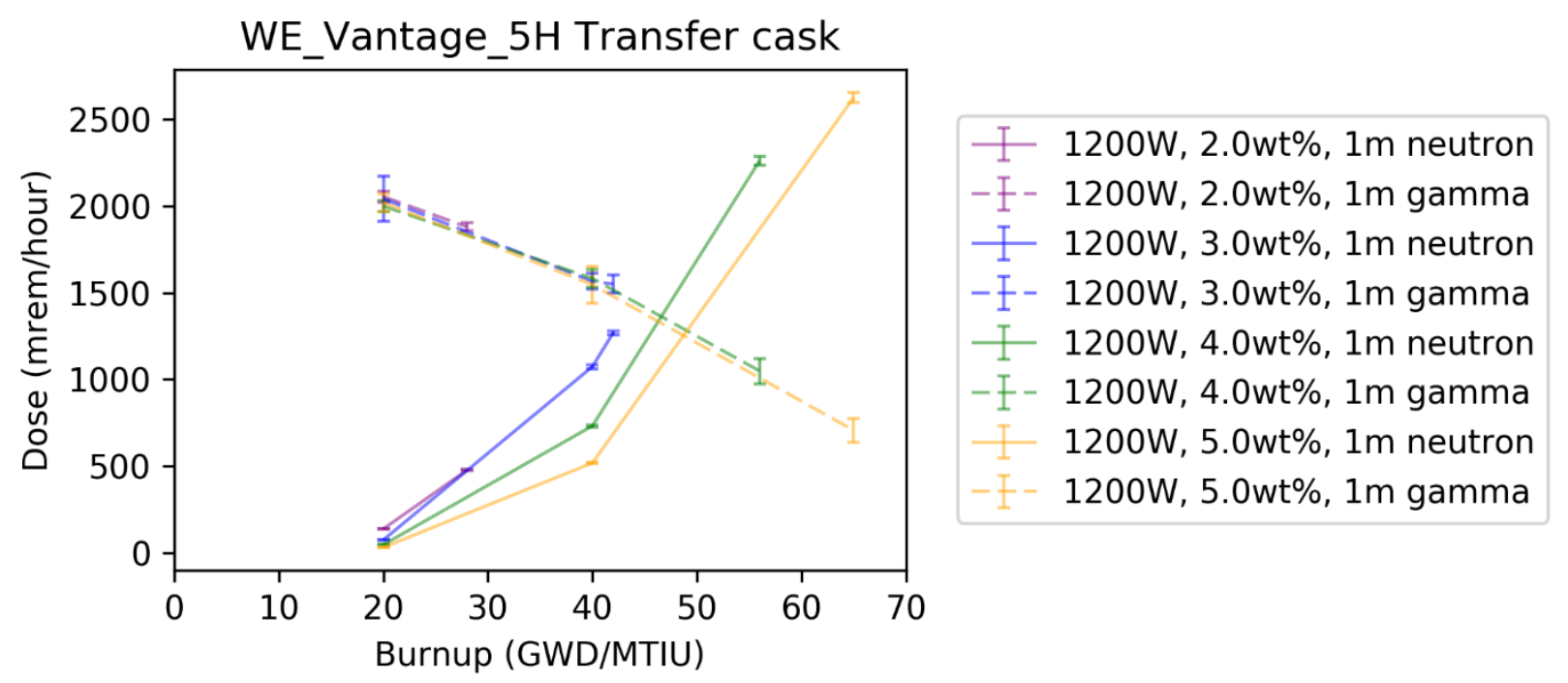

Figure 8. Isocaloric dose rate curves for neutrons and gammas for 1,200 W per assembly transfer cask, without a neutron shield, loaded with Westinghouse Vantage 5H SNF assemblies.

Figure 9 shows that the generic storage cask used in this analysis shields neutrons extremely well compared to shielding for gammas. Note that concrete composition is variable, and a dose analysis applicable to a specific concrete used should be made. In this case, the storage cask has $75 \mathrm{~cm}$ sidewalls, whereas in NUREG/CR-6700, $50 \mathrm{~cm}$ sidewalls were used. It is expected that the smaller side walls in NUREG/CR-6700 account for the larger neutron fractions (up to 12\%) of total doses that were reported in the NUREG compared to 5\% at higher burnups observed in the data underlying Figure 9. Neutron dose is shown more clearly in Figure 10. The increasing trend that appears exponential is consistent with Figure 13 of NUREG 6700. 


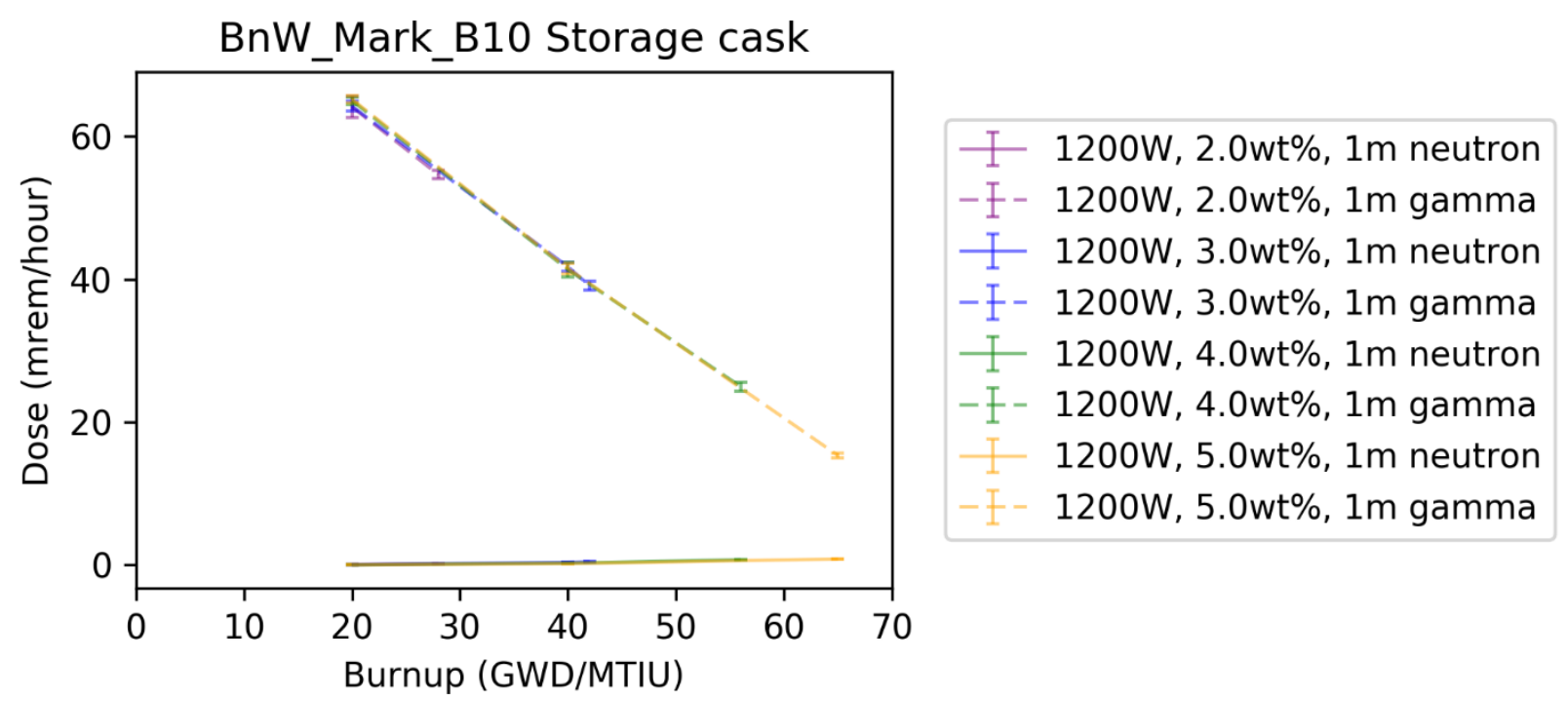

Figure 9. Isocaloric dose rate curves for neutrons and gammas for $1,200 \mathrm{~W}$ storage cask loaded with B\&W $14 \times 14$ B10 SNF assemblies.

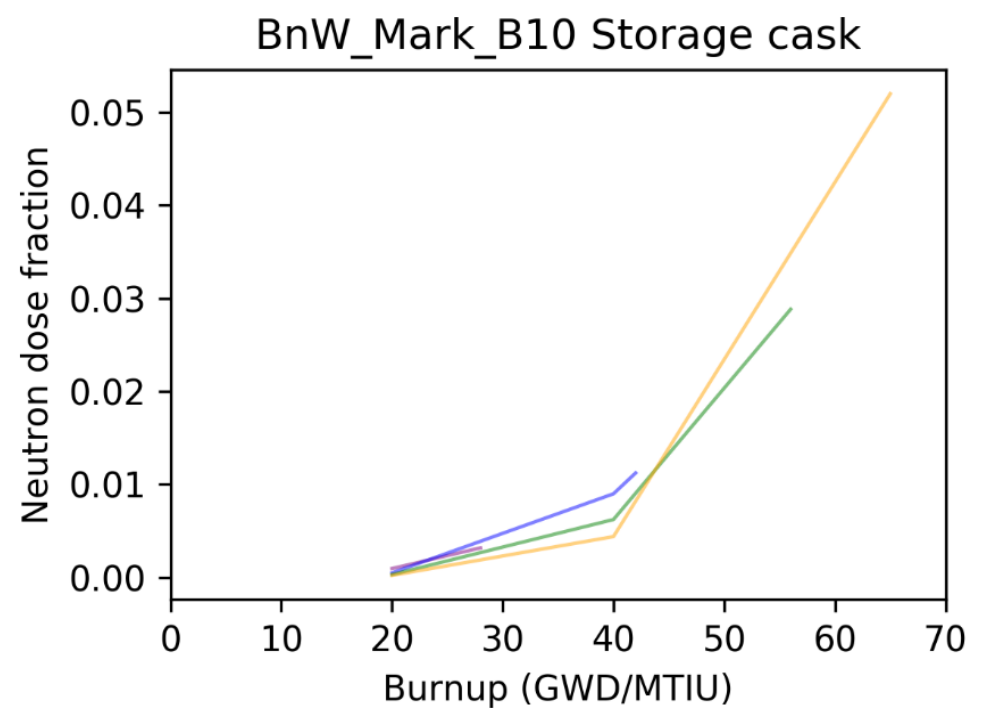

$1200 \mathrm{~W}, 2.0 \mathrm{wt} \%$ $1200 \mathrm{~W}, 3.0 \mathrm{wt} \%$ $1200 \mathrm{~W}, 4.0 \mathrm{wt} \%$ $1200 \mathrm{~W}, 5.0 \mathrm{wt} \%$

Figure 10. Isocaloric neutron dose fractions for $1,200 \mathrm{~W}$ storage cask loaded with B\&W 14×14 B10 SNF assemblies

\subsection{ISOCALORIC DOSE RATE VS. BURNUP}

The plots in Figure 11 through Figure 13 on the following pages show the total dose rate (neutron + gamma) results for assemblies loaded in the various casks when maintaining decay heat as a constant. Line style corresponds to whether a uniform loading or a map (zone loading) was used. All curves appear to be concave up, indicating that the endpoints may be bounding.

In general, the storage cask exhibits a strong gamma trend, whereas the transfer cask appears to have a heavy neutron dose component due to its lack of a neutron shield. The transportation cask with neutron shield intact exhibits gamma-dominated behavior at lower burnups, with a neutron component entering at higher burnups. In fact, dose is at a minimum at mid-range burnups. 
Enrichment tends to affect the isocaloric dose rates more at higher burnup, when neutron dose is dominant. For the case of the storage cask, neutron dose rate is never dominant, so enrichment does not have much effect on dose rate. Changing enrichment has minimal effect when only dose rates from gamma radiation are calculated. Assembly type can change dose rate, but it does not appreciably change the behavior of the isocaloric dose vs. burnup curves. As seen in Appendix A, assembly type principally shifts the cooling time for a given burnup and decay heat.

The assembly loading map used for a cask appears to shift the isocaloric dose vs. the burnup curve upward or downward, while the decay heat within the cask is kept constant. A 10-20\% change is observable here for the changing map in the transfer cask and the storage cask. 

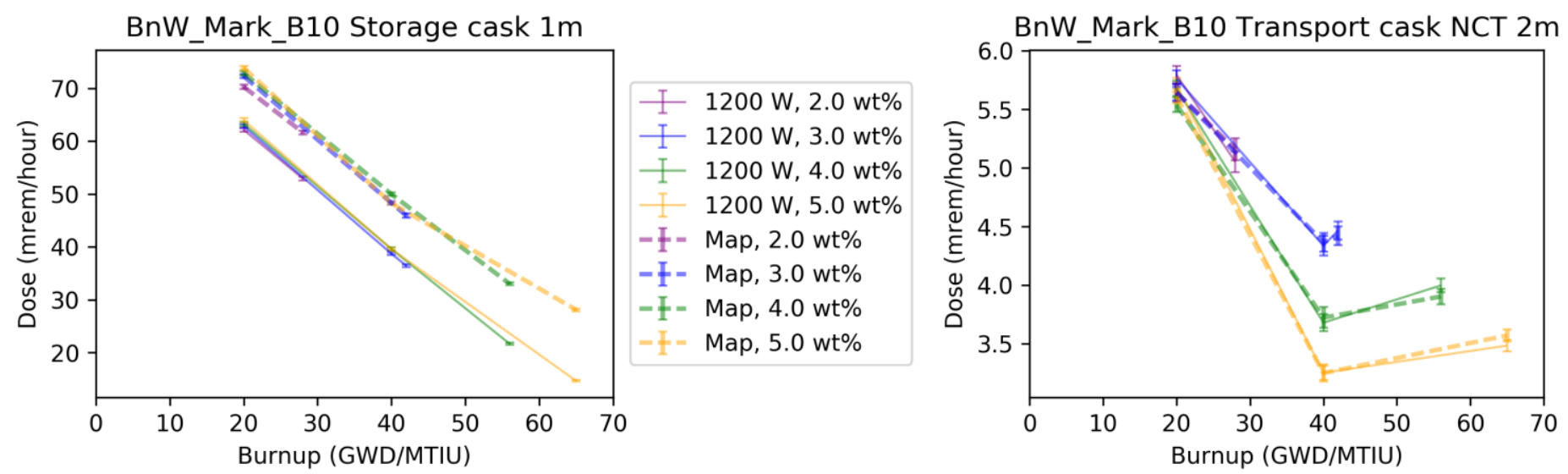
I 860 W, 2.0 wt\%
I $860 \mathrm{~W}, 3.0 \mathrm{wt} \%$
- 860 W, 4.0 wt\%
$860 \mathrm{~W}, 5.0 \mathrm{wt} \%$
- $\mathrm{f}$ - Map, 2.0 wt\%
-f- Map, $3.0 \mathrm{wt} \%$

Map, 2.0 wt\%

- Map, $3.0 \mathrm{wt} \%$

- - Map, 4.0 wt\%

Map, 5.0 wt\%
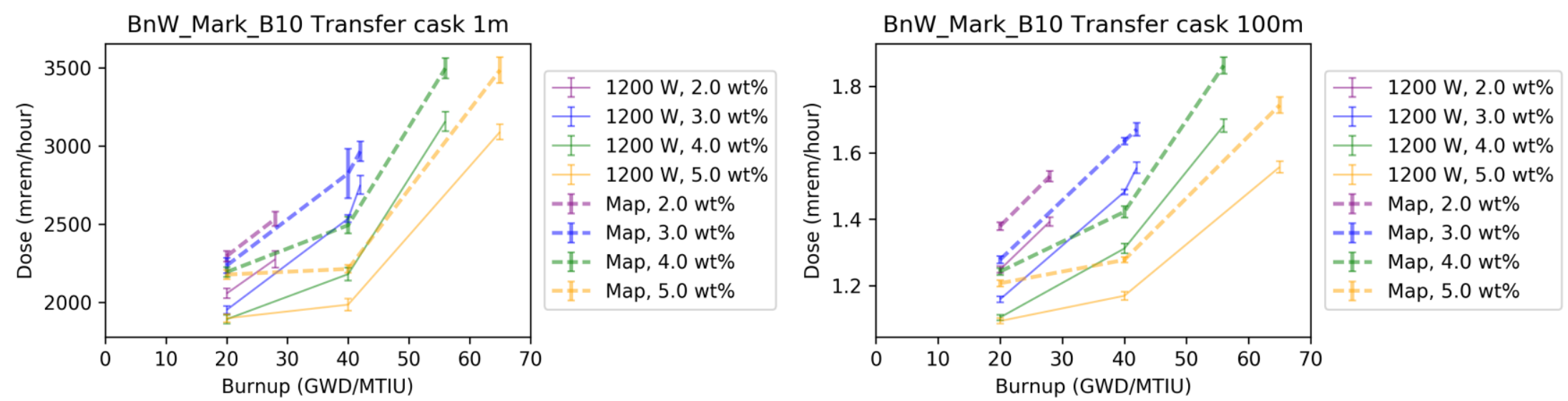

Figure 11. Isocaloric dose rate vs. burnup curves for casks loaded with B\&W 14×14 B10 SNF assemblies. 

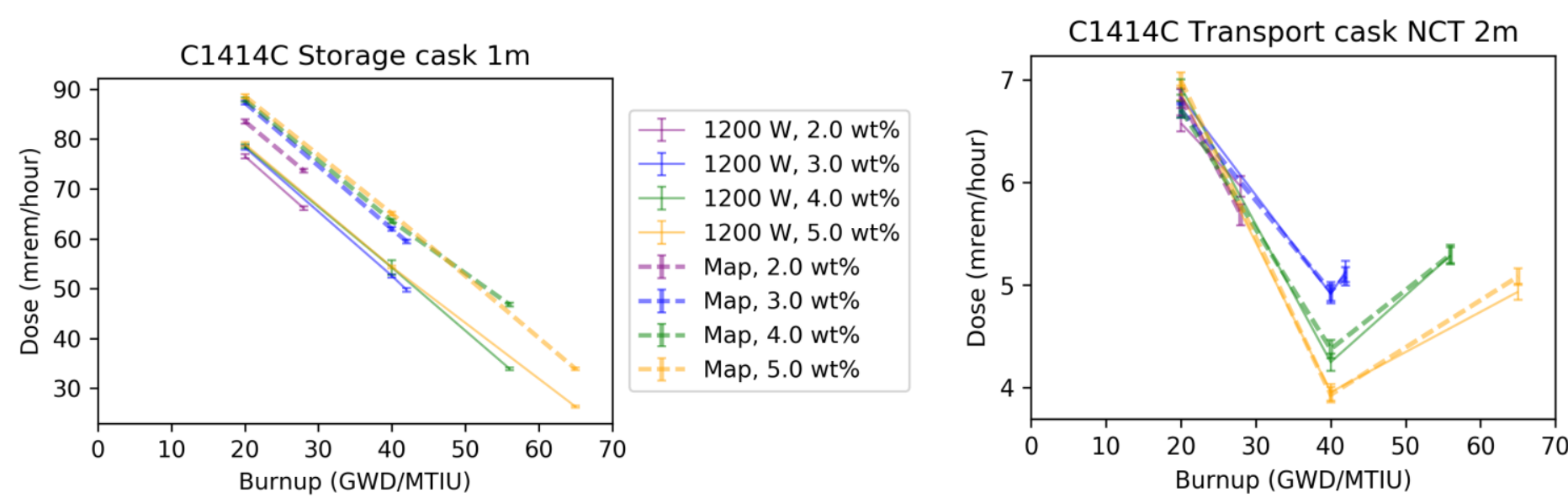

I 860 W, $2.0 \mathrm{wt} \%$

I $1200 \mathrm{w}, 2.0 \mathrm{wt} \%$

$1200 \mathrm{~W}, 3.0 \mathrm{wt} \%$

$1200 \mathrm{~W}, 4.0 \mathrm{wt} \%$

$1200 \mathrm{~W}, 5.0 \mathrm{wt} \%$

- $\mathrm{F}$ - Map, 2.0 wt\%

-F - Map, $3.0 \mathrm{wt} \%$

- - Map, 4.0 wt\%

- Map, 5.0 wt\%
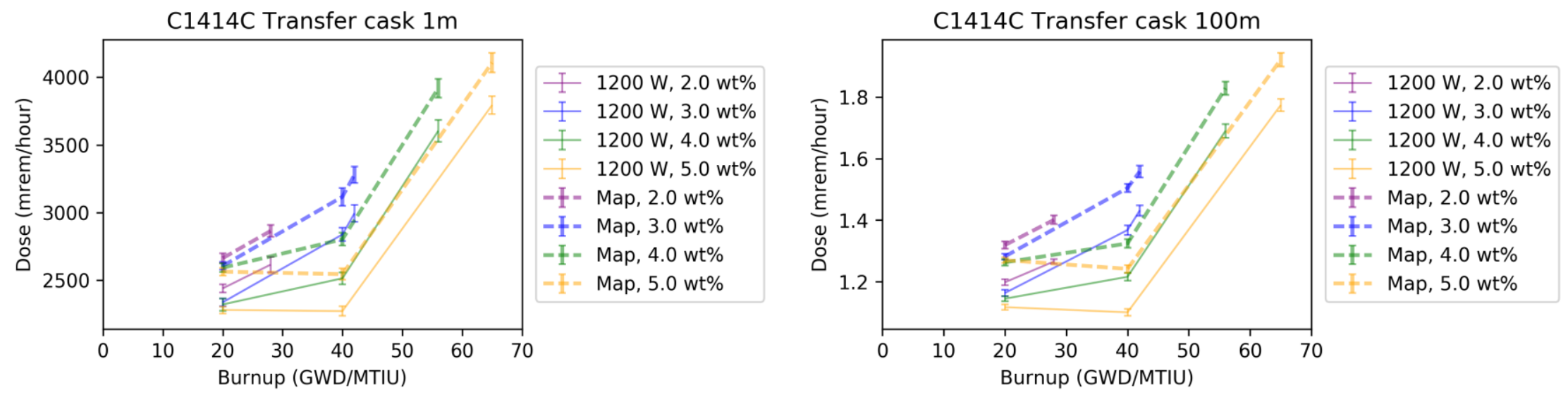

Figure 12. Isocaloric dose rate vs. burnup curves for casks loaded with CE $14 \times 14 \mathrm{C} \mathrm{SNF}$ assemblies. 

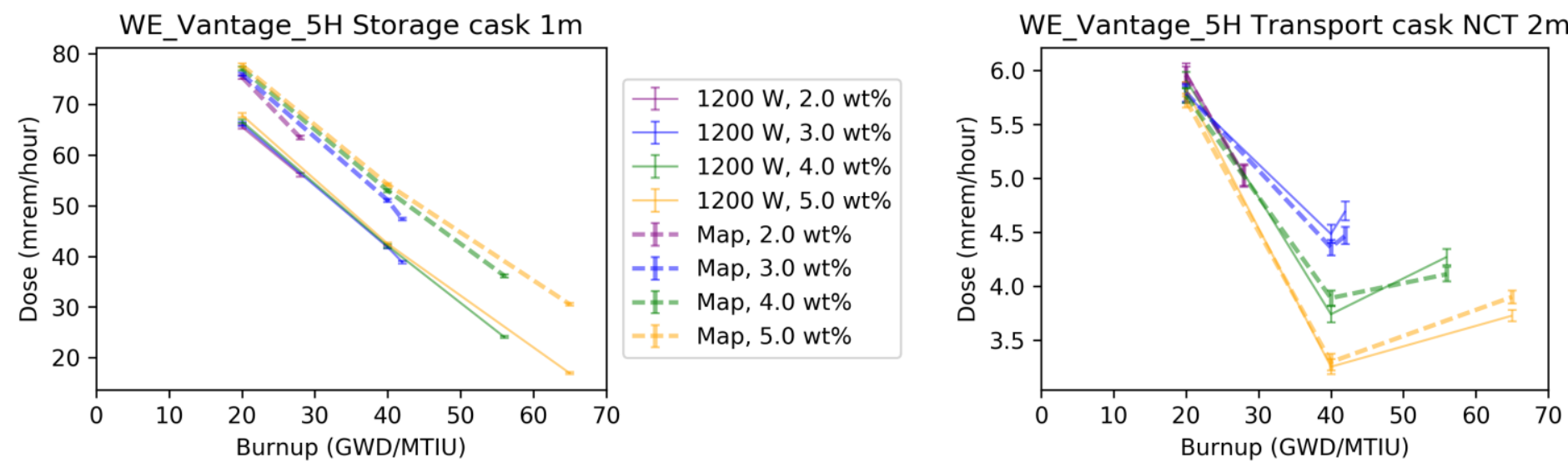

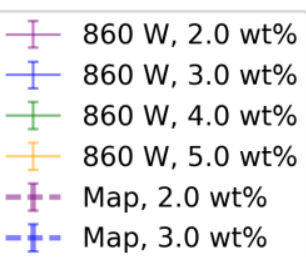

I- Map, 3.0 wt\%

-f- Map, 4.0 wt\%

Map, 5.0 wt\%
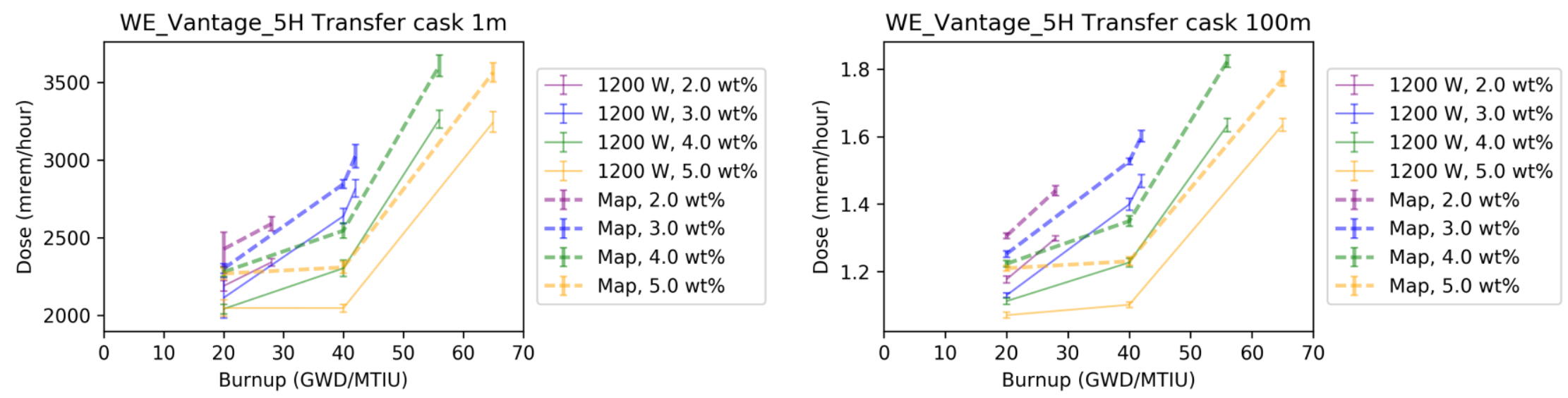

Figure 13. Isocaloric dose rate vs. burnup curves for casks loaded with Westinghouse Vantage 5H SNF assemblies. 
Figure 14 examines a dose rate axially 2 meters from the cask bottom against the side dose rate location for a transportation cask. It is seen that even though the side dose location has a minimum value near a middle burnup, dose rate at the bottom of the case increases monotonically with burnup. This is probably because the side of the cask includes a neutron shield whereas the top of the cask does not. Note that the cask is modeled in free space without impact limiters.

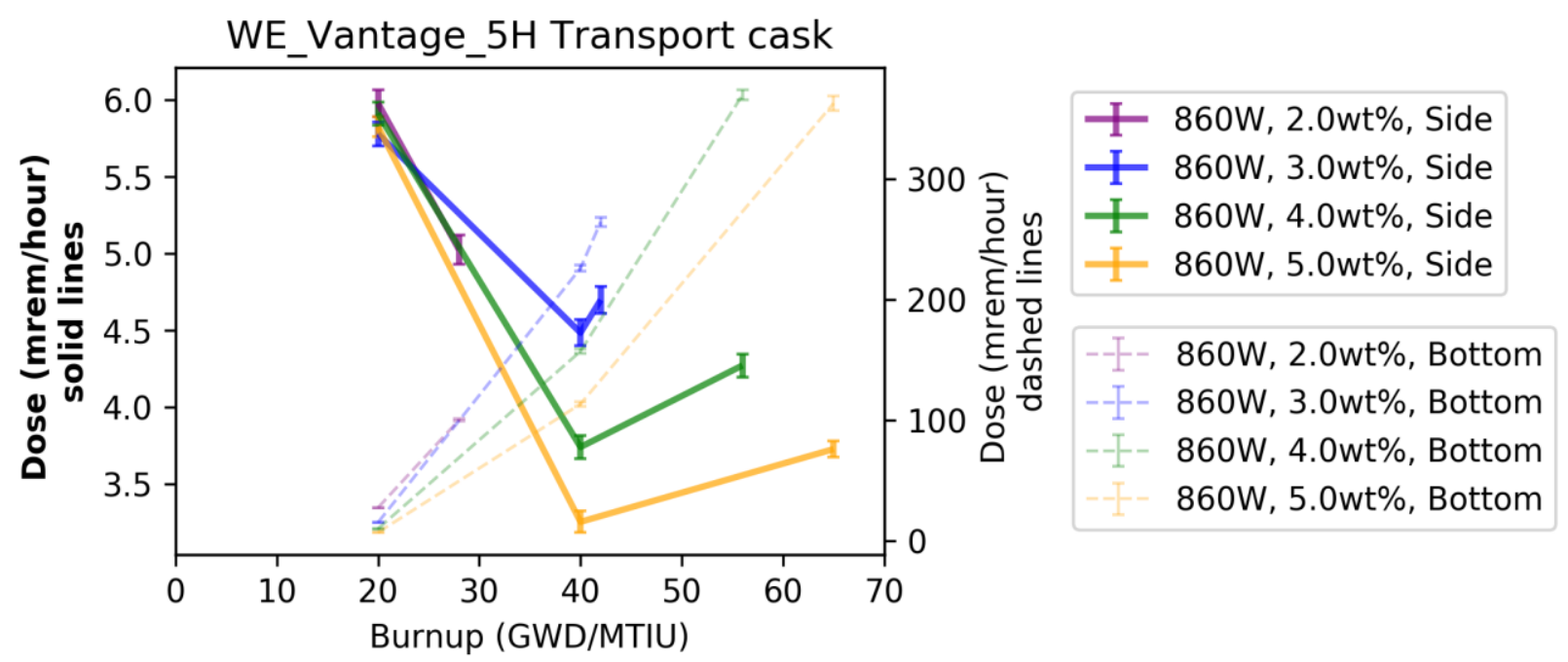

Figure 14. Isocaloric dose rates along the side and bottom of a transportation cask under normal conditions of transport.

\subsection{ISOCALORIC DOSE RATE VS. COOLING TIME}

Replotting the results against the cooling time may also yield useful insight. Because the loading map cases cannot be characterized in terms of a single cooling time (or even a derived metric), they are not included in the plots of dose rate vs. cooling time when decay heat is maintained constant (Figure 15 through Figure 17).

A salient feature of the transportation and transfer cask isocaloric dose rate charts is that dose rate increases with cooling time. Again, this is because decay heat is maintained constant, and to achieve a decay heat with increased cooling time, increased burnup is required. This results in more neutron activation for isotopes that decay relatively slowly such as ${ }^{244} \mathrm{Cm}$, the major neutron source in SNF with shorter cooling times [22,3]. The isotope has an 18-year half-life. As ${ }^{244} \mathrm{Cm}$ decays, ${ }^{241} \mathrm{Am}$ builds in, driving $(\alpha, n)$ reactions, which come to replace a large portion of the ${ }^{244} \mathrm{Cm}$ neutron source.

The source term for the storage may be from one or two isotopes. The impact of each isotope was not tracked in this effort, but NUREG/CR-6700 lists the largest gamma source term for deeply penetrating gammas as including ${ }^{60} \mathrm{Co},{ }^{134} \mathrm{Cs},{ }^{144} \mathrm{Pr}$, and ${ }^{154} \mathrm{Eu}$ in five-year cooled SNF [3]. Figure 24 of the NUREG shows that ${ }^{60} \mathrm{Co}$ and ${ }^{134} \mathrm{Cs}$ create over $80 \%$ of the dose in a concrete cask five years after discharge, regardless of burnup. Therefore, the curves in the storage cask case may simply reflect the compositions of these nuclides. ${ }^{60} \mathrm{Co}$ is from structural activation and is difficult to predict without information on assembly hardware impurities. ${ }^{134} \mathrm{Cs}$ is simply a fission product. If these two isotopes can be reliably shown to contribute the most to the dose rate from a concrete cask, then source terms could be substantially simplified. The dose rates for concrete storage appear to follow the same curves, regardless of enrichment or assembly type, as seen in Figure 18. However, this is for the single measurement location evaluated and may or may not be a generally applicable trend. 

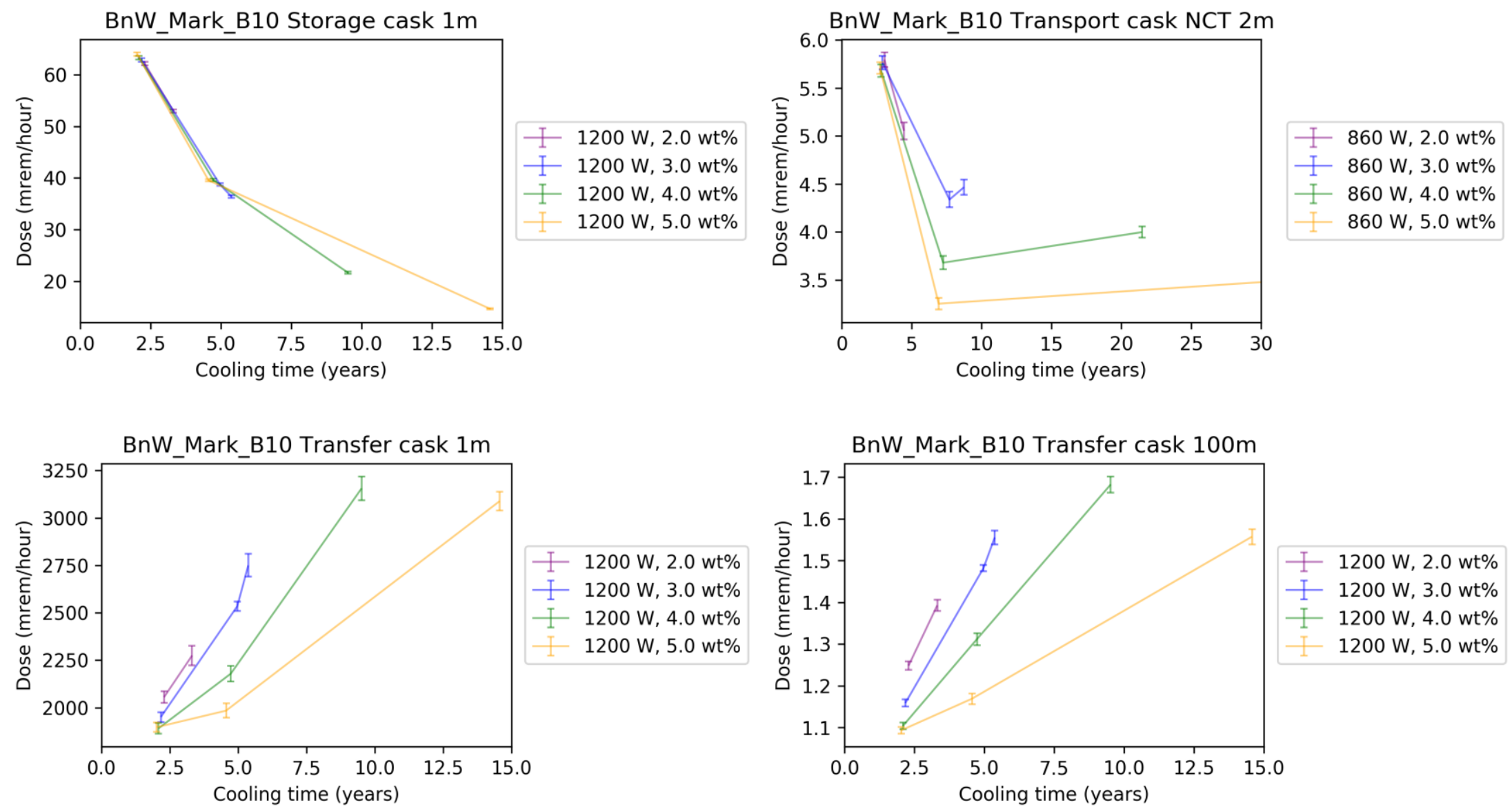

Figure 15. Isocaloric dose rate vs. cooling time curves for casks loaded with B\&W 14×14 B10 SNF assemblies. 

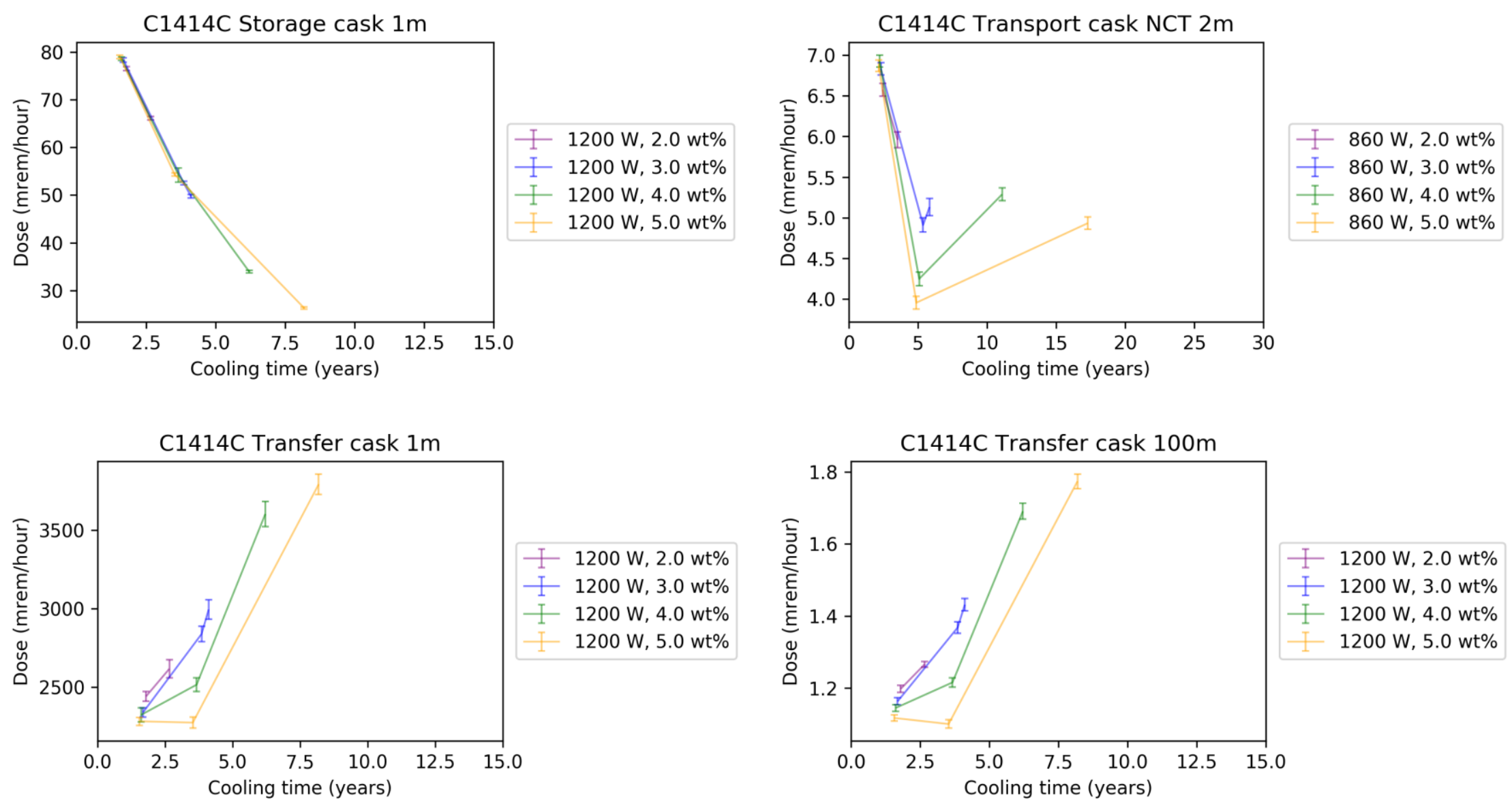

Figure 16. Isocaloric dose rate vs. cooling time curves for casks loaded with CE $14 \times 14 \mathrm{C}$ SNF assemblies. 

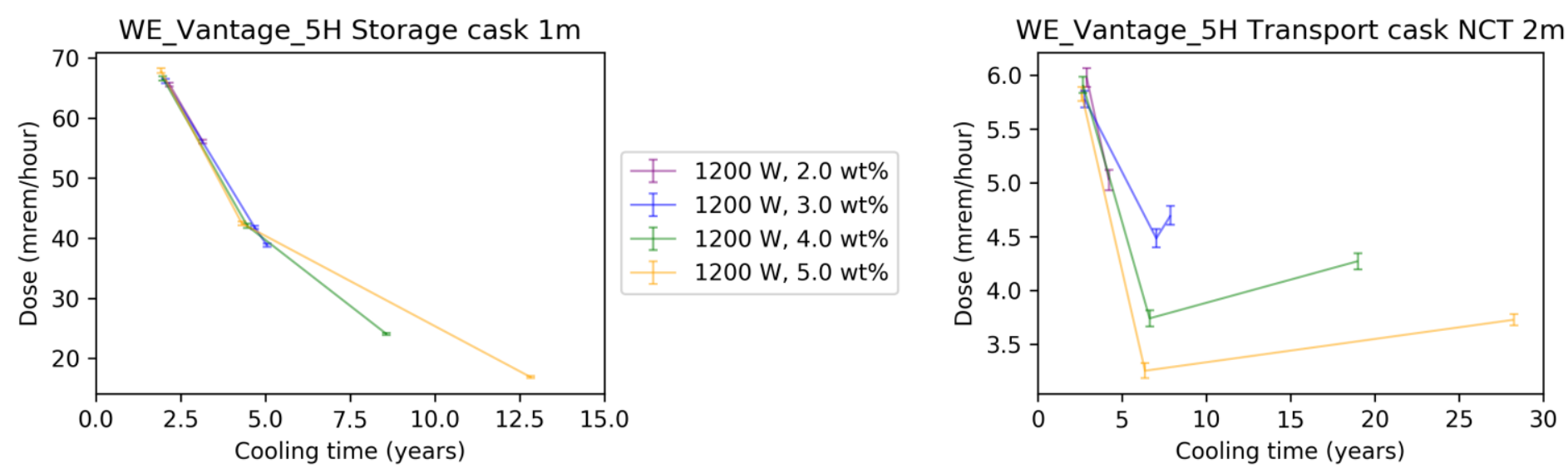

- 860 W, 2.0 wt\%

$200 \mathrm{~W}, 2.0 \mathrm{wt} \%$

$1200 \mathrm{~W}, 3.0 \mathrm{wt} \%$

$1200 \mathrm{~W}, 4.0 \mathrm{wt} \%$

1200 W, 5.0 wt\%

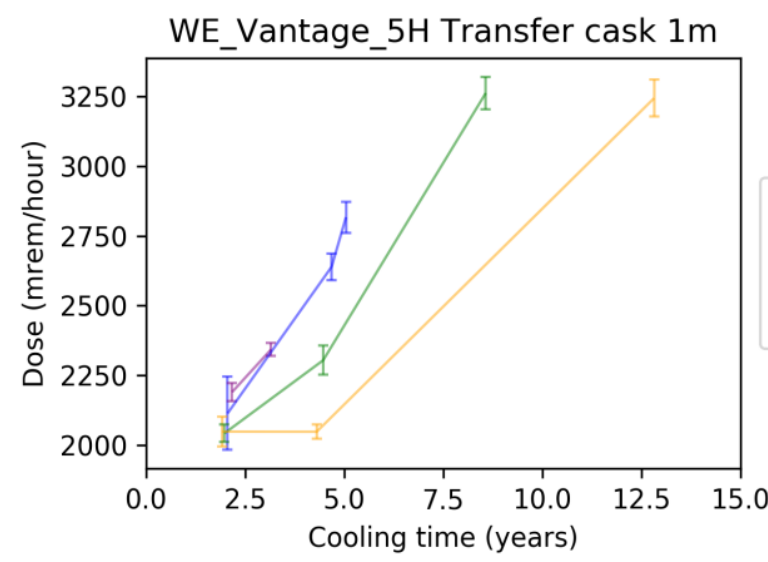

$1200 \mathrm{~W}, 2.0 \mathrm{wt} \%$ $1200 \mathrm{~W}, 3.0 \mathrm{wt} \%$ $1200 \mathrm{~W}, 4.0 \mathrm{wt} \%$ $1200 \mathrm{~W}, 5.0 \mathrm{wt} \%$

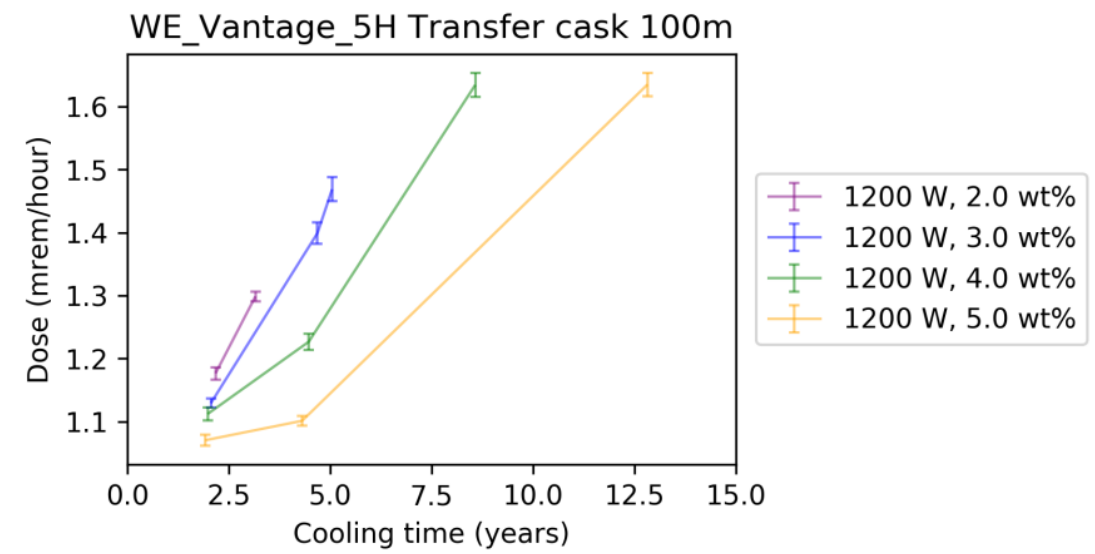

Figure 17. Isocaloric dose rate vs. cooling time curves for casks loaded with Westinghouse Vantage 5H SNF assemblies. 


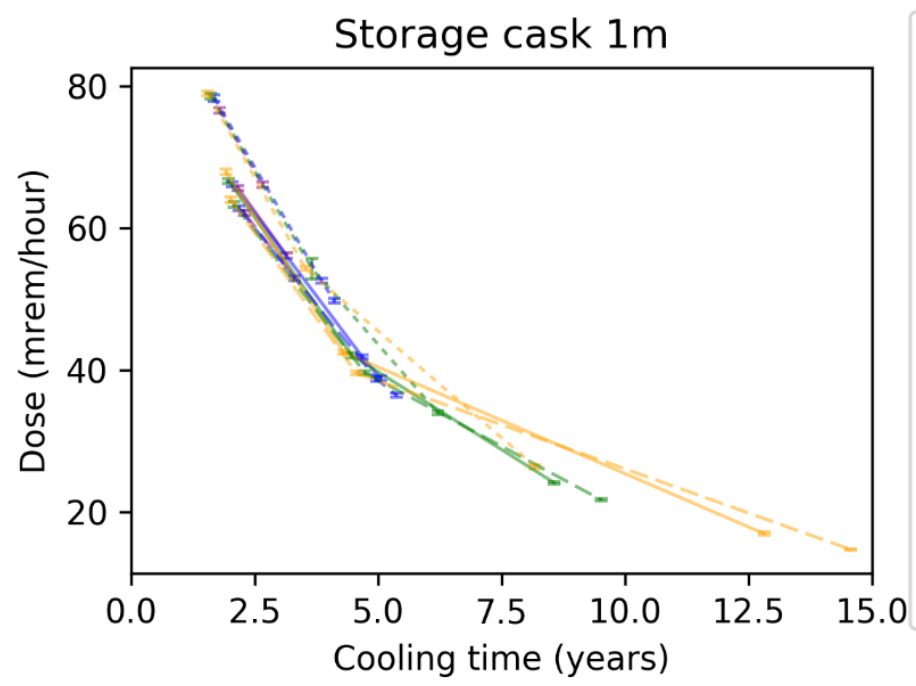

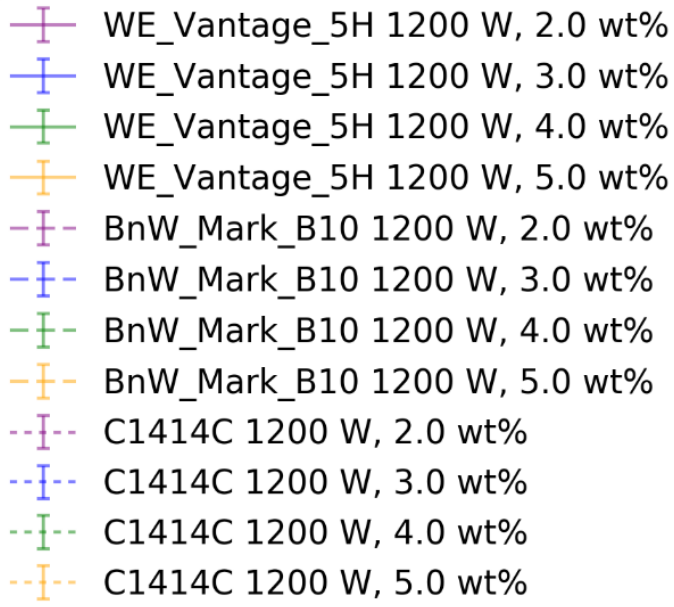

Figure 18. Concrete storage cask isocaloric dose rates for all fuel types in uniformly loaded casks.

To show the sensitivity of each tally to the factors applied, the dose rate for each cask is shown in Table 9. In the table, decay heat is held constant for each cask. The transport cask has a decay heat averaging $860 \mathrm{~W}$ per assembly, with the other casks having decay heats averaging $1.2 \mathrm{~kW}$ per assembly. Both uniform and nonuniform loadings are included in the extrema reported. While the transportation and transfer cask tallies showed smaller changes across the range considered, the storage casks did not. From Figure 6 through Figure 8, this appears to be due to the tradeoff of neutron and gamma doses as dose rate increases, so it represents coincidence rather than a fundamental phenomenon.

Table 9. Changes in dose rate for a cask with a constant decay heat load

\begin{tabular}{|c|c|c|c|}
\hline Tally & $\begin{array}{c}\text { Minimum } \\
\text { dose rate } \\
\text { (mrem/hour) }\end{array}$ & $\begin{array}{c}\text { Maximum } \\
\text { dose rate } \\
\text { (mrem/hour) }\end{array}$ & $\begin{array}{c}\text { Relative difference } \\
(\%)\end{array}$ \\
\hline Transfer cask ${ }^{\mathrm{a}} 100 \mathrm{~m}$ & 1.1 & 1.9 & 80 \\
\hline Transfer cask ${ }^{\mathrm{b}} 1 \mathrm{~m}$ & 1,900 & 4,100 & 120 \\
\hline Storage cask $1 \mathrm{~m}$ & 15 & 88 & 500 \\
\hline Transport cask NCT $2 \mathrm{~m}$ & 3.2 & 7.0 & 120 \\
\hline
\end{tabular}

\section{FOLLOW-ON: LOADING A HIGH-DOSE TRANSPORTATION CASK}

Due to the concave up nature of many dose-burnup curves, it was suspected that casks loaded with uniform burnup SNF were not bounding when uniform decay heat loadings were used. To examine that, a transportation cask was simulated with $860 \mathrm{~W}$ assemblies of various burnups, as shown in Figure 19. Lower burnup assemblies were placed on the outer ring. In the factorial study, the low burnup assemblies for the transportation cask produced the highest dose rates when decay heat was maintained at $860 \mathrm{~W}$ per assembly. Centrally located assemblies often have their gamma dose attenuated by assemblies on the outer ring, more so than neutron dose. Thus the interior locations were loaded with high burnup 
assemblies in an attempt to maximize neutron dose. The CE14x14 assembly type was used because it produced the highest dose rates in the transportation cask in the factorial study.

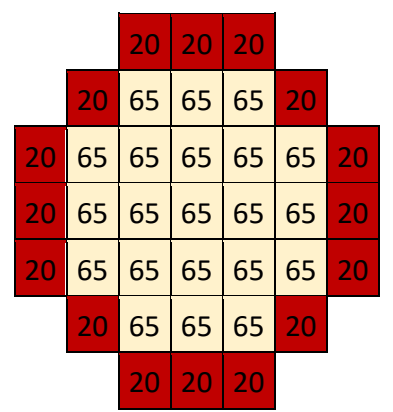

Figure 19. Burnup map for $860 \mathrm{~W}$ per assembly uniformly loaded (from decay heat perspective) transportation cask (GWd/MTU)

The dose rate for this cask at the $2 \mathrm{~m}$ radial tally location was $8.34 \mathrm{mrem} /$ hour with a relative Monte Carlo uncertainty of $1.7 \%$. The maximum dose rate from uniformly loaded transportation casks in the factorial study was $7.0 \mathrm{mrem} /$ hour. The minimum dose rate for a transportation cask loaded with assemblies averaging $860 \mathrm{~W}$ per assembly decay heat is $3.2 \mathrm{mrem} /$ hour, so the dose rate from assemblies with uniform decay heat can vary by $160 \%$.

\section{DISCUSSION/CONCLUSION}

Simulations in this study show that when decay heat is held constant, neutron dose rate generally increases with increasing cooling time and burnup, while gamma dose rate decreases. Each dose for each cask is a combination of the neutron and gamma dose rates. Therefore, few generally applicable heuristics are clearly apparent. For the case of gamma-only dose rates, such as for a storage cask, it appears that initial enrichment does not strongly affect dose rate. However, that is not true in the neutron case, or even storage casks generally, if neutron leakage is a substantial fraction of dose. A substantial neutron field is present for both transportation and transfer casks, and this makes dose rates dependent on all factors considered in this study. Dose location is another important factor as for a given cask design some locations could be gamma dominated, while the other locations are neutron dominated.

A possible explanation exists for the gamma and neutron dose trends observed in this study. At higher burnups, there is an increased neutron source, and a larger gamma source. Neutron production tends to be dominated by actinides, whereas the gamma source tends to be dominated by fission products as seen in NUREG/CR 6700 [3] and NUREG/CR 6802 [5]. Actinides are often the result of multiple neutron absorptions, so their production accelerates with increasing burnup, whereas fission product production is roughly proportional to burnup. Thus at higher burnups, the actinide inventory represents a larger proportion of the SNF than it does at lower burnups. Actinides also tend to have longer half-lives than fission products, and to achieve the same overall decay heat at higher burnups, a longer cooling time is necessary. Finally, increased cooling time causes the shorter-lived fission products to decay away faster than the actinides. Therefore, under isocaloric condition, neutron dose generally increases with increased burnup fueled by more long-lived actinide productions and gamma dose decreases with increase burnup driven by higher cooling time and decay of short-lived fission products.

One observation made in this study is that all the total dose rate curves are either concave up or monotonic. This may indicate that the endpoints are bounding in the decay heat, burnup, and cooling time ranges studied. This study only evaluates a single mid-point per curve, so it is unclear if this behavior is robust. To know endpoints are indeed bounding for each given dose location, the following must be demonstrated: (a) ensure that this applies to all burnups, (b) ensure that this applies to all shield materials 
and geometries, (c) determine a bounding assumption to account for a nonuniform loading pattern, and (d) somehow ensure that BWR assemblies also follow this trend.

Assembly type affects the cooling time and burnup to maintain constant decay heat. This is principally due to the difference in mass. All other things equal, lower mass assemblies tend to require less cooling time to reach a given decay heat. Because burnup is per unit mass, the lower mass assemblies produce less decay heat per assembly than higher mass assemblies with the same burnup and enrichment. To maintain a constant decay heat, a change in assembly type will require a change in the assembly's cooling time, all other things equal.

Change of the cask loading pattern, whether in terms of decay heats or in terms of assembly burnups affects dose rate. The one factor that did not vary in this study was the total decay heat inside the cask. All storage and transfer casks had heat loads of $44.4 \mathrm{~kW}$, whereas transportation casks had heat loads of 31.8 $\mathrm{kW}$. From the few cases reviewed in this study, the dose rate may scale with the decay heat of the outer ring of SNF in a cask if burnup, enrichment, cask type, and assembly type remain constant, but this is not clear from the results, and it is by no means a firm conclusion. Furthermore, sensitivity to loading map was not examined aside from using a single nonuniform loading map per cask. Sensitivity to specific power during depletion was similarly not examined.

Potential for simplification of licensing analysis may exist in the fact that all isocaloric dose rate vs. burnup curves were either monotonic or concave up. If that behavior can be shown robust, evaluation of only the end points may prove enough to show compliance if applied carefully. Impacts of nonuniform loading in terms decay heat or burnup would need to be accounted for in such an approach. Furthermore, it is unclear if such a method is an improvement over defining a limiting set of burnup/enrichment/cooling time values to cover both decay heat and dose rate.

The conclusion of this study is clear: dose rate is not a function of decay heat alone. This study found that burnup, enrichment, cask type and loading map all impact dose rate at a given location to varying degrees. For a given decay heat, burnup and cooling time are covariates, so cooling time could influence dose rate, as well. Finally, to state the obvious, a higher thermal limit does not mean that higher activity SNF can be safely loaded from dose perspective, and often can mean the reverse. 


\section{REFERENCES}

1. US Nuclear Regulatory Commission, Regulatory Guide 3.54, Revision 2 Spent Fuel Heat Generation in an Independent Spent fuel Storage Installation, December 2018.

2. I. C. Gauld et al., "Isotopic Depletion and Decay Methods and Analysis Capabilities in SCALE," Nucl. Technol. 174(2), 169-195 (2011).

3. I. C. Gauld and J. C. Ryman, Nuclide Importance to Criticality Safety, Decay Heating, and Source Terms Related to Transport and Interim Storage of High-Burnup LWR Fuel," NUREG/CR-6700, ORNL/TM-2000/284, US Nuclear Regulatory Commission, Oak Ridge National Laboratory (2000).

4. National Nuclear Data Center, NUDAT 2.8, accessed January 2019, www.nndc.bnl.gov/nudat2

5. B. L. Broadhead, Recommendations for Shielding Evaluations for Transport and Storage Packages, NUREG CR/6802, US NRC, Oak Ridge National Laboratory, May 2003.

6. SCALE Code System, B. T. Rearden and M. A. Jessee Editors, ORNL/TM-2005/39 Version 6.2, (2017).

7. D. E. Peplow, "Monte Carlo Shielding Analysis Capabilities with MAVRIC," Nucl. Technol. 174(2), 289-313 (2011).

8. R. Cumberland, K. Banerjee, "Baselining a Spent Nuclear Fuel Shielding Model," Radwaste Solutions, Spring (2018).

9. K. Banerjee, J. B. Clarity, R. M. Cumberland, R. A. Lefebvre, H. K. Liljenfeldt, L. P. Miller, J. L. Peterson-Droogh, G. Radulescu, K. R. Robb, and J. M. Scaglione, Used Nuclear Fuel-Storage, Transportation \& Disposal Analysis Resource and Data System (UNF-ST\&DARDS). Computer software, Version 00. May 20, 2017.

10. G. Radulescu, R. A. Lefebvre, D. E. Peplow, M. L. Williams, and J. M. Scaglione, "Dose Rate Analysis Capability for Actual Spent Fuel Transportation Cask Contents," Institute of Nuclear Materials Management (INMM)-55 ${ }^{\text {th }}$ Annual Meeting Atlanta, Georgia USA, July 20-24, 2014.

11. B. T. Rearden, M. T. Sieger, S. M. Bowman, and J. P. Lefebvre, Quality Assurance Plan for the SCALE Code System, SCALE-QAP-005, Rev. 4, May 2013.

12. A. Luksic, "Spent Fuel Assembly Hardware: Characterization and 10 CFR 61 Classification for Waste Disposal," Volume 1, PNL-6906, pg vi. 1989

13. Office of Civilian Radioactive Waste Management, "Characteristics of Spent Fuel, High-Level Waste, and Other Radioactive Wastes which may Require Long-Term Isolation," DOE/IW0184-Vol.3, Appendix 2A, 1987.

14. A. G. Croff, M. A. Bjerke, G. W. Morrison, L. M. Petrie, "Revised Uranium-Plutonium PWR and BWR Models for the ORIGEN Computer Code," ORNL/TM-6051, (1978).

15. M. D. DeHart, Sensitivity and Parametric Evaluations of Significant Aspects of Burnup Credit for PWR Spent Fuel Packages, ORNL/TM-12973, Oak Ridge National Laboratory (1996). 
16. B. L. Broadhead et al., Investigation of Nuclide Importance to Functional Requirements Related to Transport and Long-Term Storage of LWR Spent Fuel, ORNL/TM-12742, Oak Ridge National Laboratory (1995).

17. J. C. Wagner, D. E. Peplow, and S. W. Mosher, "FW-CADIS Method for Global and Regional Variance Reduction of Monte Carlo Radiation Transport Calculations," Nucl. Sci. Eng. 176(1), 37-57 (2014).

18. T. M. Evans et al., "Denovo: A New Three Dimensional Parallel Discrete Ordinates Code in SCALE," Nucl. Technol. 171(2), 171-200 (2010).

19. American National Standard Neutron and Gamma-Ray Flux-to-Dose-Rate Factors, ANSI/ANS 6.1.1-1977, American Nuclear Society, La Grange Park, Ill (1977).

20. R. A. Lefebvre, P. Miller, J. M. Scaglione, K. Banerjee, J. L. Peterson, G. Radulescu, K. R. Robb, A. B. Thompson, H. Liljenfeldt \& J. P. Lefebvre, "Development of Streamlined Nuclear Safety Analysis Tool for Spent Nuclear Fuel Applications," Nuclear Technology, 199:3, 227-244, (2017).

21. Energy Information Administration, Nuclear Fuel Data Survey Form GC-859, Washington, D.C.:2012. OMB No. 1901-0287

22. I. Harkness, T. Zhu, Y. Liang, E. Rauch, A. Enqvist, and K. A. Jordan, "Development of Neutron Energy Spectral Signatures for Passive Monitoring of Spent Nuclear Fuels in Dry Cask Storage," EPJ Web Conf. 17007004 (2018). 


\section{APPENDIX A. COMPARISON OF RG 3.54 AND UNF-ST\&DARDS DECAY HEATS}

\section{A1. INTRODUCTION}

For the evaluation of isocaloric curves, some means is needed to determine burnup or cooling time from decay heat and other parameters. Options include interpolating between existing evaluations in the UNFST\&DARDS, successive ORIGEN computations, or using an approximate method. The NRC issued Regulatory Guide 3.54 revision 2 (RG3.54r2) to facilitate decay heat computations for SNF. These calculations are applicable for PWR fuel having enrichments between 2 and $5 \mathrm{wt} \%$, burnups of 10 to 65 $\mathrm{GWd} / \mathrm{MTU}, 1$ to 100 years of cooling time, and average specific powers between 12 and $50 \mathrm{~W} / \mathrm{gU}$. BWR $\mathrm{SNF}$ is not considered here. The decay heat is computed from lookup tables and formulas designed to roughly follow the isotopic contributors to decay heat. There is a fission production term, an actinide activation product term, two fission product activation terms, and a structural activation term, as well as a safety factor [1]. Each term is computed from formulas and lookup tables provided in the regulatory guide. The regulatory guide algorithm performs the evaluation quickly on a modern machine, and it accounts for the factors considered in the dose rate study. Therefore, this algorithm was selected as a means to more quickly converge on the proper value of cooling time to produce a given decay heat through use of a root finder algorithm, specifically a variation of Brent's method. Initially, it was expected that the burnups from the root finder algorithm would be used directly to define shielding source terms, so these comparisons were made to UNF-ST\&DARDS. However, an iterative approach was taken ultimately relying on the Origen calculations performed by UNF-ST\&DARDS to ensure that decay heats would be extremely close to the UNF-ST\&DARDS calculation. They are reported regardless to show the comparison between the two methods.

\section{A2. METHODS}

\section{A2.1 Encoding the RG3.54r2 Algorithm}

The RG3.54r2 algorithm was encoded into a python script to evaluate decay heat. The script was verified against the example results in the Regulatory Guide, with the assumption that the final burnup step was 339 days long at a specific power of $28.3 \mathrm{~W} / \mathrm{g}$. This appears to be the correct value given the other calculated values in the example and considering that the last four values in Table A-1 of the Regulatory Guide for the cycle 4 column are identical to those for the first cycle. The specific power of $28.3 \mathrm{~W} / \mathrm{g}$ was obtained from the mid-cycle burnup listed in Table A-2, and the burn time was obtained from Table A-3 of the Regulatory Guide [1]. With this correction, the results from the python program matched those in Appendix A of the Regulatory Guide to within $0.4 \%$.

\section{A2.2 Determining a representative time that assemblies remain in-core}

Prior to developing isocaloric characteristic curves for various PWR assemblies, the decay heats predicted by RG3.54r2 are compared to bounding ORIGAMI decay heat calculations stored in UNF-ST\&DARDS. These ORIGAMI calculations assume bounding values for moderator densities, axial power profiles, burnable absorber loadings, and soluble boron concentrations.

Prior to developing comparisons, a representative in-core exposure time was found to feed as an input to the RG3.54r2 algorithm. The time during which PWR assemblies in the UNF-ST\&DARDS were burned is shown in Figure 20 as a cumulative distribution function. The median $5^{\text {th }}$ and $95^{\text {th }}$ percentile values are identified in the figure. 


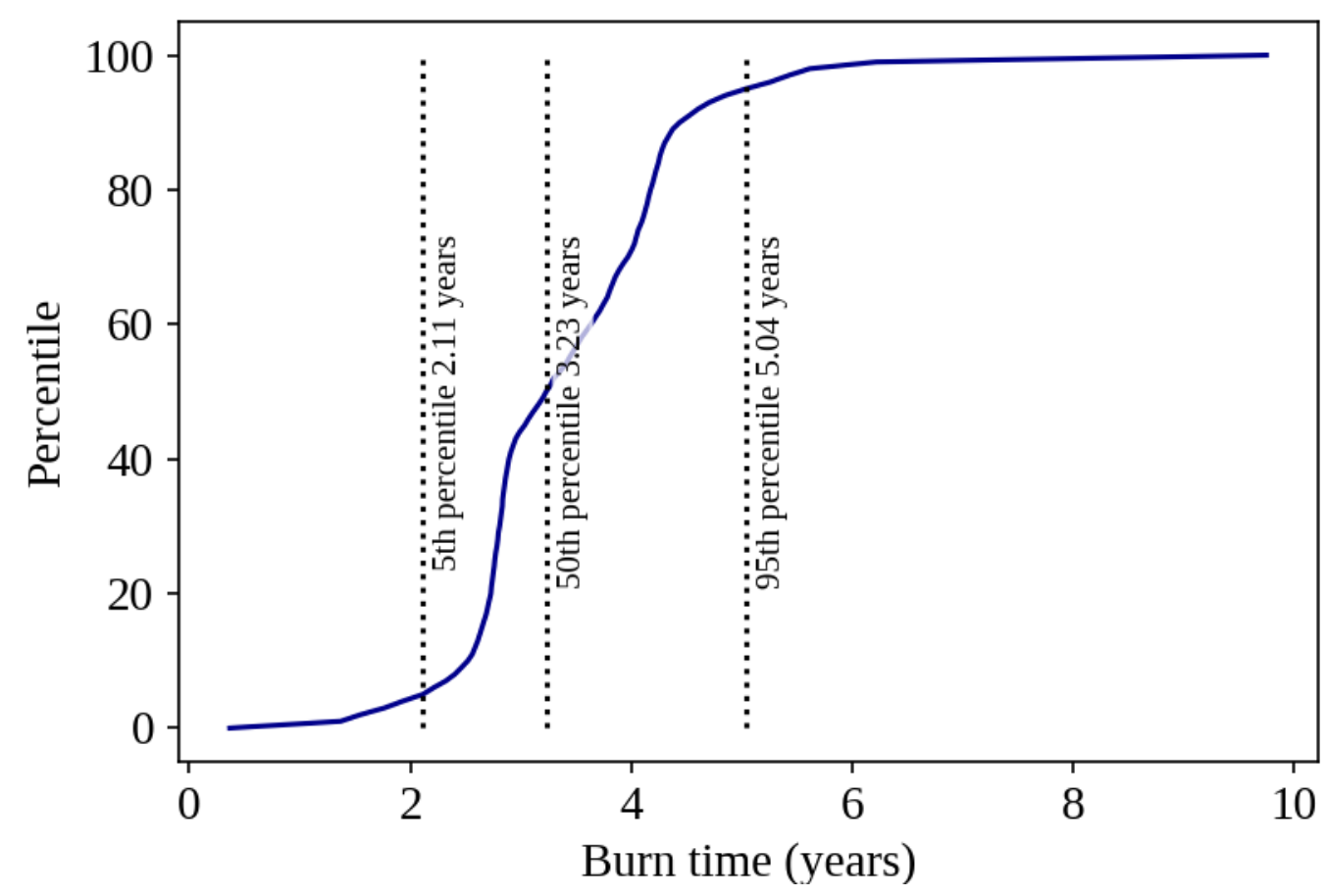

Figure 20. Cumulative distribution of time PWR assemblies in the UDB were operated at power.

To compute decay heats using RG3.54r2, the burnup and burn time were used to burn the fuel in a single burnup step of constant specific power. For comparison to UNF-ST\&DARDS data, all decay heats were normalized to the initial mass of uranium in the fuel assembly. Both the UDB and Regulatory Guide estimates are conservative. The RG3.54r2 includes a safety factor, which is a function of cooling time. The UDB data are conservative estimates based upon automatic rapid processing (ARP) libraries that assume low moderator density, high boron concentration, and control rods inserted for the entire time the assembly is in the reactor. Note that RG3.54r2 is limited in its range of applicability to $65 \mathrm{GWd} / \mathrm{MTU}$, or $14 \mathrm{GWd} / \mathrm{MTU}$ times the enrichment in weight percent ${ }^{235} \mathrm{U}$, whichever is less. Thus, contours for low enrichments do not extend through the full range of burnups.

To compute burnups or cooling times for a given decay heat, Brent's algorithm was used. It is a combination of the bisection and secant methods. All other parameters aside from cooling time (or burnup) are supplied directly to the RG3.54r2 algorithm, and it finds the value that produces the desired decay heat. This algorithm was used to produce contour lines to compare with the UNF-ST\&DARDS.

\section{A3. RESULTS}

The first comparisons of UNF-ST\&DARDS data to RG3.54r2 can be seen in Figure 21 and Figure 22. The RG3.54r2 data are plotted as isocaloric curves, showing combinations of burnups and cooling times that produce identical decay heats. The UDB data are plotted as color-coded points if they fall within $2 \%$ of an isocaloric curve. If a UDB decay heat is not within $2 \%$ of an isocaloric curve, it is color coded gray. The assumed burn time for the isocaloric curves is 3.23 years, but there is no limit on the value for the UNF-ST\&DARDS data. Each curve's label is color coded to the corresponding decay heat. It can be seen that the UNF-ST\&DARDS data follow the isocaloric contours produced using RG3.54r2, with a few exceptions. Note that the color coding differs between zoomed plots and full-scale plots. 
Some UNF-ST\&DARDS points fall above their corresponding isocaloric curve. This is further examined in Figure 23 and Figure 24 by plotting the UDB data against isocaloric curves for cases in which 5\% enrichment is assumed, with burn time being varied between the $5^{\text {th }}$ and $95^{\text {th }}$ percentile values. Roughly speaking, the effect of burn time on decay heat is greater than that of the enrichment at short cooling times.

This is further examined in figures by limiting the burn time of the UNF-ST\&DARDS datapoints plotted to be greater than the assumed RG3.54r2 burn time. In Figure 25 and Figure 26, a burn time of 2.11 years is assumed in the generation of the isocaloric curves, as well as a lower cutoff for the UNF-ST\&DARDS data. Thus, all UNF-ST\&DARDS data in a bin should be bounded on the bottom by its isocaloric curve. This is mostly the case, except at higher burnups with about 20-30 years of cooling time where the UNFST\&DARDS data points appear slightly more conservative than those of RG3.54. This may result from the conservative UNF-ST\&DARDS assumptions, which produce an excess of actinides in the SNF, as opposed to the conservative RG3.54r2 safety factor, which is a function of cooling time.

Limiting burn time to 3.23 years in Figure 27 and Figure 28 and then limiting it further to 5.04 years in Figure 29 and Figure 30 results in similar trends. 


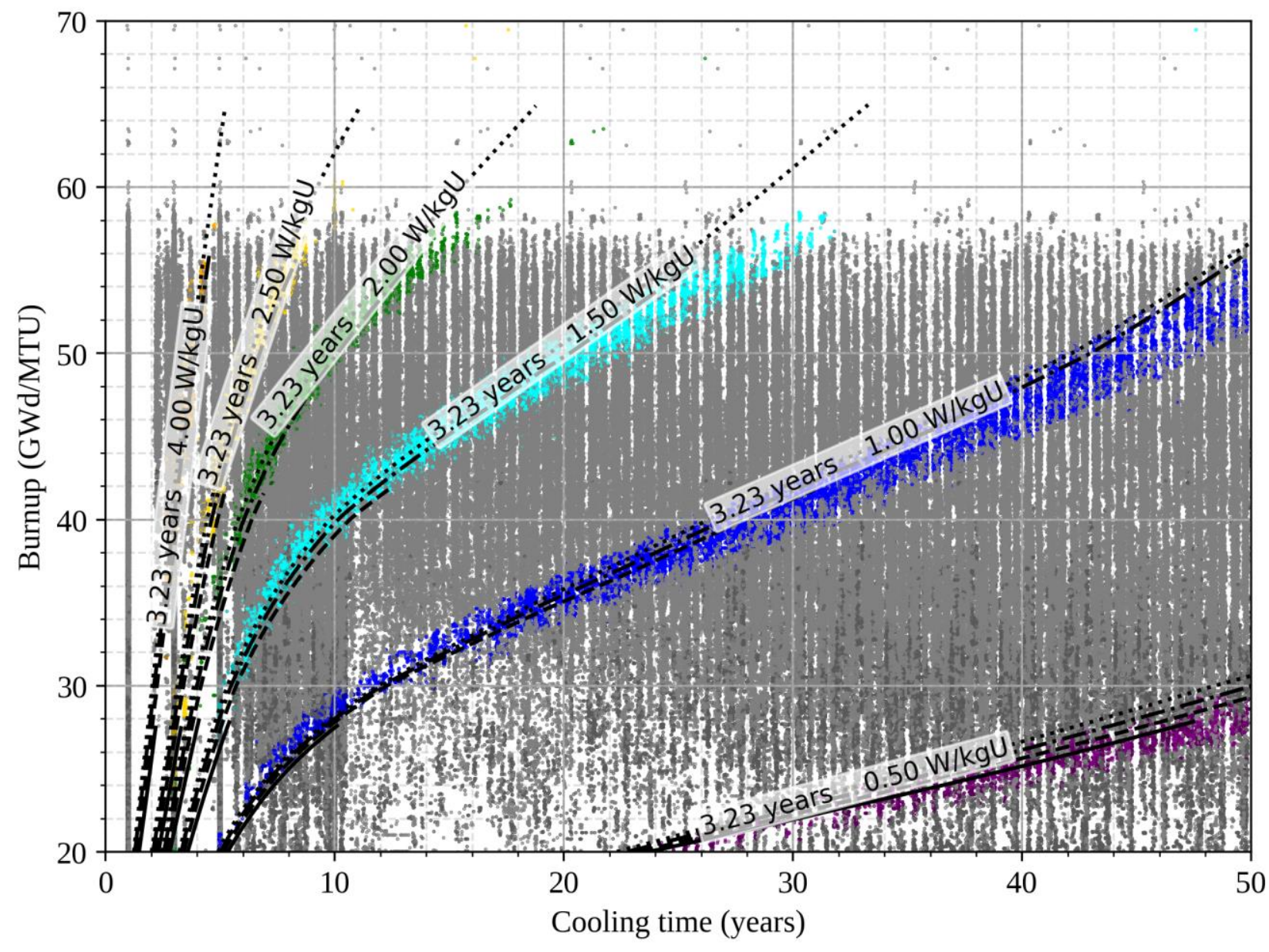

Decay heat within $2 \%$ of
Other
$0.50 \mathrm{~W} / \mathrm{kgU}$
$1.00 \mathrm{~W} / \mathrm{kgU}$
$1.50 \mathrm{~W} / \mathrm{kgU}$
$2.00 \mathrm{~W} / \mathrm{kgU}$
$2.50 \mathrm{~W} / \mathrm{kgU}$
$4.00 \mathrm{~W} / \mathrm{kgU}$

\section{Enrichment}

- 2.0\%

-- $3.0 \%$

-. $4.0 \%$

...... $5.0 \%$

Figure 21. Comparison of UDB bounding decay heat data for all PWR assemblies to RG3.54r2 isocaloric decay heat curves for PWR fuel. 


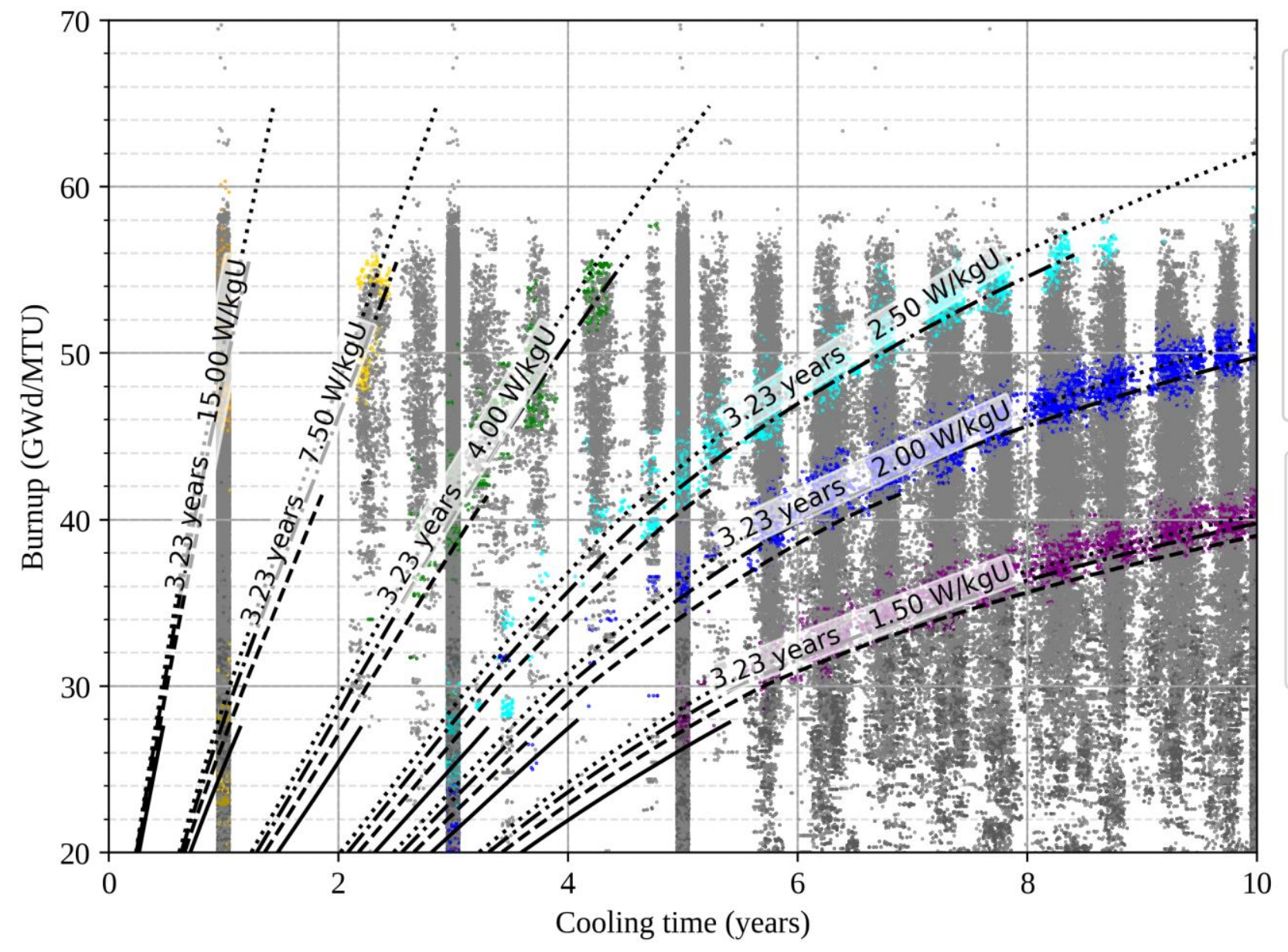

Decay heat within $2 \%$ of

Other

$1.50 \mathrm{~W} / \mathrm{kgU}$

$2.00 \mathrm{~W} / \mathrm{kgU}$

$2.50 \mathrm{~W} / \mathrm{kgU}$

$4.00 \mathrm{~W} / \mathrm{kgU}$

$7.50 \mathrm{~W} / \mathrm{kgU}$

$15.00 \mathrm{~W} / \mathrm{kgU}$

\section{Enrichment}

$-2.0 \%$

- $3.0 \%$

$-\cdot-4.0 \%$

…... $5.0 \%$

Figure 22. Comparison of UDB bounding decay heat data for all PWR assemblies to RG3.54r2 isocaloric decay heat curves for PWR fuel, zoomed time scale. 


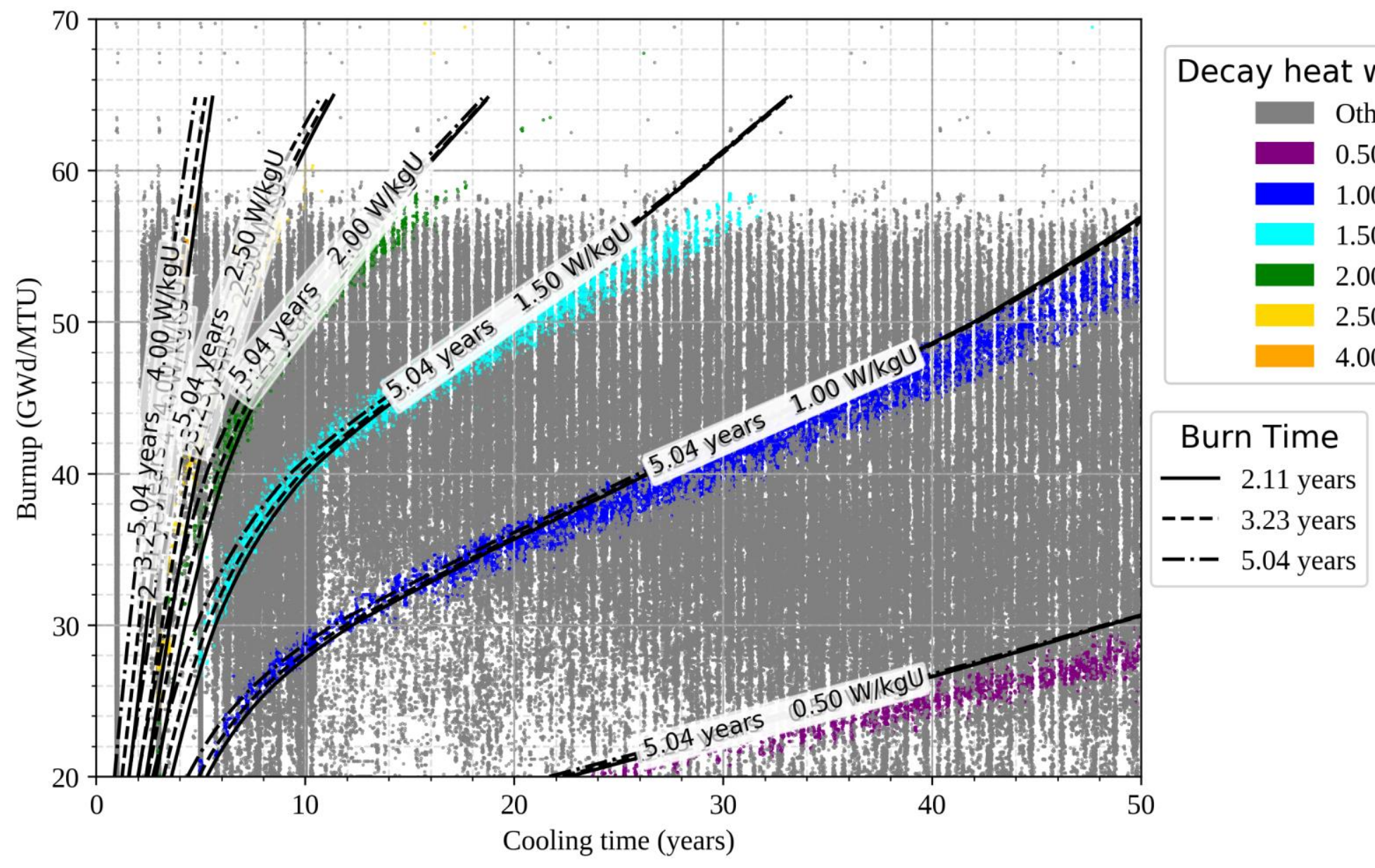

Figure 23. Comparison of UDB bounding decay heat data for PWR assemblies to RG3.54r2 isocaloric decay heat curves for $5 \%$ enriched fuel burned for various times. 


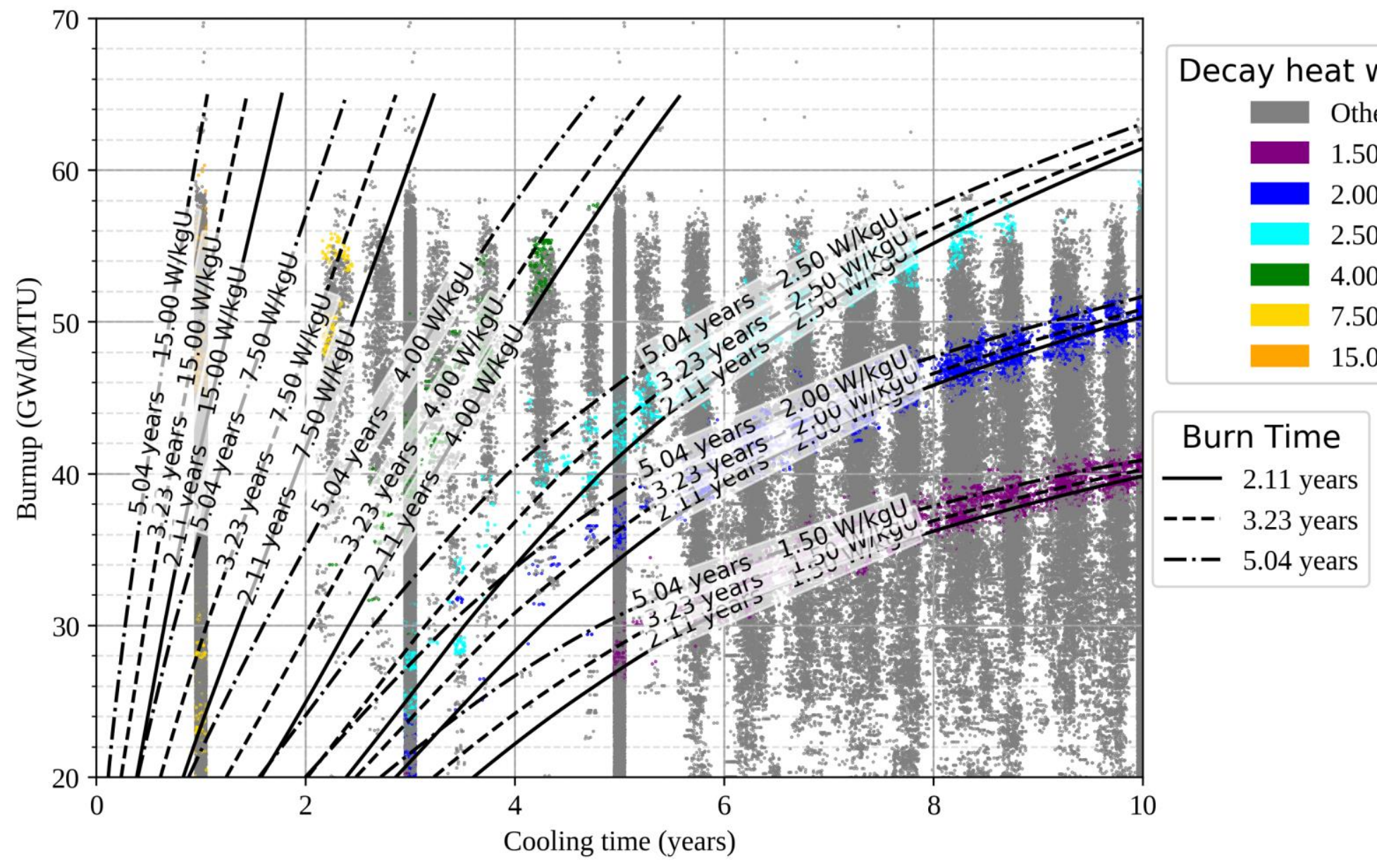

Figure 24. Comparison of UDB bounding decay heat data for PWR assemblies to RG3.54r2 isocaloric decay heat curves for $5 \%$ enriched fuel burned for various times, zoomed time scale. 


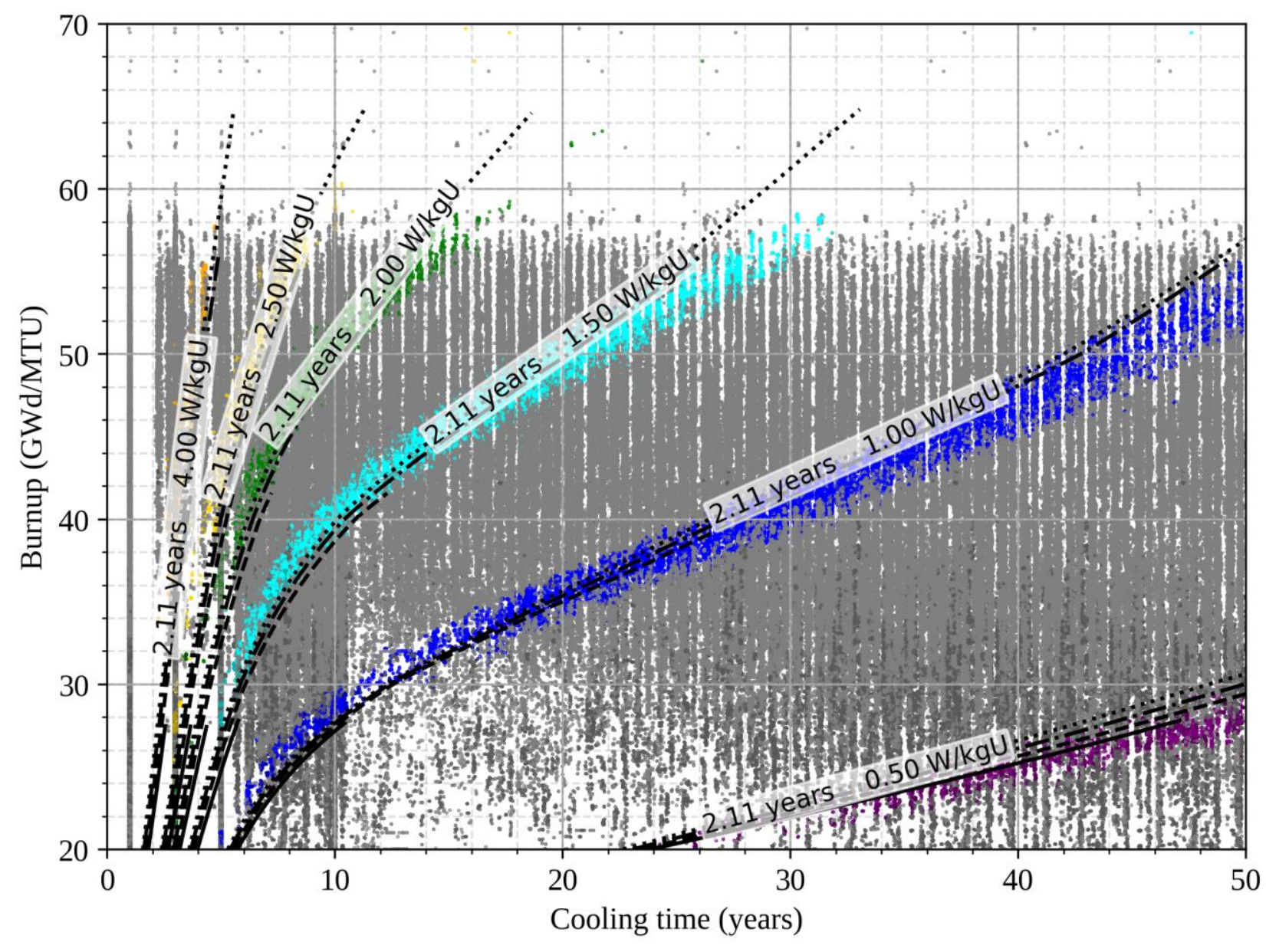

Decay heat within $2 \%$ of
Other
$0.50 \mathrm{~W} / \mathrm{kgU}$
$1.00 \mathrm{~W} / \mathrm{kgU}$
$1.50 \mathrm{~W} / \mathrm{kgU}$
$2.00 \mathrm{~W} / \mathrm{kgU}$
$2.50 \mathrm{~W} / \mathrm{kgU}$
$4.00 \mathrm{~W} / \mathrm{kgU}$

\section{Enrichment}

- 2.0\%

-- $3.0 \%$

-. $4.0 \%$

…. $5.0 \%$

Figure 25. Comparison of UDB bounding decay heat data for assemblies burned for over 2.11 years to RG3.54r2 isocaloric decay heat curves for PWR fuel. 


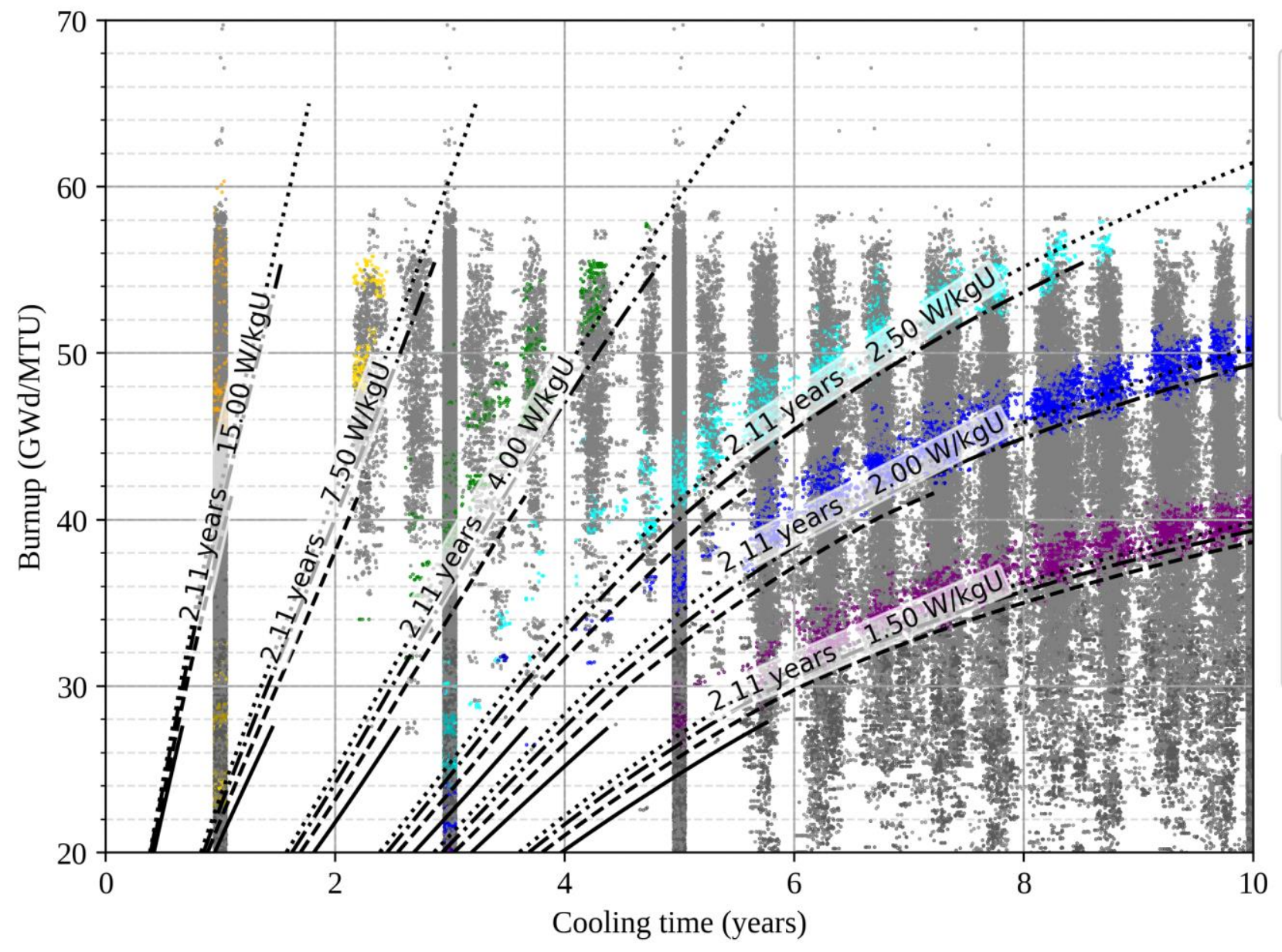

Decay heat within $2 \%$ of

Other

$1.50 \mathrm{~W} / \mathrm{kgU}$

— $2.00 \mathrm{~W} / \mathrm{kgU}$

$2.50 \mathrm{~W} / \mathrm{kgU}$

$4.00 \mathrm{~W} / \mathrm{kgU}$

$7.50 \mathrm{~W} / \mathrm{kgU}$

$15.00 \mathrm{~W} / \mathrm{kgU}$

\section{Enrichment}

- $2.0 \%$

-- $3.0 \%$

- - $4.0 \%$

…... $5.0 \%$

Figure 26. Comparison of UDB bounding decay heat data for assemblies burned for over 2.11 years to RG3.54r2 isocaloric decay heat curves for PWR fuel, zoomed time scale. 


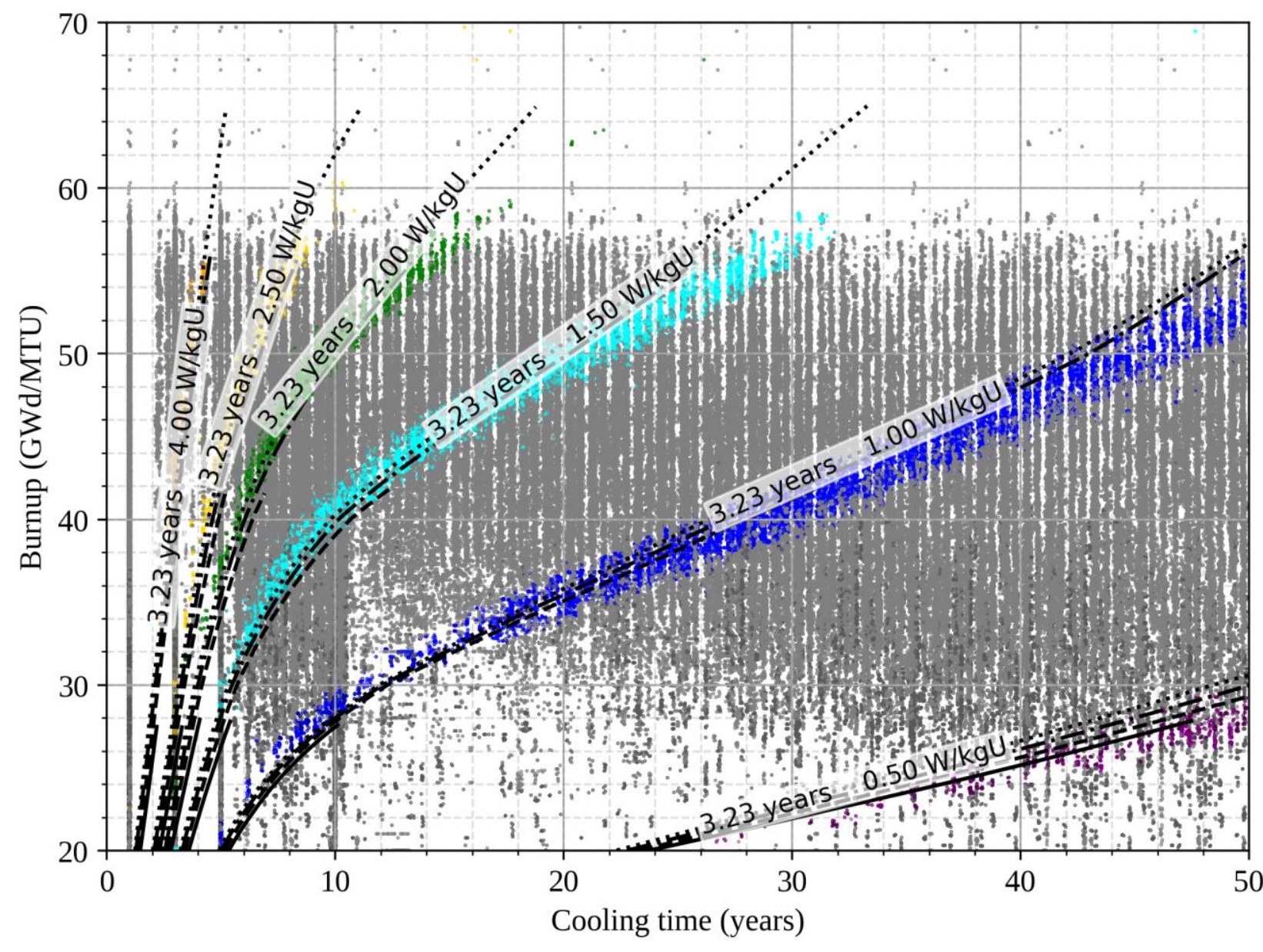

Decay heat within $2 \%$ of
Other
$0.50 \mathrm{~W} / \mathrm{kgU}$
$1.00 \mathrm{~W} / \mathrm{kgU}$
$1.50 \mathrm{~W} / \mathrm{kgU}$
$2.00 \mathrm{~W} / \mathrm{kgU}$
$2.50 \mathrm{~W} / \mathrm{kgU}$
$4.00 \mathrm{~W} / \mathrm{kgU}$

\section{Enrichment}

- 2.0\%

-- $3.0 \%$

-. $4.0 \%$

...... $5.0 \%$

Figure 27. Comparison of UDB bounding decay heat data for assemblies burned for over 3.23 years to RG3.54r2 isocaloric decay heat curves for PWR fuel. 


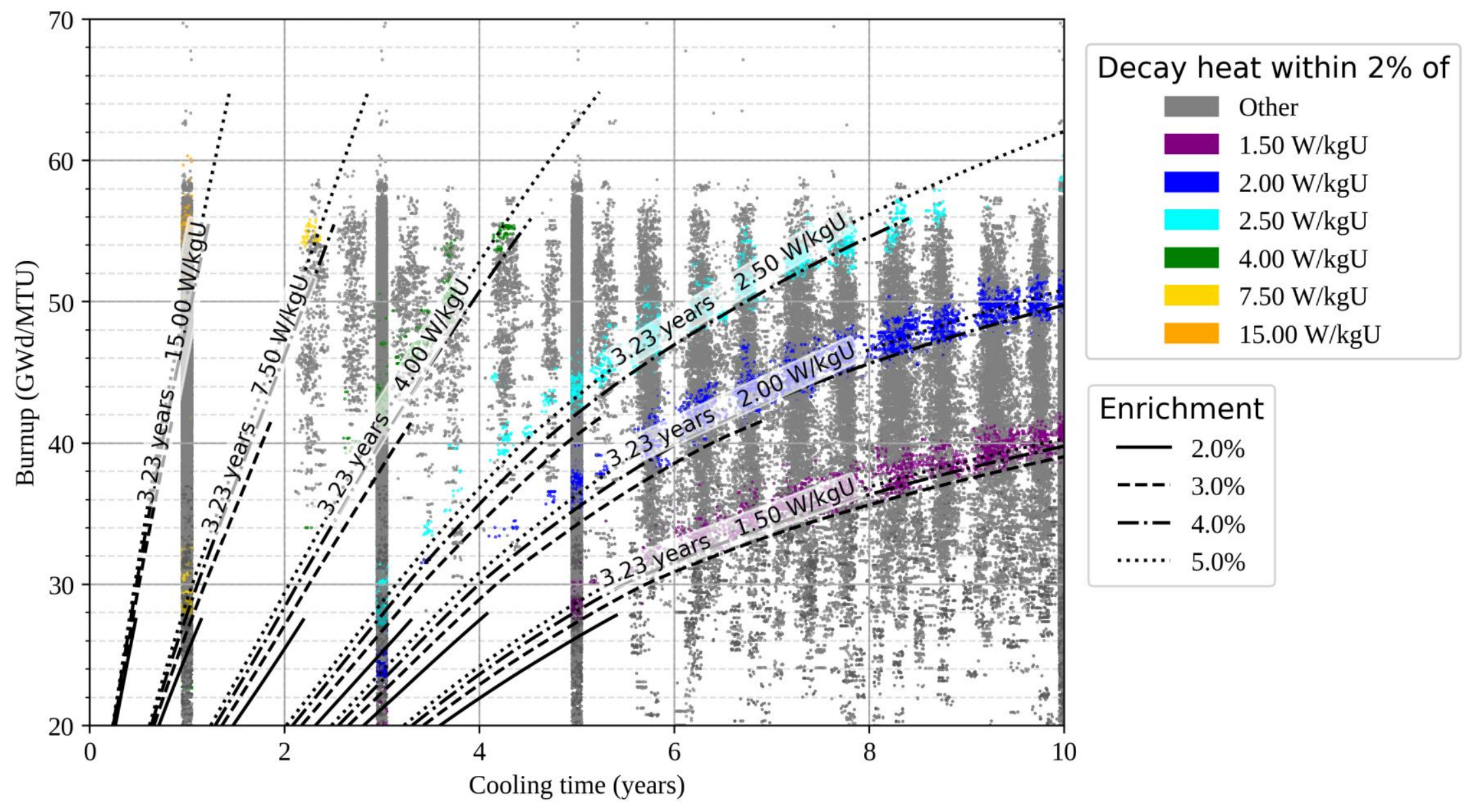

Figure 28. Comparison of UDB bounding decay heat data for assemblies burned for over 3.23 years to RG3.54r2 isocaloric decay heat curves for PWR fuel, zoomed time scale. 


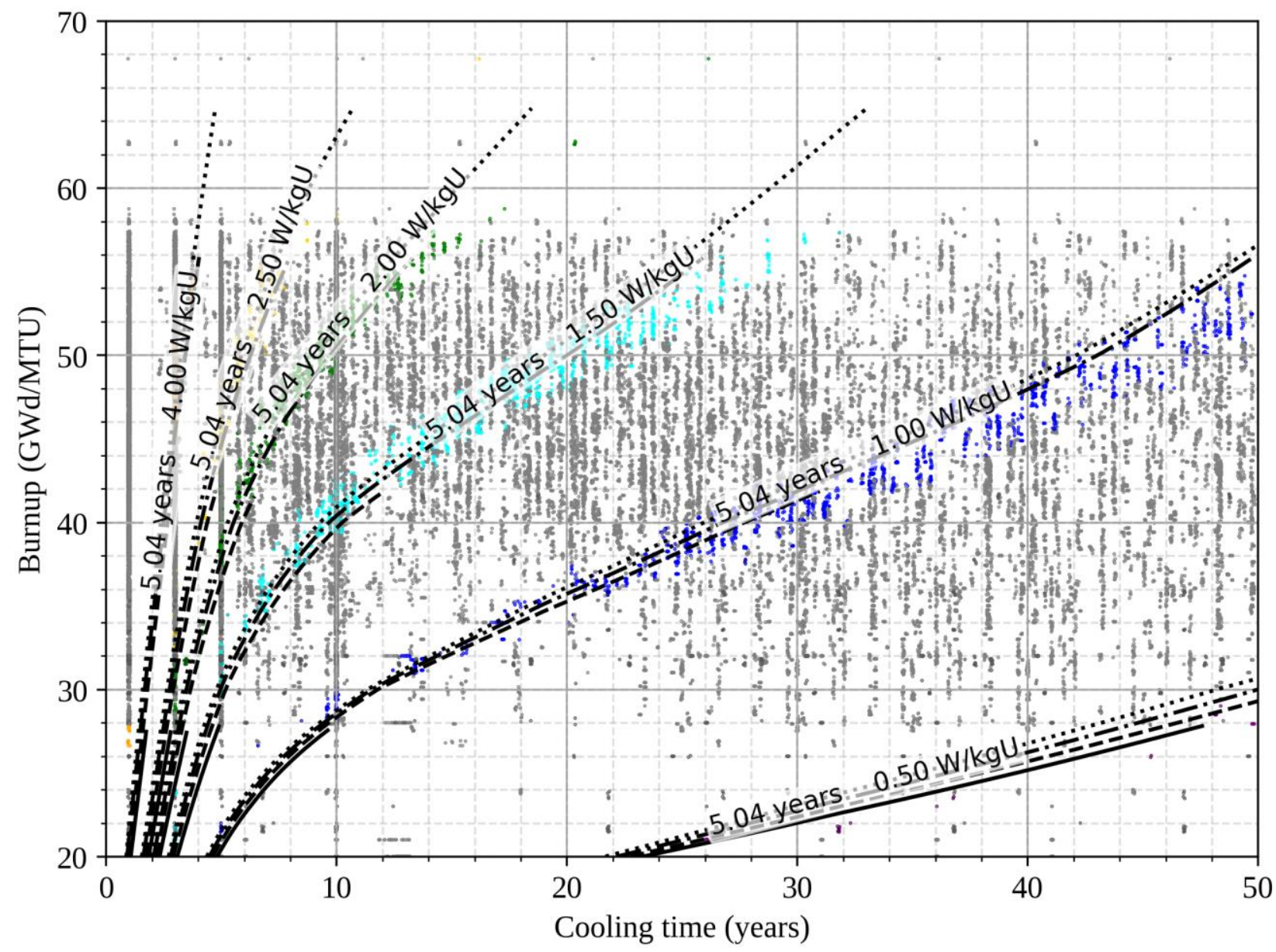

Decay heat within $2 \%$ of

Other

$0.50 \mathrm{~W} / \mathrm{kgU}$

— $1.00 \mathrm{~W} / \mathrm{kgU}$

$1.50 \mathrm{~W} / \mathrm{kgU}$

$2.00 \mathrm{~W} / \mathrm{kgU}$

$2.50 \mathrm{~W} / \mathrm{kgU}$

$4.00 \mathrm{~W} / \mathrm{kgU}$

\section{Enrichment}

- $2.0 \%$

-- $3.0 \%$

- - $4.0 \%$

…... $5.0 \%$

Figure 29. Comparison of UDB bounding decay heat data for assemblies burned for over 5.04 years to RG3.54r2 isocaloric decay heat curves for PWR fuel. 


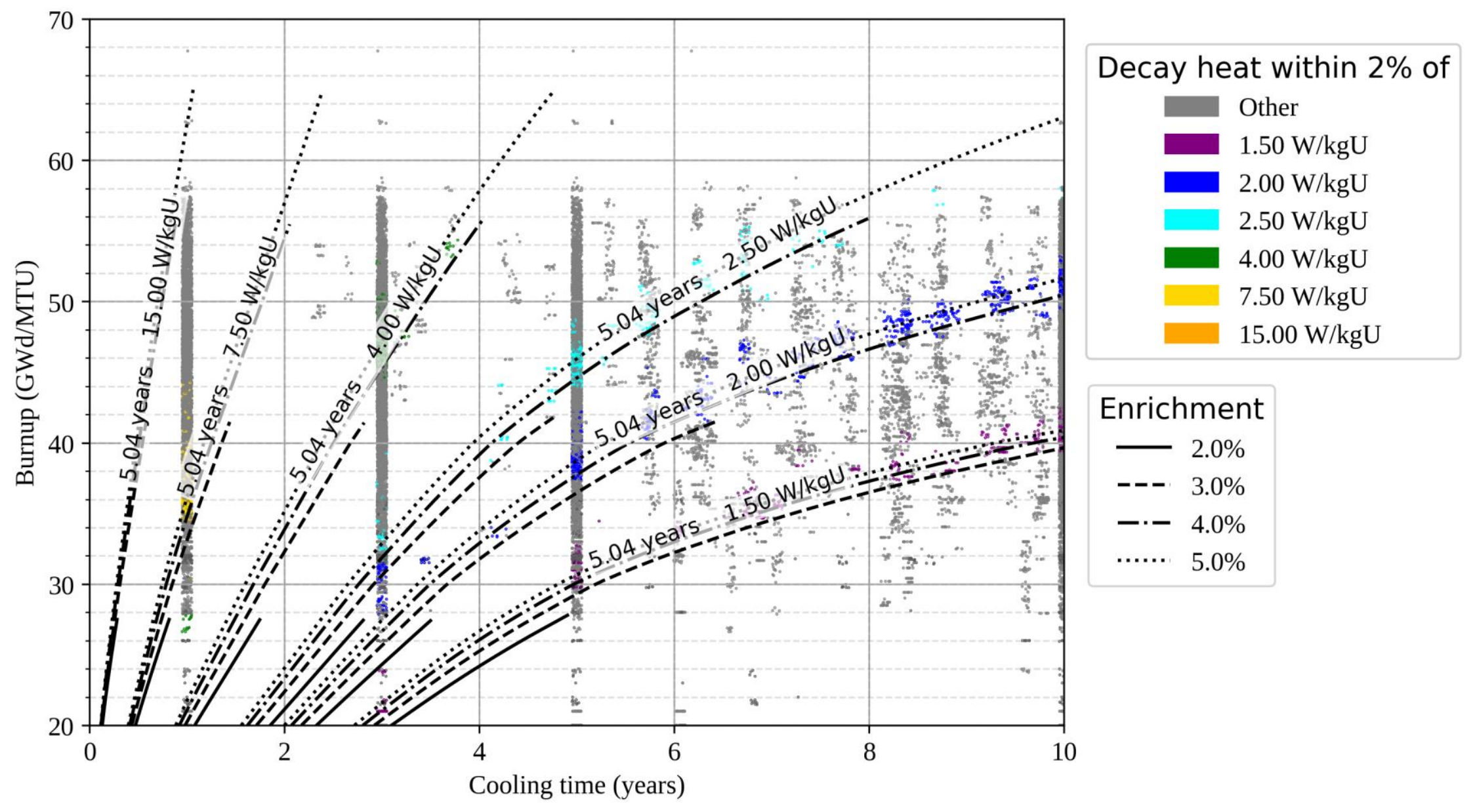

Figure 30. Comparison of UDB bounding decay heat data for assemblies burned for over 5.04 years to RG3.54r2 isocaloric decay heat curves for PWR fuel, zoomed time scale. 
As a final examination of RG3.45r2, the decay heat components are plotted for various cooling times along the isocaloric curve for 5\% enriched PWR SNF that has been burned for 3.23 years, producing $1.5 \mathrm{~W} / \mathrm{kgU}$ of decay heat. This is shown in Figure 31. Burnup corresponding to the cooing time is shown on a secondary y-axis. Until 6 years of cooling time, the primary decay heat components are fission products and ${ }^{134} \mathrm{Cs}$ resulting from ${ }^{133} \mathrm{Cs}$ activation. After 6 years and $30 \mathrm{GWd} / \mathrm{MTU}$, the ${ }^{134} \mathrm{Cs}$ activation products decay away, and actinide decay heat increases due to increased burnup level. Note that burnup changes with cooling time in the plot.

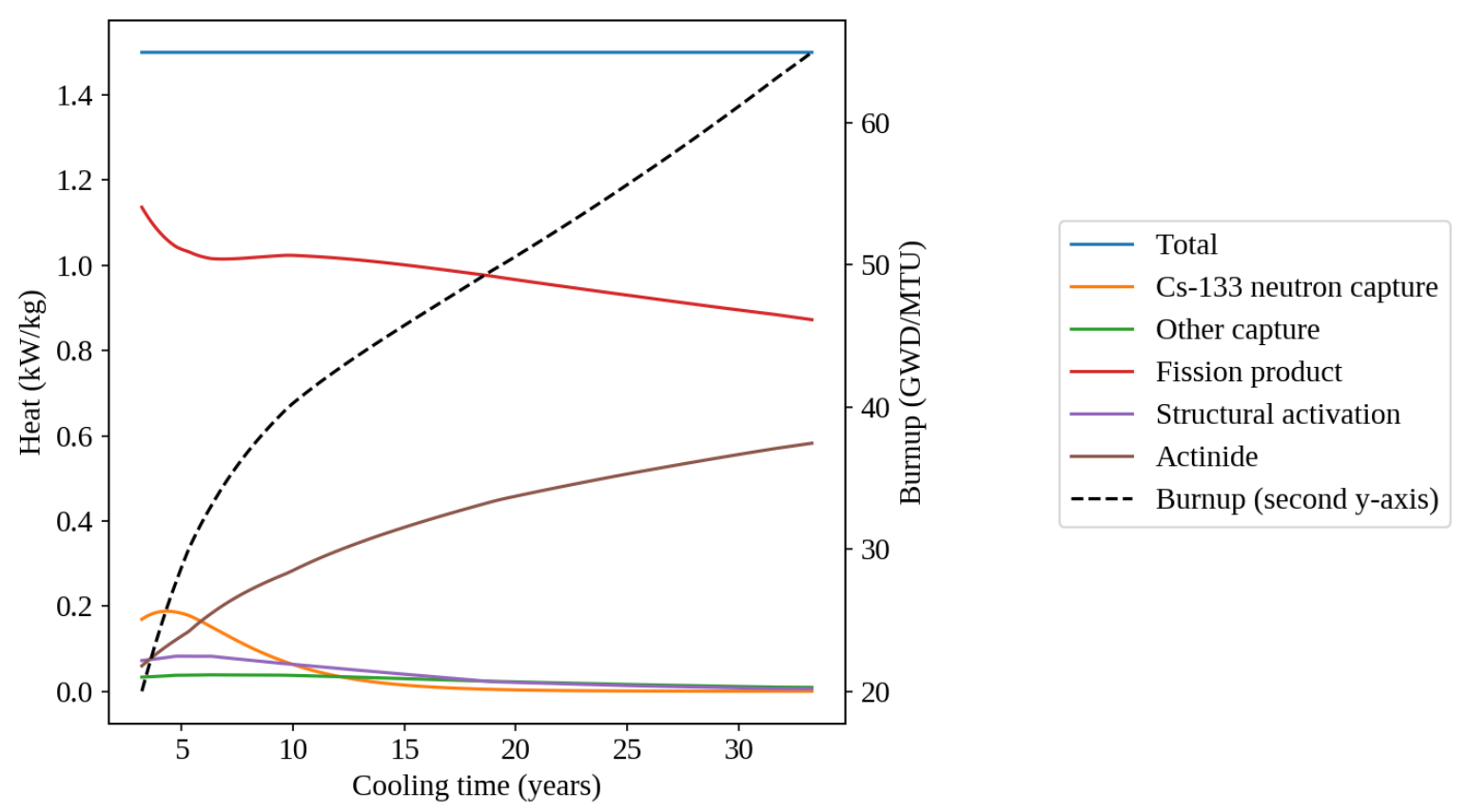

Figure 31. Components of SNF decay heat as predicted by RG3.54r2 for 5\% enriched PWR SNF burned for 3.23 years, producing $1.5 \mathrm{~W} / \mathrm{kgU}$ of decay heat. Burnup to obtain $1.5 \mathrm{~W} / \mathrm{kgU}$ of decay heat is plotted on the secondary $\mathrm{y}$-axis. 


\section{A3.1 Isocaloric Curves for Various Assembly Types}

Masses for three PWR assembly types were applied to the RG3.54R2 calculation to produce isocaloric characteristic curves. The assemblies are shown in Table 10, and corresponding figure numbers are specified in the far right column. For each assembly type, the first two figures show isocaloric curves with various enrichments, and the last two plots show isocaloric curves for various burn times. UNF-

ST\&DARDS points showing decay heat calculation points are shown as dots. If they fall within $2 \%$ of an isocaloric curve, then they are color coded. Similar trends are seen as in the case of the figures plotted on a per-unit mass basis. However, the number of UNF-ST\&DARDS points is substantially lower than when all PWR assemblies are plotted.

Table 10. Summary of assembly type data in UNF-ST\&DARDS database

\begin{tabular}{lccc}
\hline Assembly & $\begin{array}{c}\text { Uranium } \\
\text { mass (kgU) }\end{array}$ & $\begin{array}{c}\text { Number of decay heat } \\
\text { calculations in UDB }\end{array}$ & $\begin{array}{c}\text { Figure } \\
\text { numbers }\end{array}$ \\
\hline Westinghouse Vantage 5H & 462 & 40,581 & $32-35$ \\
Combustion Engineering 14×14 C & 382 & 54,776 & $36-39$ \\
Babcock and Wilcox Mark B10 & 486 & 7,466 & $40-43$ \\
\hline
\end{tabular}




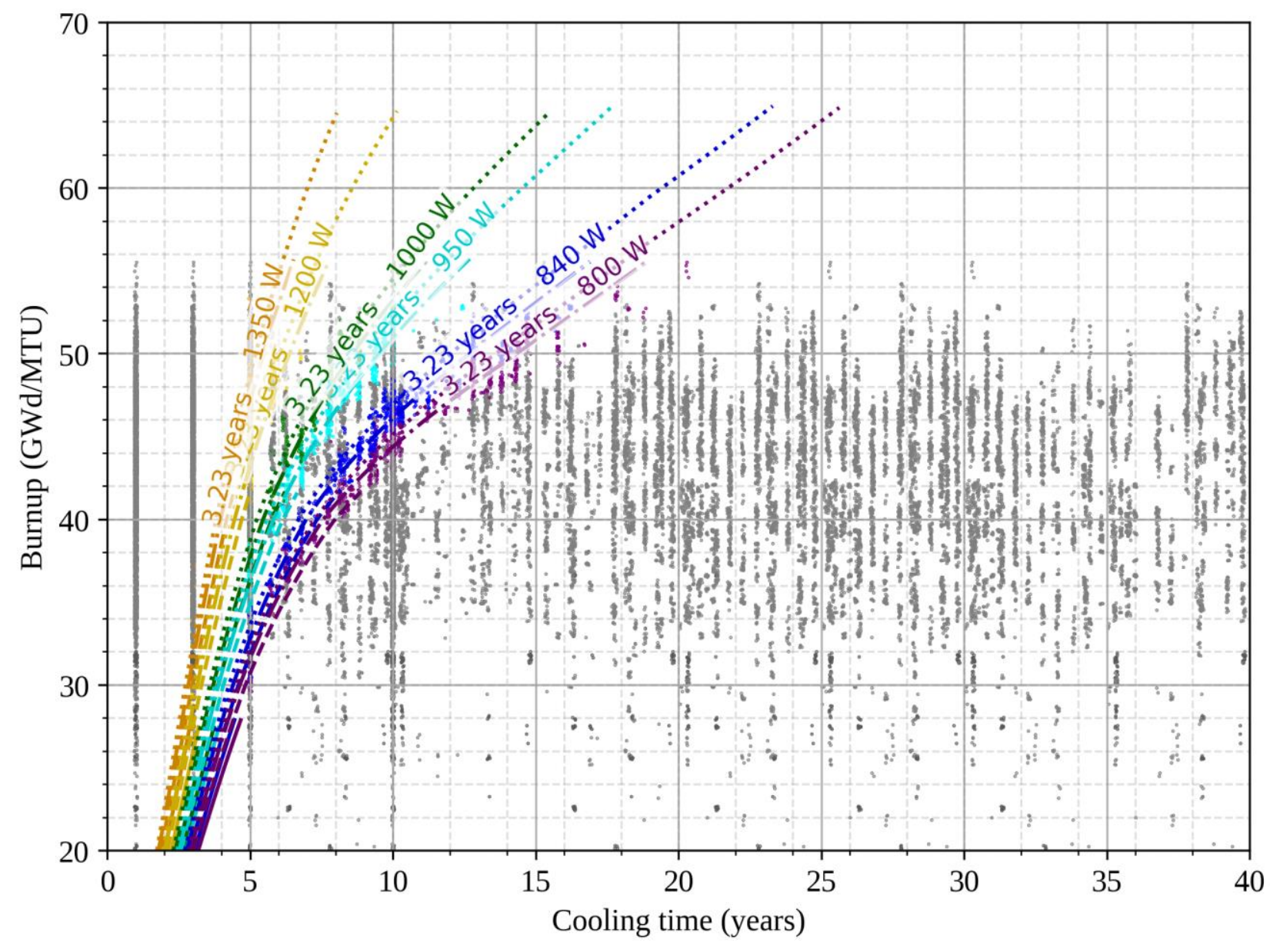

Decay heat within $2 \%$ of
Other
$800.00 \mathrm{~W}$
$840.00 \mathrm{~W}$
$950.00 \mathrm{~W}$
$1000.00 \mathrm{~W}$
$1200.00 \mathrm{~W}$
$1350.00 \mathrm{~W}$

\section{Enrichment}

- 2.0\%

-- $3.0 \%$

-. $4.0 \%$

…... $5.0 \%$

Figure 32. Comparison of UDB bounding decay heat data for Westinghouse Electric (WE)

Vantage 5H assemblies to RG3.54r2 isocaloric decay heat curves. 


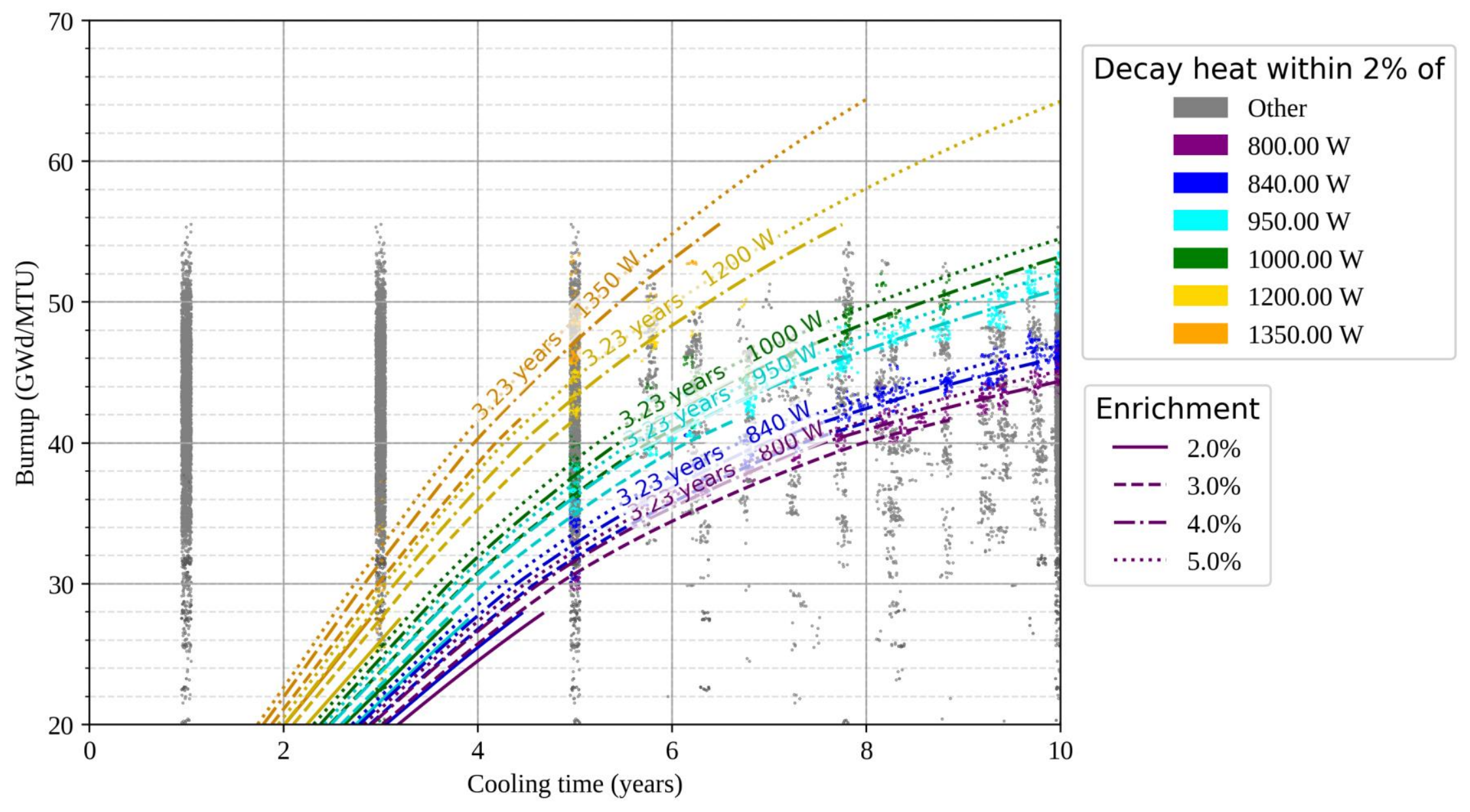

Figure 33. Comparison of UDB bounding decay heat data for WE Vantage $5 \mathrm{H}$ assemblies to RG3.54r2 isocaloric decay heat curves, zoomed time scale. 


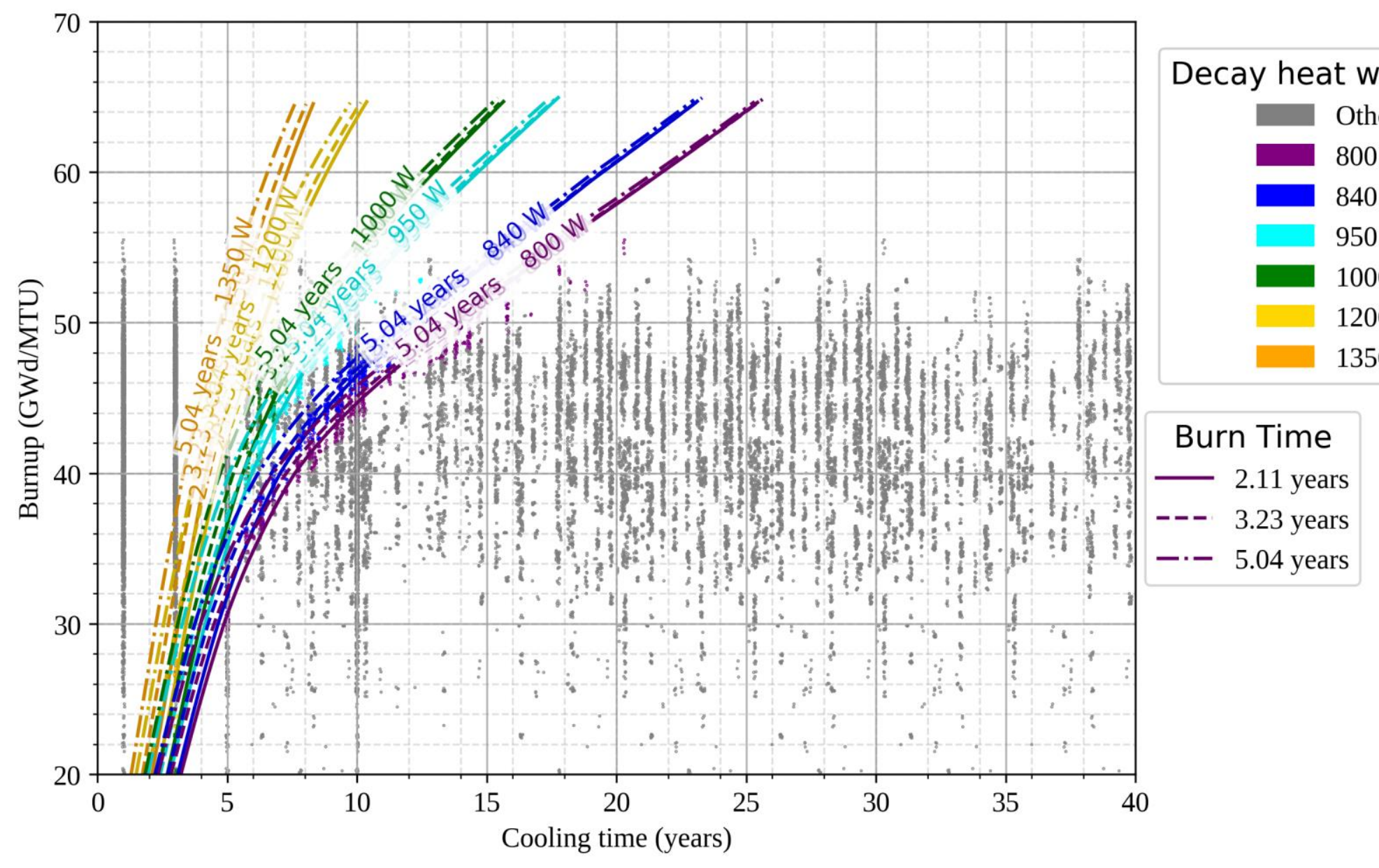

Figure 34. Comparison of UDB bounding decay heat data for WE Vantage $5 \mathrm{H}$ assemblies to RG3.54r2 isocaloric decay heat curves for $5 \%$ enriched fuel burned for various times. 


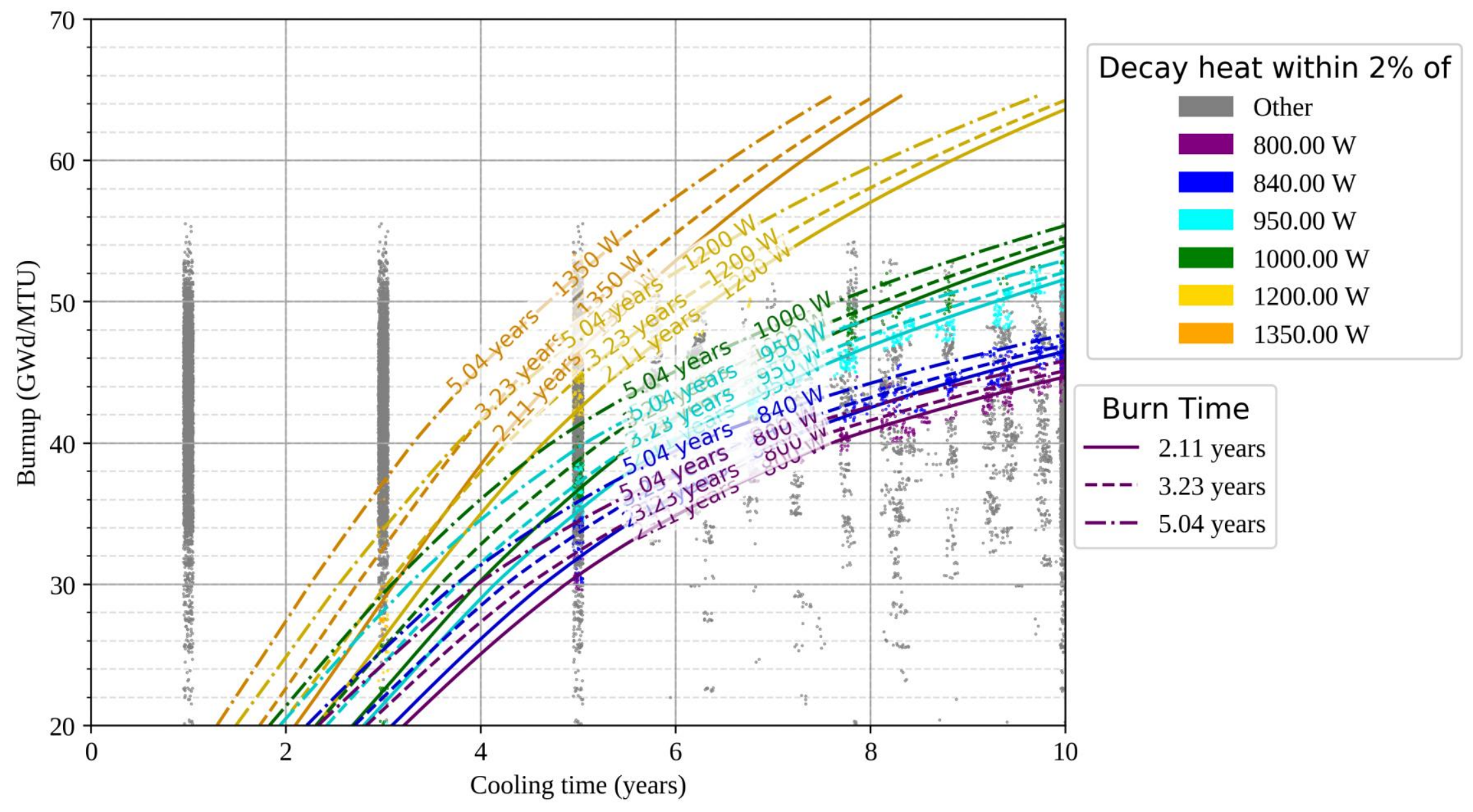

Figure 35. Comparison of UDB bounding decay heat data for WE Vantage 5H assemblies to RG3.54r2 isocaloric decay heat curves for $5 \%$ enriched fuel burned for various times, zoomed time scale. 


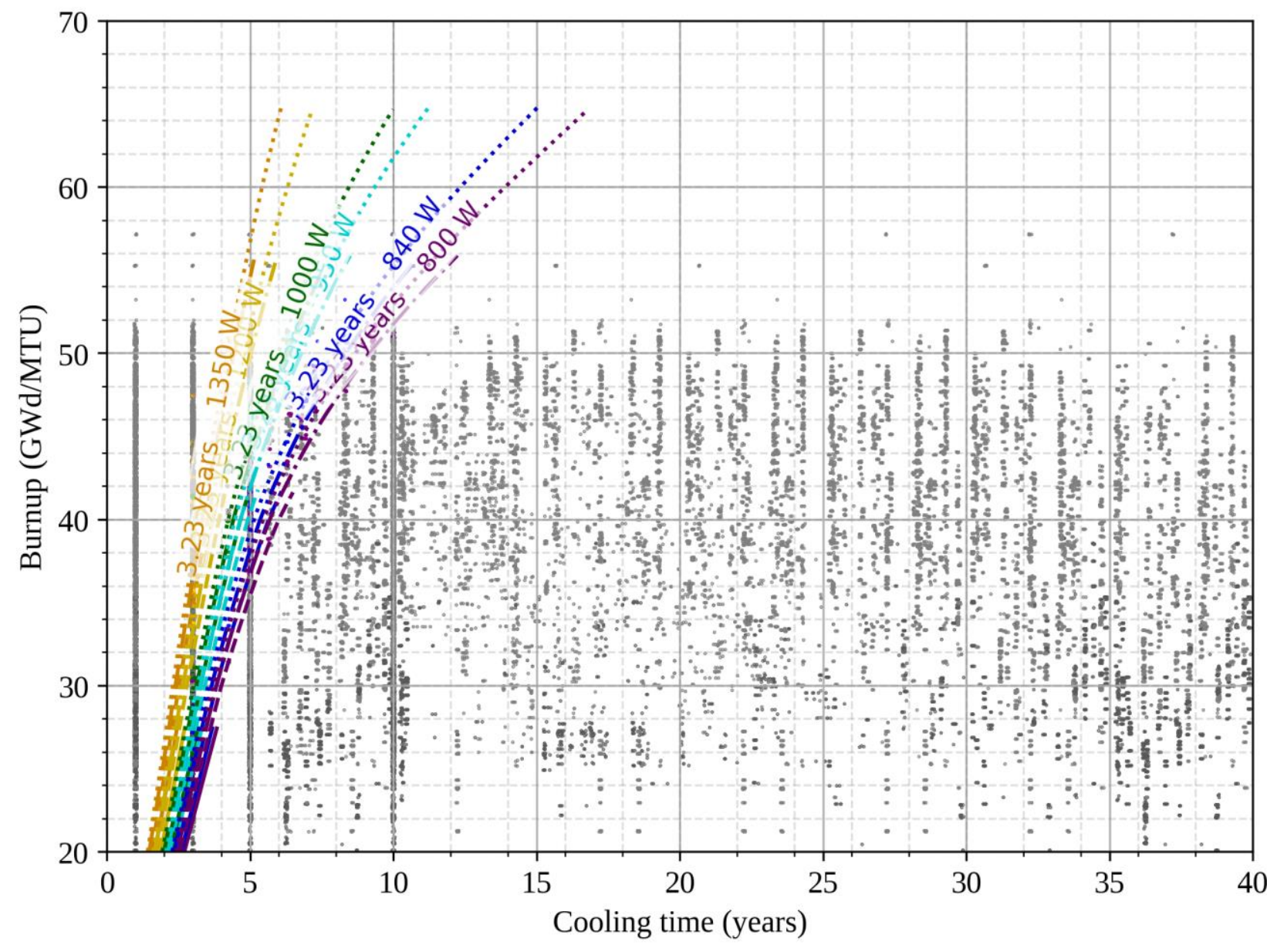

Decay heat within $2 \%$ of Other

$800.00 \mathrm{~W}$

$840.00 \mathrm{~W}$

$950.00 \mathrm{~W}$

$1200.00 \mathrm{~W}$

$1350.00 \mathrm{~W}$

\section{Enrichment}

- $2.0 \%$

-- $3.0 \%$

$-\cdot-4.0 \%$

…... $5.0 \%$

Figure 36. Comparison of UDB bounding decay heat data for CE $14 \times 14$ C assemblies to RG3.54r2 isocaloric decay heat curves. 


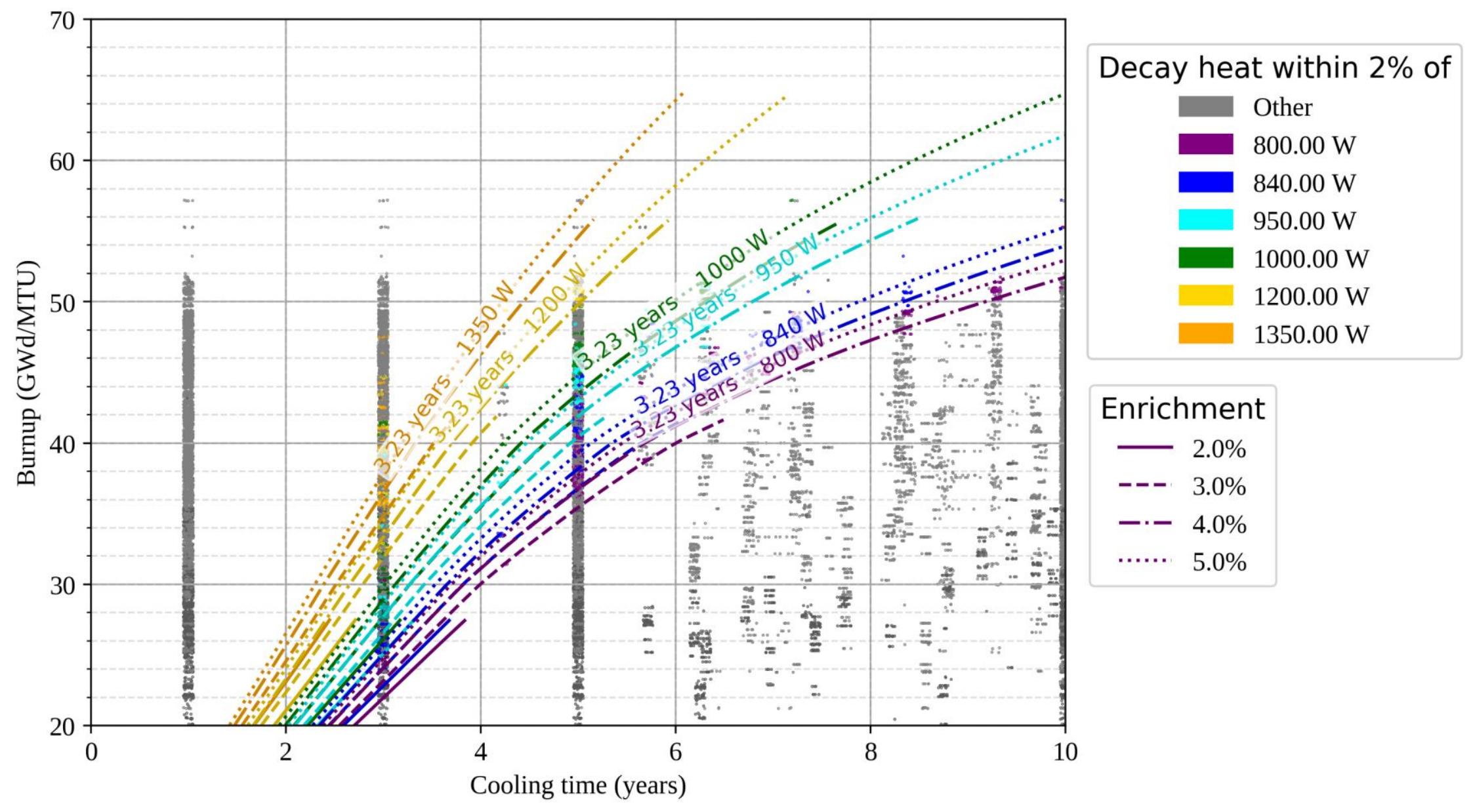

Figure 37. Comparison of UDB bounding decay heat data for CE $14 \times 14 \mathrm{C}$ assemblies to RG3.54r2 isocaloric decay heat curves, zoomed time scale. 


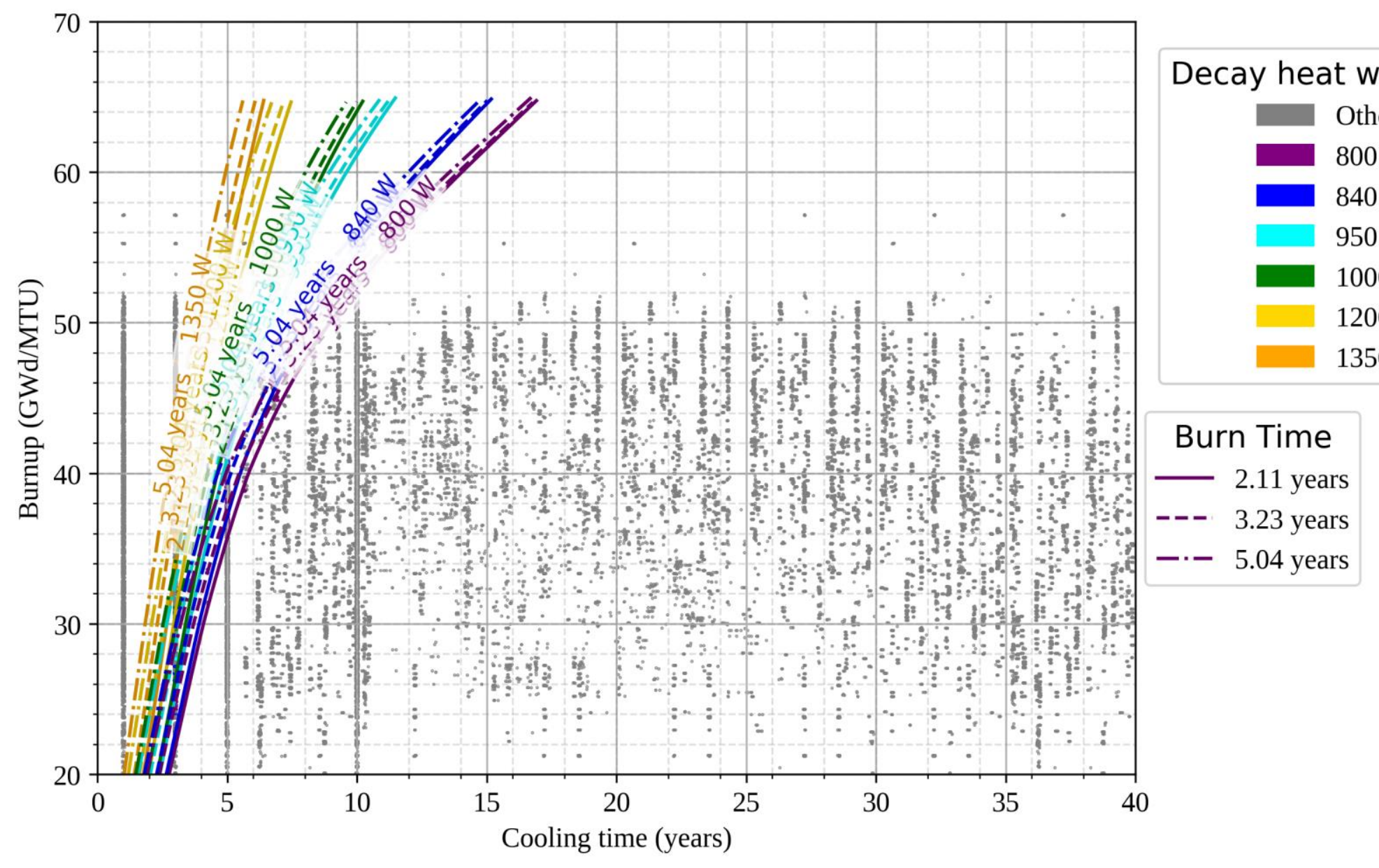

Figure 38. Comparison of UDB bounding decay heat data for CE $14 \times 14 \mathrm{C}$ assemblies to RG3.54r2 isocaloric decay heat curves for $5 \%$ enriched fuel burned for various times. 


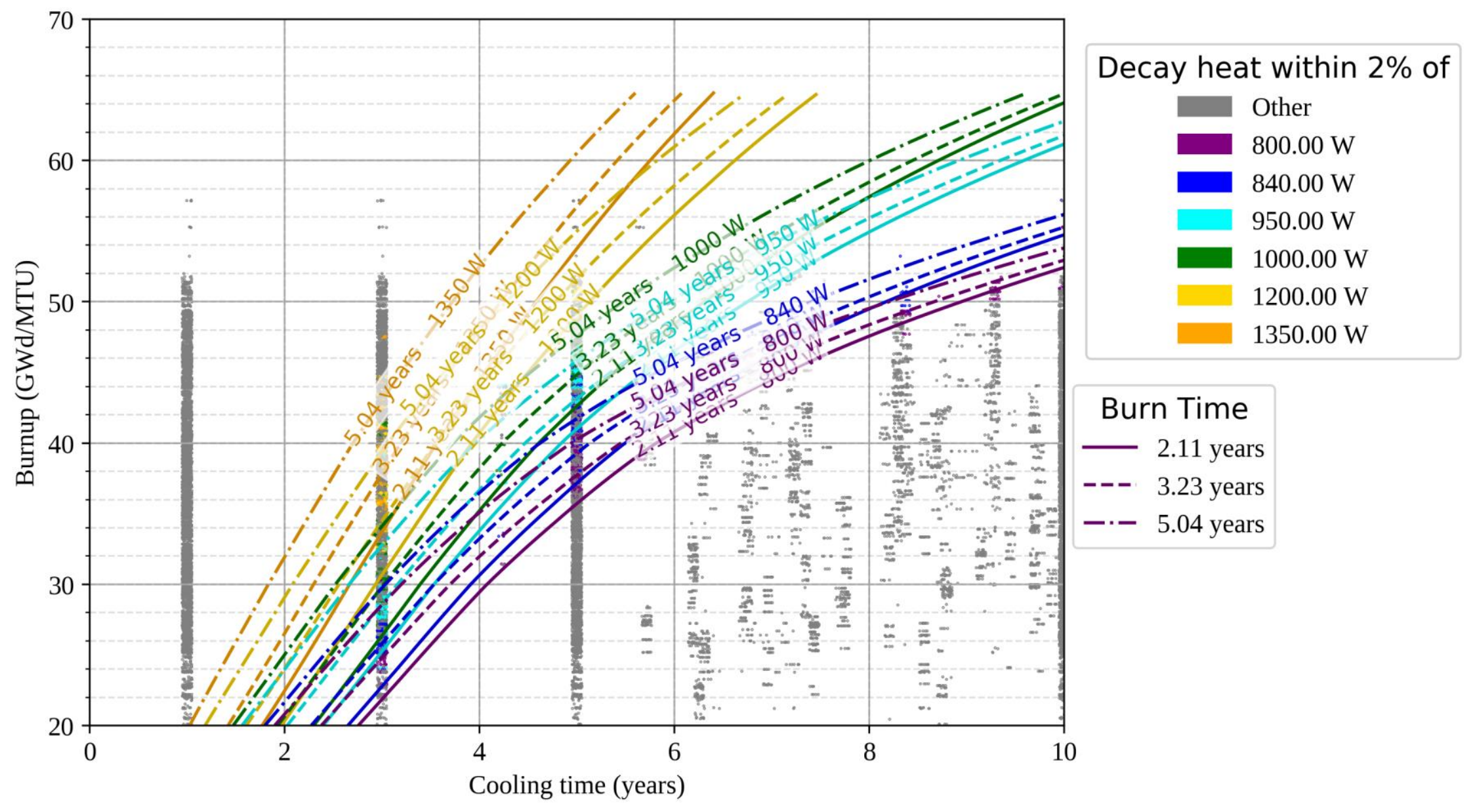

Figure 39. Comparison of UDB bounding decay heat data for CE $14 \times 14 \mathrm{C}$ assemblies to RG3.54r2 isocaloric decay heat curves for $5 \%$ enriched fuel burned for various times, zoomed time scale. 


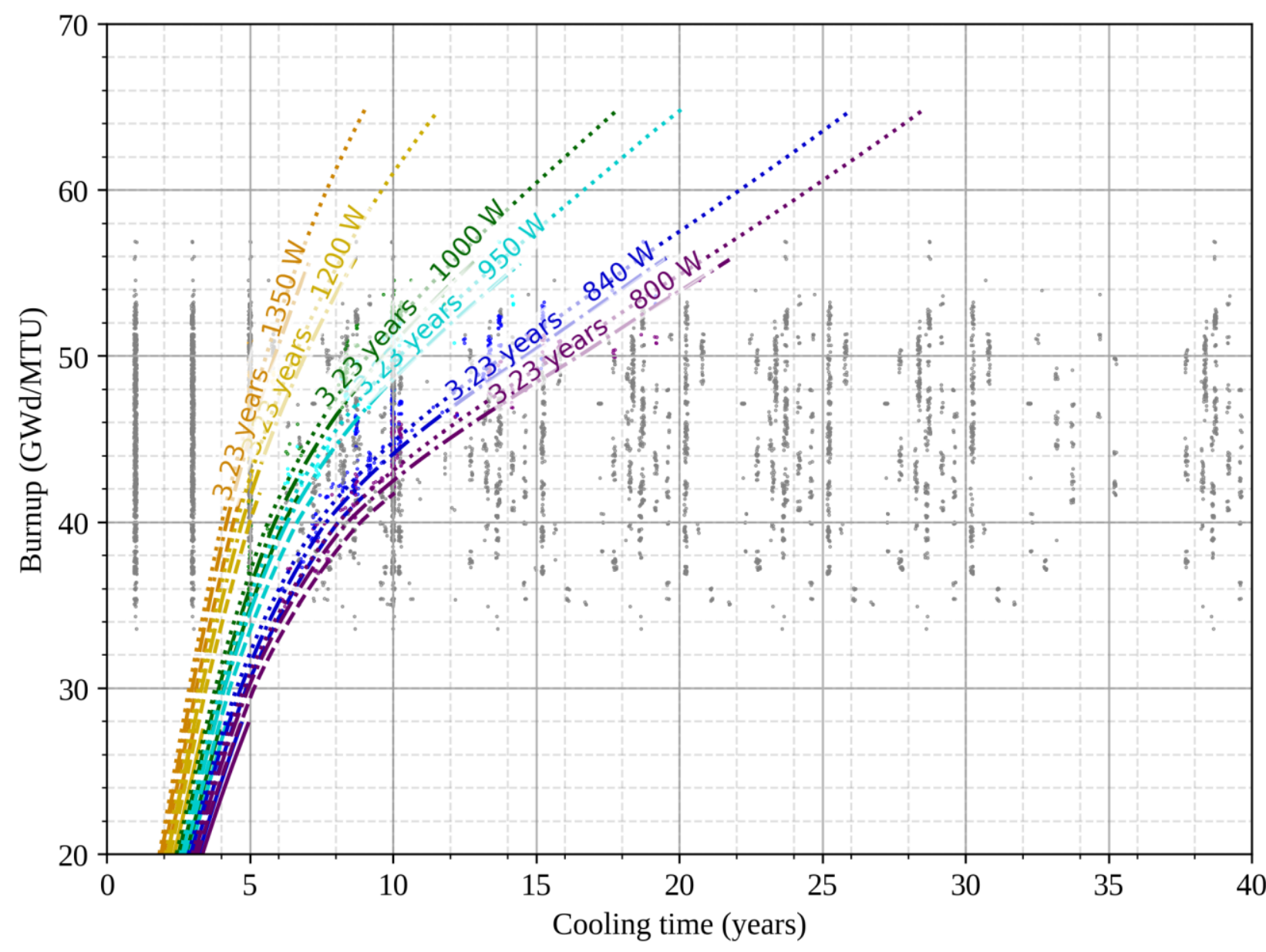

Decay heat within 2\% of
Other
$800.00 \mathrm{~W}$
$840.00 \mathrm{~W}$
$950.00 \mathrm{~W}$
$1000.00 \mathrm{~W}$
$1200.00 \mathrm{~W}$
$1350.00 \mathrm{~W}$

\section{Enrichment}

- 2.0\%

-- $3.0 \%$

$-\cdot-4.0 \%$

…... $5.0 \%$

Figure 40. Comparison of UDB bounding decay heat data for B\&W Mark B10 assemblies to RG3.54r2 isocaloric decay heat curves. 


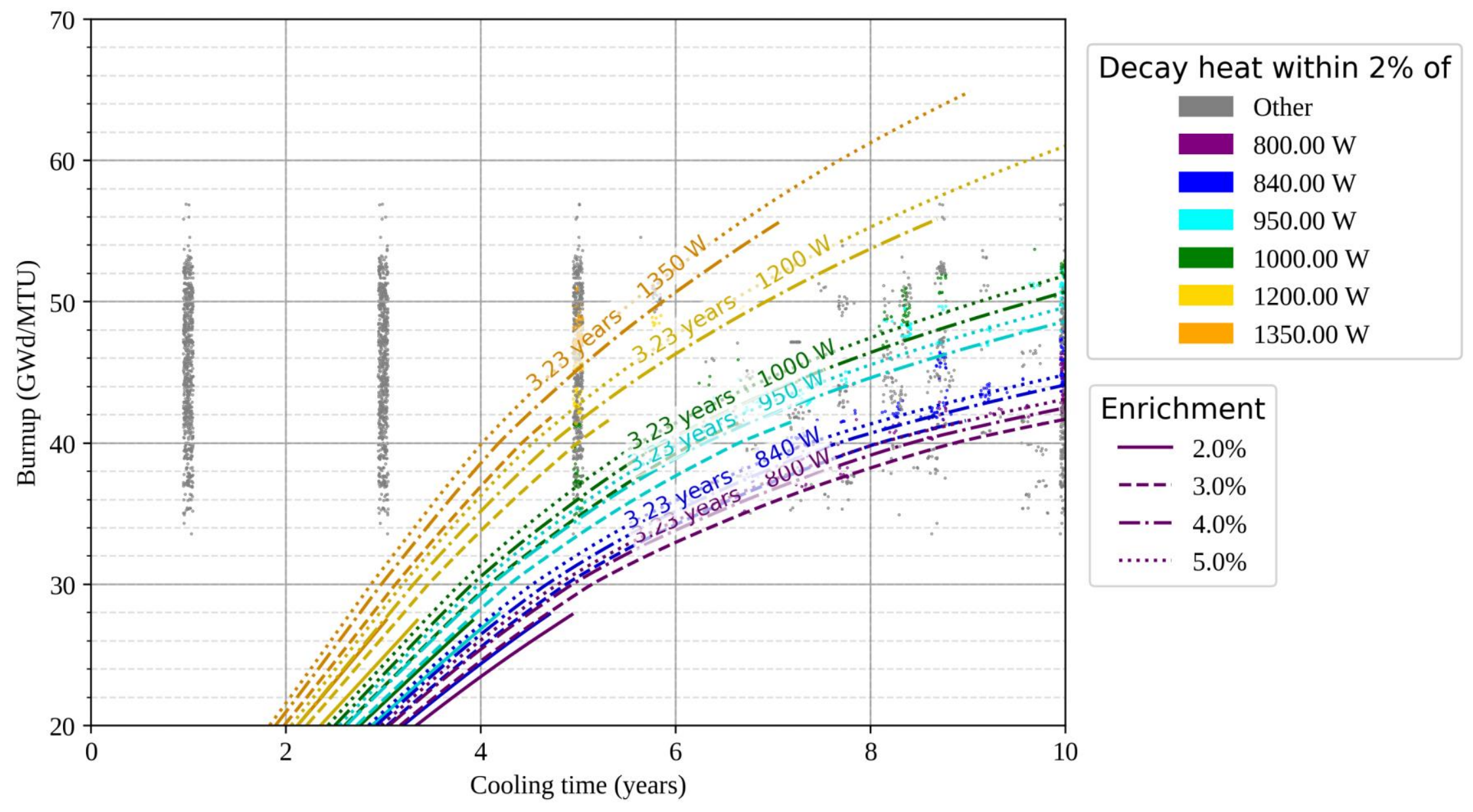

Figure 41. Comparison of UDB bounding decay heat data for B\&W Mark B10 assemblies to RG3.54r2 isocaloric decay heat curves, zoomed time scale. 


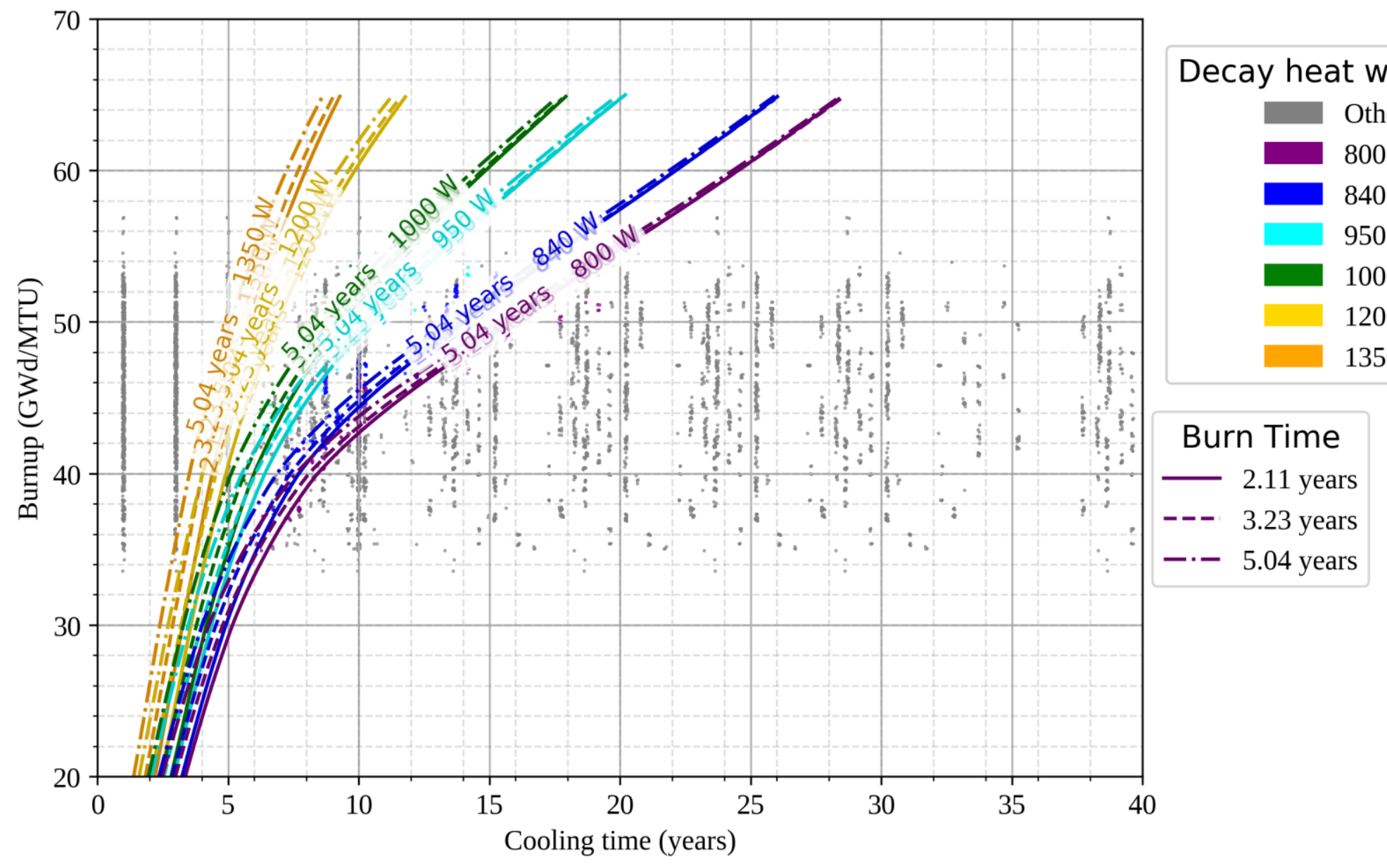

Figure 42. Comparison of UDB bounding decay heat data for B\&W Mark B10 assemblies to RG3.54r2 isocaloric decay heat curves for $5 \%$ enriched fuel burned for various times. 


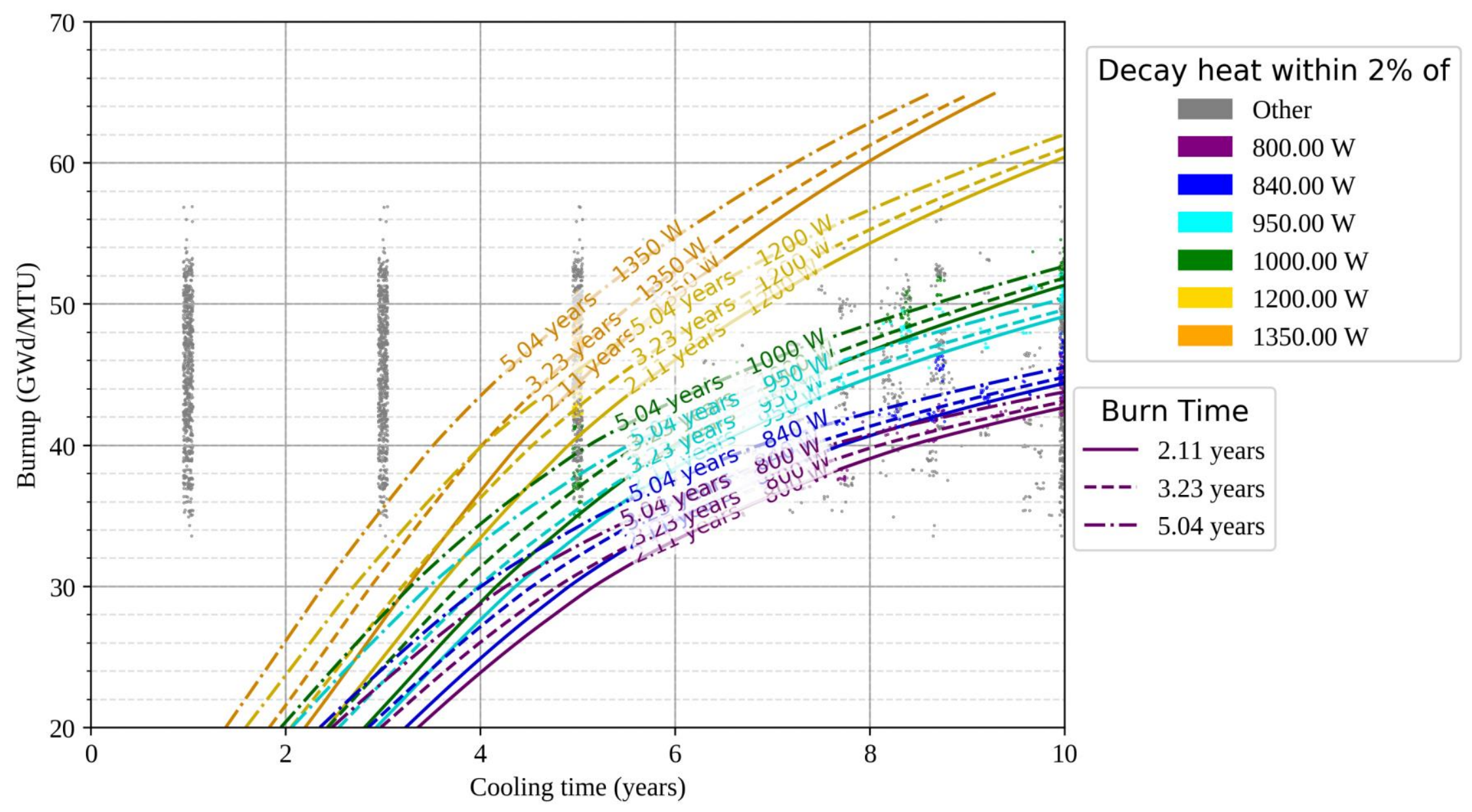

Figure 43. Comparison of UDB bounding decay heat data for B\&W Mark B10 assemblies to RG3.54r2 isocaloric decay heat curves for $5 \%$ enriched fuel burned for various times, zoomed time scale. 


\section{A.4 CONCLUSION}

This appendix compares UNF-ST\&DARDS bounding calculations to those produced by NRC Regulatory Guide 3.54 revision 2. Based on visual inspection for a given cooling time, the two methods produce burnups within $5 \mathrm{GWd} / \mathrm{MTU}$. This value is likely an overestimate, because enrichment in the UNFST\&DARDS was not shown in the plots examined. UNF-ST\&DARDS appears to predict higher decay heats for lower burnups than the regulatory guide. At lower cooling times and burnups, it appears that changing in-core time corresponds to a larger change in cooling time studied than a change in enrichment across the representative ranges studied. At higher burnups, enrichment influences decay heat more than at low burnups, which is expected due to the increased actinide production at higher burnups and lower enrichments. 